University of San Diego

Digital USD

2011-5

\title{
A Quantitative Inquiry into Moral Distress and Psychological Empowerment in Critical Care Nurses Caring for Adults during End of Life
}

Annette Marie Browning PhD, RN, CNS

University of San Diego

Follow this and additional works at: https://digital.sandiego.edu/dissertations

Part of the Nursing Commons

\section{Digital USD Citation}

Browning, Annette Marie PhD, RN, CNS, "A Quantitative Inquiry into Moral Distress and Psychological Empowerment in Critical Care Nurses Caring for Adults during End of Life" (2011). Dissertations. 913. https://digital.sandiego.edu/dissertations/913 


\section{UNIVERSITY OF SAN DIEGO}

Hahn School of Nursing and Health Sciences

DOCTOR OF PHILOSPHY IN NURSING

A QUANTITATIVE INQUIRY INTO MORAL DISTRESS

AND PSYCHOLOGICAL EMPOWERMENT IN CRITICAL CARE NURSES

CARING FOR ADULTS DURING END OF LIFE

By

Annette Marie Browning, RN; PhD(c); CNS

A dissertation presented to the

FACULTY OF HAHN SCHOOL OF NURSING AND HEALTH SCIENCE

UNIVERSITY OF SAN DIEGO

In partial fulfillment of the requirements for the degree of

DOCTOR OF PHILOSOPHY IN NURSING

May 2011

Dissertation Committee

Ann Mayo, RN; DNSc

Jane M. Georges, $\mathrm{PhD}, \mathrm{RN}$

Anita Hunter, PhD, RN, CPNP, FAAN 
Copyright 2011 


\begin{abstract}
Background Critical care nurses care for many adults at end of life and it is known that these nurses can experience moral distress. Moral distress occurs when nurses are unable to perform what they believe is ethically correct. There has been speculation that psychological empowerment may ameliorate moral distress among critical care nurses. However, research has yet to examine the relationship between moral distress and psychological empowerment in the population of critical care nurses.
\end{abstract}

Objectives To describe the relationships between moral distress, psychological empowerment and select demographics in critical care nurses caring for patients at EOL.

Method Using a quantitative correlational survey design a sample of critical care nurses $(n=277)$ was recruited using the American Association of Critical Care Nurses online Newsletter. Instruments included the Moral Distress Scale (MDS) for Intensity and Frequency each having the subscales of a) not in patient's best interest, b) individual responsibility, and c) deception and the Psychological Empowerment Instrument (PEI) with subscales of a) meaning, b) competence, c) self-determination, and d) impact.

Results MDS intensity mean score was high $(\mathrm{m}=5.34, \mathrm{SD}=1.32)$ and positively correlated with age $(r=.179, p=.011)$ and ELNEC critical care training $(r=.185, p=.008)$. MDS frequency mean score was moderate $(\mathrm{m}=2.51, \mathrm{SD}=0.87)$ and correlated with nurse collaboration in EOL patient care conferences $(r=-.191, p=.007)$, with nurses reporting more collaboration experiencing moral distress less frequently. PEI scores $(\mathrm{m}=5.31$, $\mathrm{SD}=1.00)$ were high and positively correlated with age $(r=.139, p=.031)$, years of critical care experience $(r=.165, p=.010)$, collaboration in EOLC conferences $(r=.163, p=.012)$, 
EOLC education in the past year $(r=.221, p=.001)$. Total PEI scores negatively correlated with moral distress frequency scores $(r=-.194 ; p=.010)$. Multiple regression analysis indicated that for every 1 - point increase on the PEI, moral distress frequency scores decreased by 0.222 points $(p=<.01)$.

Conclusion This study contributes to the understanding of the relationship between moral distress and psychological empowerment in critical care nurses caring for patients in end of life. The significant negative correlation between psychological empowerment and moral distress frequency in this population of nurses is of particular interest and can serve as the first step in testing interventions to decrease moral distress. 


\section{DEDICATION}

I dedicate this endeavor primarily to the Lord who orchestrated the amazing timing of this opportunity to achieve one of my life's greatest aspirations. I also want to dedicate this work to the following individuals who have contributed to making my doctoral degree possible:

My Mom and Dad who instilled in me at an early age the value of education

My eldest son Greg who encouraged me and filled in the gaps

My son Adam who has come along side me and been helpful in so many ways

My daughter Emily who has loved me and cared for our family when I was not able to

My son Kevin who has been flexible and cheerfully adapted to the needs of our family

My daughter Meg who has been amazing and supportive every step of the way

My brother Richard \& his wife Mary who I can always count on to cheer me on

My brother Paul, although passed, encouraged me \& would be so proud of his little sister

My brother Tony, who loves me in his own way

My friend Sue who has been my confidant and encourager

My friend Kim who provides laughter and joy in my life

My friend Nancy who is an anchor of God's word

My friend Carrie who exemplifies lifelong learning

My friend Joe for his expertise and emotional support

My girlfriends at church who have supported and prayed for me 


\section{ACKNOWLEDGEMENTS}

It is with great thanks that I acknowledge the following people who encouraged and supported me in my $\mathrm{PhD}$ journey:

My chair, Dr. Ann Mayo, a nurse scientist, scholar and mentor, who inspired me and diligently affirmed my passionate research interests. You have been consistently available and have given me the confidence I needed to forge ahead.

Dr. Jane Georges, a nurse scholar and role model, thank you for your kind spirit that nurtured and encouraged me. You expanded my ways of thinking and viewing professional nursing and I will be forever grateful to you for your guidance.

Dr. Anita Hunter, another amazing scholarly role model, thank you for your unending encouragement, your positivism and your intellectualism that made me want to reach that much further.

Thank you to my traveling colleague, Rachel Van Niekerk, for your gift of listening and supporting me through difficult personal times during our doctoral studies and for always saving me a seat on the train.

Thank you to my cohort of fellow doctoral students, for our many hours of stimulating discussion and discovery of new ideas.

Thank you to the critical nurses who gave of their time to participate in this study.

Thank you to my employer, Biola University, for supporting me on many levels, to Walt Stangl, my Dean at Biola, who stood behind me all the way.

Thanks to my colleagues at work for their endless understanding, and to the US Federal Government for their financial support.

Thanks to all of you for endeavoring to advance the Nursing Profession! 


\section{Table of Contents}

Title

Abstract

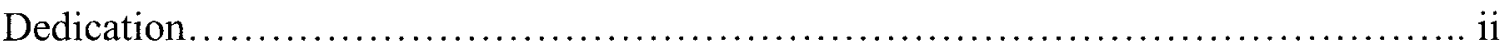

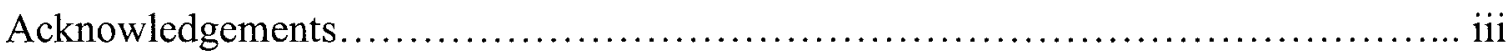

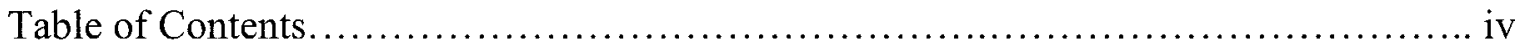

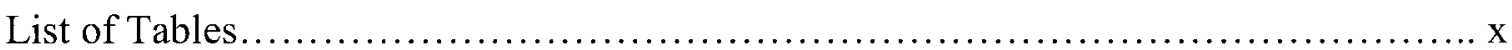

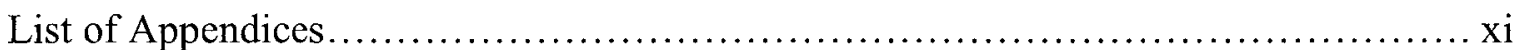

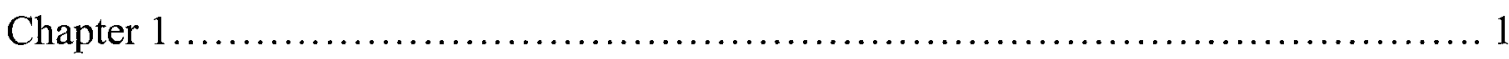

Overview of the Problem................................................. 1

Background and Significance....................................... 3

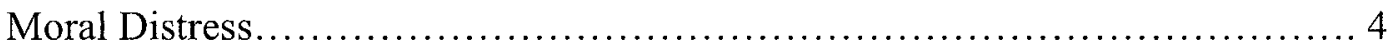

End of life care (EOLC): cause for moral distress in critical care nurses... 6

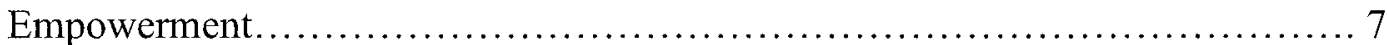

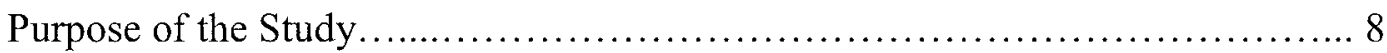

The Research Questions................................................ 8

Conceptual Framework............................................. 10

Definition of Terms.................................................. 13

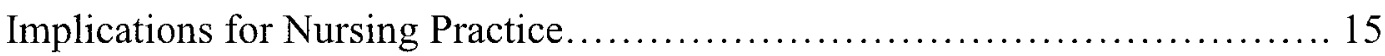


Chapter 2 . 18

Literature Review. ........................................... 18

Moral Distress................................................. 18

Moral distress in nursing instrumentation....................... 22

Moral distress in critical care nurses related to end of life care $\ldots \ldots \ldots . .25$

Moral distress related to futile care at EOL ........................ 26

Qualitative and mixed methods relating futile care to moral

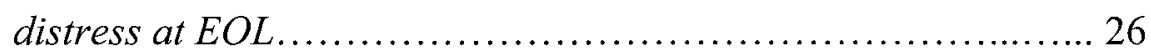

Quantitative methods relating futile care to moral distress at

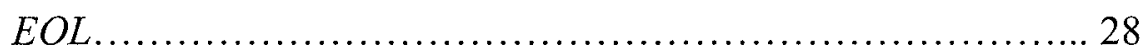

Empowerment............................................... 31

Theories of Psychological Empowerment........................ 32

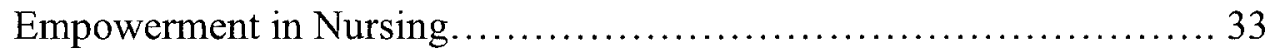

Critical Care Nursing Expertise in the Delivery of Patient Care at EOL........ 35

Active collaboration in multidisciplinary EOL patient care conferences. 35

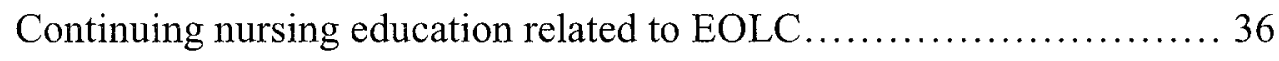

The End-of-Life Nursing Education Consortium (ELNEC) critical care

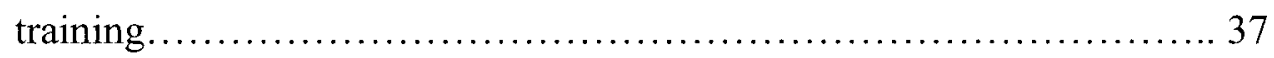

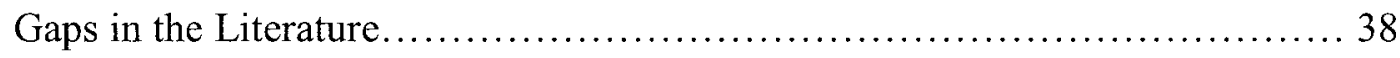


Chapter 3 .

Methodology .................................................... 41

Research Design................................................... 42

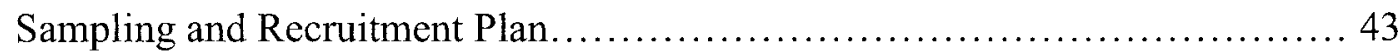

Sample Size.................................................. 43

Recruitment............................................... 43

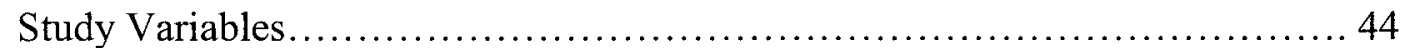

Dependent Variables...................................... 44

Independent Variables....................................... 44

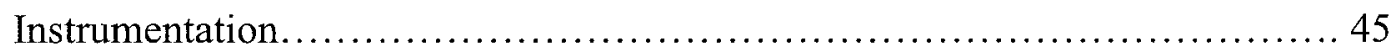

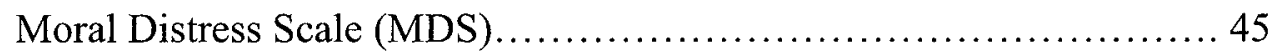

The Psychological Empowerment Instrument (PEI) ..................... 47

Demographic Data.............................................. 48

Data Collections Procedures........................................... 49

Data Collection........................................................... 50

Data Analysis................................................. 50

Protection of Human Subjects....................................... 51

Risks............................................................. 51

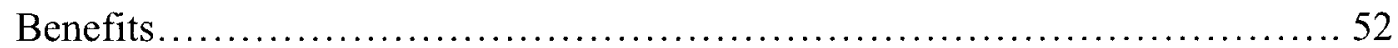

Limitations and Strengths of the Study............................... 52 


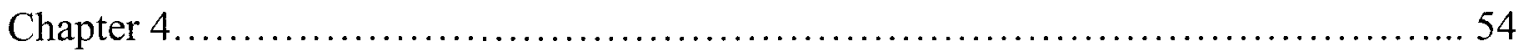

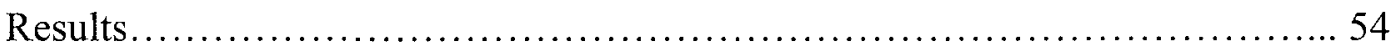

Demographics........................................................ 55

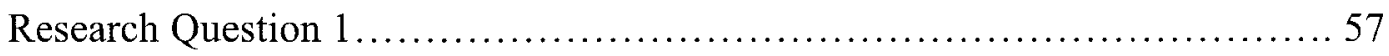

Moral Distress Intensity and Moral Distress Frequency..................... 57

Individual items............................................ 57

Subscale total scores......................................... 58

Total moral distress intensity and total moral distress frequency scores.. 58

Psychological Empowerment Instrument (PEI) .......................... 61

PEI items..................................................... 61

PEI subscales and total score ................................... 61

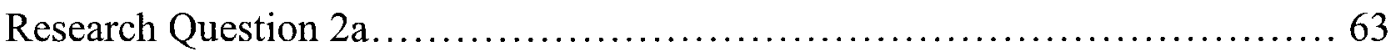

Moral distress intensity and demographics......................... 64

Moral distress frequency and demographics......................... 65

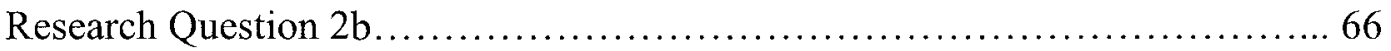

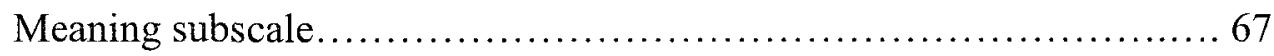

Competence subscale............................................ 67

Self-determination subscale..................................... 67

Impact subscale.............................................. 68 
Research Question 3a................................................. 69

Psychological empowerment and moral distress intensity ...............69

Psychological empowerment and moral distress frequency............ 71

Research Question 3b............................................ 72

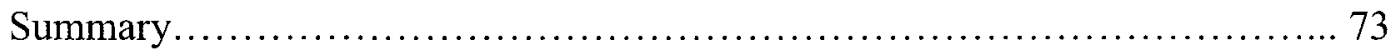

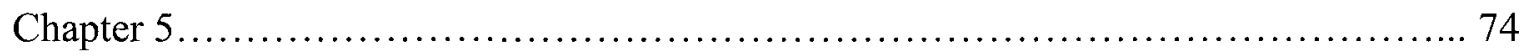

Discussion.............................................................. 74

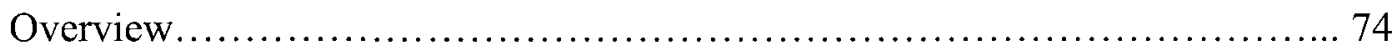

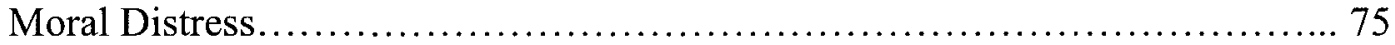

Moral distress intensity ........................................ 75

Critical care nurse characteristics and moral distress intensity ....76

Nurse / MD orders and collaboration............................ 77

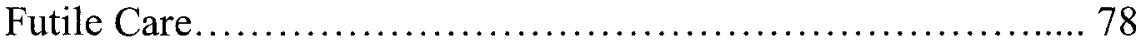

Moral distress frequency........................................... 79

Demographics related to moral distress frequency............... 79

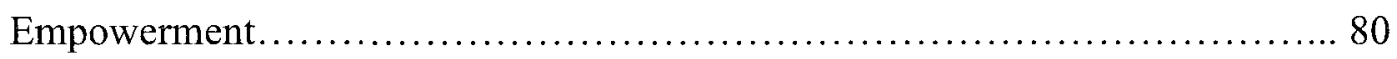

Demographics related to empowerment............................ 81

Moral distress intensity and empowerment........................ 82

Moral distress frequency and empowerment........................ 83

Empowerment and nursing characteristics related to moral distress..... 83 
Strength and limitations........................................ 85

Implications for future nursing research $\ldots \ldots \ldots \ldots \ldots \ldots \ldots \ldots \ldots \ldots . \ldots 5$

Bioethical considerations related to moral distress................ 86

EOLC education........................................... 87

Increasing collaborative efforts between professions: nursing and medicine.................................................... 87

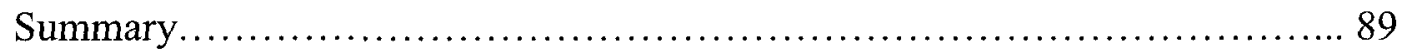

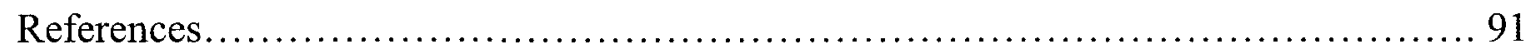




\section{List of Tables}

Table 1: $\quad$ Respondent Descriptive Statistics................................. 56

Table 2: $\quad$ Moral Distress Respondent Intensity and Frequency $(\mathrm{n}=277)$ according to subscales: Not in patient's best interest, Individual responsibility and Deception)

Table 3: Psychological Empowerment $(\mathrm{n}=277)$ according to subscales, Meaning, Competence, Self-Determination \& Impact

Table 4a: $\quad$ Relationship between Moral Distress \& Demographics................... 65

Table 4b: Relationship between Moral Distress Frequency \& Demographics...... 66

Table 5: $\quad$ Relationship between Psychological Empowerment and Demographics. 69

Table 6a: Pearson's $r$ Level of Moral Distress Intensity with Degree of

Psychological Empowerment.................................. 70

Table 6b: Pearson's $r$ Level of Moral Distress Frequency with Degree of

Psychological Empowerment.............................................. 72 


\section{List of Appendices}

Appendix A: Moral Distress Scale.................................................... 99

Appendix B: Psychological Empowerment Instrument............................. 106

Appendix C: Demographic Survey ....................................... 112

Appendix D: AACN Newsletter Subscribers Letter............................ 114

Appendix E: Institutional Review Board University of San Diego................... 115 


\section{CHAPTER 1}

One-fifth of the patients cared for by critical care nurses die in the intensive care unit (Bechstrand \& Kirchhoff, 2005). There is a growing concern by the American Association of Colleges of Nursing (2007) and the International Council of Nurses (2006) related to an increase in the use of inappropriate life support treatments related to end of life care (EOLC). In cases of futility, aggressive medical treatment during end of life (EOL) is well documented in the literature as a cause for moral distress in critical care nurses (Guteirrez, 2005). Moral distress results in nurses when they are unable to perform according to what they believe to be ethically correct. Increasing psychological empowerment in nurses is a means of strengthening the impact nurses have to innovatively influence patient care decision-making (Knol \& van Linge, 2009). A lack of psychological empowerment may be contributing to moral distress in critical care nurses caring for adults at EOL.

\section{Overview of the Problem}

The advent of life support technology over the last half century has drastically changed the focus of caring for the dying individual. Critical care units were developed in order to appropriately monitor critically ill patients and critical care nurses were 
provided specialized education for the purpose of optimally caring for critically ill patient populations. Although advanced technology has brought with it the promise of more efficient treatment modalities, extending life inappropriately and the futile prolongation of patient suffering have become commonplace phenomena for critical care nurses now caring for patients at end of life (EOL) (Morton \& Fontaine, 2009), thus potentiating moral distress in critical care nurses. Jameton (1984) was the first to define moral distress in the nursing literature. Moral distress was defined as discomfort or internal conflict related to ethical dilemmas encountered in nursing practice when constraints prevented the nurse from following the course of action believed to be right. Obstacles contributing to the inability to act upon what the nurse believes to be right have many origins. Bechstrand and Kirchhoff (2005) identified several obstacles that critical care nurses perceived while providing EOLC $(\mathrm{N}=864)$ as coinciding with moral distress. These obstacles included nurses having to continue the provision of treatments to dying patients because of financial benefit to the hospital and nurses' perceiving that nurses' opinions related to patient EOLC care decisions were not being recognized and valued. In 2006, The American Association of Critical Care Nurses (AACN) identified EOLC challenges as a significant source of moral distress in critical care nurses. AACN has established a position statement on moral distress proclaiming it a serious problem in nursing (2006):

It (moral distress) results in significant physical and emotional stress, which contributes to nurses' feelings of loss of integrity and dissatisfaction with their work environment. Studies demonstrate that moral distress is a major contributor to nurses leaving the work setting and profession. It affects relationships with 
patients and others and can affect the quality, quantity, and cost of nursing care (p.1)

Empowerment is defined as giving power or authority, enabling or permitting. Synonyms for empowerment include warrant, commission, license, qualification or the investment of power from one individual or group to another, especially legally or officially (Pickett, 2000). Empowerment is a mechanism by which people gain mastery over their affairs. It may come from within or it may be facilitated externally. Perceived empowerment in nursing refers to the nurse's view of oneself as having control over one's practice (Page, 2004) and the ability to act according to one's knowledge and judgment in the context of one's nursing practice (Laschinger, Finegan, Shamian, \& Wilk, 2004).

Psychological empowerment is a motivational construct demonstrated in four cognitions: meaning, competence, self-determination, and impact (Thomas \& Velthouse, 1990), and will be the type of empowerment measured in this study. A lack of psychological empowerment in critical care nurses caring for adults during EOL may contribute to moral distress in critical care nurses. No studies have been found to date that specifically examine the relationship between moral distress and empowerment in nursing, thus this study seeks to determine if this relationship exists.

\section{Background and Significance}

Situations surrounding caring for adults during EOLC have been identified as causing significant moral distress in critical care nurses. Identifying factors that determine the relationship between levels of moral distress and perceived empowerment may potentially provide additional information used to decrease levels of moral distress 
by establishing and promoting ways of increasing perceived empowerment. As critical care nurses develop a more active voice in collaboration with physicians, ethics committees, and members of the multidisciplinary health care team, the facilitation of empowerment among them may have the potential to decrease moral distress and enhance patient care outcomes at EOL.

\section{Moral Distress}

Prior to Jameton (1984), nurses' perceived adverse experience related to ethical dilemmas was referred to as nursing stress. In nursing stress the course of action is uncertain while in moral distress the ethically correct course of action is known, however the nurse is unable to carry out the action. The origins of the inability to carry out ones actions believed to be correct were identified as obstacles related to conflicting medical or family decisions, hospital policy or legal issues (Corley, Elswick, Gorman, \& Clor, 2001).

Corley (1995) differentiated between moral distress intensity and moral distress frequency. Moral distress intensity was defined as the level of painful feeling experienced by the nurse as a result of the stressful situation and moral distress frequency was defined as how often the nurse experienced the painful feeling. Corley (2001) identified three categories of situations within moral distress intensity and moral distress frequency whereby nurses experience moral distress: 1) not in patient's best interest, 2) individual responsibility, and 3) deception. Not in patient's best interest is defined as participating in care that the nurse considers inappropriate due to futility for the patient. Individual responsibility refers to the nurse participating in care not agreed with or ignoring actions the nurse should take. Deception refers to the nurse not addressing 
issues related to impending death of a patient honestly. These categories became subscales in Corley's moral distress instrumentation for intensity and frequency.

Corley (2002) identified sources of moral distress in nurses as inadequate staffing and conflicting organizational policies and procedures that make it difficult for nurses to meet the needs of patients. Lack of collaboration between members of the health care team related to patient care decision making has been identified as one of the major causes of moral distress (Gutierrez, 2005). Such lack of collaboration increases the sense of powerlessness in the nurse, and may potentially increase the moral distress the nurse experiences.

LaSala \& Bjarnason (2010) suggest that working environments that support moral courage in nurses may have the potential to combat moral distress. Nurses who consistently practice moral courage base their decisions on ethical principles and standards they believe to be right regardless of personal risk. LaSala further suggests that working environments that are supportive of empowerment in nurses may have a greater propensity to decrease moral distress in nurses resulting in the promotion of more positive patient care outcomes.

Following Jameton's (1984) identification of the phenomena of moral distress, studies have continued to explore and identify moral distress in nurses working in various areas of nursing practice (Fenton,1987; Rodney, 1988; Corley, 1995; Powell, 1998; Hefferman \& Heilig 1999; Hamric, 2000; Gutierrez, 2005; Corley, 2005; Hamric \& Blackhall, 2007; Kain, 2007; Zuzelo, 2007; Rice, Rady, Hamrick, Verheijde \& Pendergast, 2008; Pauly, Vercoe, Storch, \& Newton, 2009). Examples of target populations include adult and neonatal critical care nurses, adult medical surgical nurses, 
nursing supervisors, and nurse educators. The majority of the studies conducted on moral distress have been performed in critical care settings.

\section{End of life care (EOLC): cause for moral distress in critical care nurses.}

Following Jameton's initial work on moral distress, Wilkinson (1987/88) studied moral distress specifically in intensive care nurses. Moral distress in critical care nurses caring for adults at EOL, has been selected for this study because moral distress related to EOLC decision-making has been identified as a significant problem that critical care nurses frequently encounter (Guitierrez 2005). Guiteirrez reported that in critical care nurses' perceptions of moral distress, $92 \%$ of the participants identified overly aggressive treatment as a source of moral conflict. Other sources of moral distress identified in this study included inappropriate use of healthcare resources and patient wishes being disregarded by physicians.

Situations in which adults are being cared for in critical care units at EOL are prolific. More than 2.4 million deaths are recorded yearly in the United States. Most of these deaths $(80 \%)$ occur in hospital settings, where one-fifth of intensive care unit patients die (Beckstrand \& Kirchhoff, 2005).

The adverse effects of moral distress in critical care nurses related to EOLC are well documented in the literature (AACN, 2006; Gutierrez, 2005; Elpern, 2005; Meltzer \& Huckabay 2004). The administration of aggressive medical care, when the patient is not expected to benefit from that care, produced the highest level of moral distress for critical care staff nurses (Elpern, 2005). 


\section{Empowerment}

Although empowerment is thought to be a contemporary concept that has accelerated in the span of its interpretive meaning since the civil rights and women's movements of the sixties and seventies, the concept actually dates back to the mid-1 $7^{\text {th }}$ century, having its origin in legal terminology. Soon after its original usage its meaning expanded encompassing, "to enable or permit." Its most popular usage today is in the fields of politics, business, sociology, and psychology, with increasing application in professional nursing.

Conger and Kanungo (1988) suggested that when subordinates feel powerless, empowerment is necessary for optimum productivity. They expounded on the definition of empowerment to include self-efficacy. Self-efficacy is the tendency of an individual or group to perform a given behavior, influenced by the expectation of ones ability to perform successfully. The intended result is then improved behavioral outcomes.

Thomas and Velthouse (1990) conjectured that empowerment is complex and cannot be represented by a one dimensional concept such as self-efficacy. Therefore, they expanded the definition of empowerment, focusing on the psychological aspect of empowerment as having four cognitions: 1) Meaning 2) Competence (synonymous with self-efficacy) 3) Self-determination and 4) Impact. Psychological empowerment in nursing, as it will be examined in this study, is the nurse's view of oneself as having control over ones practice (Page, 2004) and the ability to act according to ones knowledge and judgment in context of ones nursing practice (Laschinger et al., 2004).

Having to act in ways not in accordance with ones personal and professional values can cause significant disruption in motivation and in ones confidence and sense of 
self-efficacy. Moral distress may be associated with the nurse's perceived lack of empowerment resulting in a lack of ability to act in accordance with the Nurses' Code of Ethics in the areas of patient advocacy, veracity, justice, beneficence and maleficence (American Nurses Association, 2001).

\section{Purpose of the Study}

The primary purpose of this cross sectional, descriptive study was to examine the relationship between moral distress and psychological empowerment in critical care nurses caring for adults during EOL.

Secondly, the following nursing characteristics: age, years of practice in critical care, work status, active collaboration in EOL patient care conferences, educational level, American Association of Critical Care Nurses (AACN) Certification, End-of-Life Nursing Education Consortium (ELNEC) critical care training, EOLC continuing education in the previous year, and AACN membership were examined in their relationship to moral distress and psychological empowerment in critical care nurses caring for adults at EOL.

This research study sought to examine if a relationship existed between moral distress and nurses' psychological empowerment. No studies to date have examined if such a relationship exists. If increased psychological empowerment is related to decreased moral distress in critical care nurses, then future strategies designed to increase empowerment may have the potential to decrease moral distress in critical care nurses.

This descriptive study is the first step in a program of research.

\section{The Research Questions}

This research study sought to answer three questions: 
Question 1:

What is the degree of moral distress [not in patient's best interest, individual responsibility, and deception] intensity and moral distress [not in patient's best interest, individual responsibility, and deception] frequency and psychological empowerment [meaning, competence, self-determination and impact] in critical care nurses caring for adults at EOL?

Question 2a:

Is there a relationship between moral distress [not in patient's best interest, individual responsibility, and deception] intensity and moral distress [not in patient's best interest, individual responsibility, and deception] frequency in critical care nurses caring for adults at EOL and select nurse demographics [age, years of critical care nursing experience, work status, active collaboration in EOL patient care conferences, level of education, AACN (American Association of Critical Care Nurses) certification, End-ofLife Nursing Education Consortium (ELNEC) critical care training, continuing EOLC education in the last year and AACN membership]?

Question 2b:

Is there a relationship between psychological empowerment [meaning, competence, self-determination and impact] in critical care nurses caring for adults at EOL and select demographics [age, years of critical care nursing experience, work status, active collaboration in EOL patient care conferences, level of education, AACN certification, End-of-Life Nursing Education Consortium (ELNEC) critical care training, continuing EOLC education in the last year, and AACN membership]? 
Question 3a:

What is the relationship between psychological empowerment [meaning, competence, self-determination and impact] and moral distress [not in patient's best interest, individual responsibility, and deception] intensity and moral distress [not in patient's best interest, individual responsibility, and deception] frequency in critical care nurses caring for adults at EOL?

Question 3b:

What is the relationship/association of psychological empowerment [meaning, competence, self-determination and impact] and select demographics [age, years of critical care nursing experience, work status, active collaboration in EOL patient care conferences, level of education, AACN certification, End-of-Life Nursing Education Consortium (ELNEC) critical care training, continuing EOLC education in the last year, and AACN membership] with moral distress [not in patient's best interest, individual responsibility, and deception] intensity and moral distress [not in patient's best interest, individual responsibility, and deception] frequency?

\section{Conceptual Framework}

Investigating a possible relationship between moral distress and psychological empowerment and examining the relationship between these two phenomena and select demographics informed the foundation of the conceptual framework. Three instruments, the moral distress scale (MDS), the psychological empowerment instrument (PEI), and a demographic questionnaire were used to examine all associations.

Moral distress as it is found in the conceptual framework refers to a feeling of frustration or unrest experienced by critical care nurses when caring for adults during 
EOL, when the nurse is unable to carry out the course of action that the nurse perceives to be ethically correct. Moral distress has three attributes a) not in patient's best interest, $b$ ) individual responsibility, and c) deception. Each of these attributes is conceptualized in terms of moral distress intensity and moral distress frequency. Psychological empowerment as it is found in the conceptual framework refers to the critical care nurse's sense of having control over the influence the nurse has related to the nurse's individual practice and in his or her contribution to appropriate EOLC decisions for adult patients being cared for in the critical care unit. Nursing characteristics that may be associated with nurses' moral distress intensity and moral distress frequency and psychological empowerment in critical care nurses caring for adults at EOL are as follows, listed in the conceptual framework.

Empowerment may be maintained through increased knowledge that is acquired by furthering ones education and level of expertise (Rafael, 1996). Although nurses may perceive themselves as having some degree of empowerment in relationship to nursing practice and the ability to be autonomous according to their knowledge base, nurses perceive themselves as frequently unable to significantly contribute to ethical decisions believed to be correct related to patient care. This "gap" between nurses having empirical knowledge and not being able to effectively apply that knowledge led to the impetus of this study that sought to explore the association between moral distress intensity, moral distress frequency and psychological empowerment in critical care nurses caring for adults at EOL. 


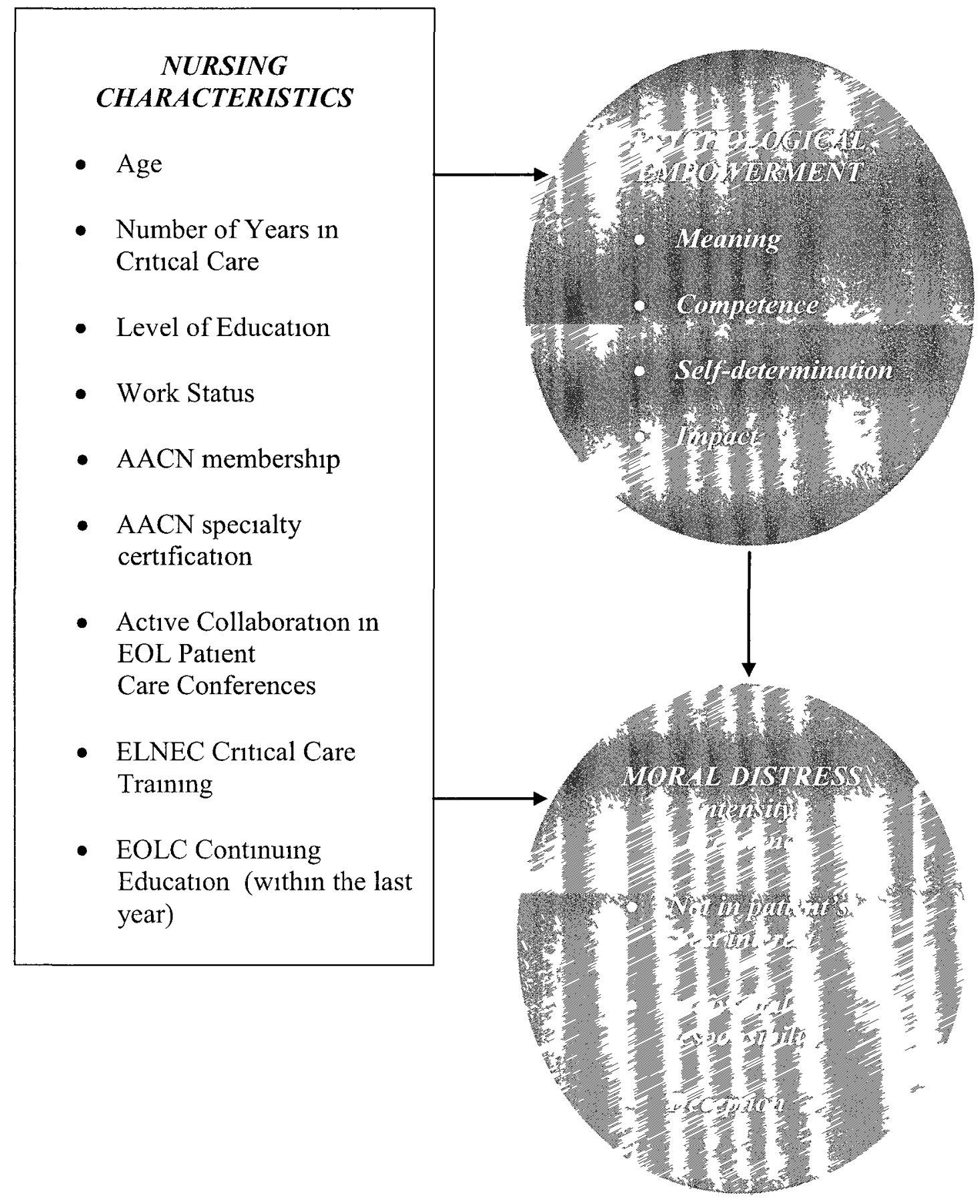

Conceptual Framework for the relationship between Moral Distress (Intensity and Frequency), Psychological Empowerment, and select demographics 


\section{Definition of Terms}

Moral Distress is defined as discomfort or internal conflict related to ethical dilemmas encountered in nursing practice when constraints prevent the nurse from following the course of action believed to be right (Jameton, 1984).

Moral distress (not in patient's best interest) refers to participating in care that the nurse considers inappropriate due to futility for the patient.

Moral distress (individual responsibility) refers to the nurse participating in care not agreed with or ignoring actions one should take.

Moral distress (deception) refers to the nurse not addressing issues related to impending death of a patient honestly.

Moral Distress Intensity is defined as the level at which the nurse experiences painful feelings related to a given situation.

Moral Distress Frequency is defined as how often the nurse experiences the situation causing painful feelings.

Empowerment is a mechanism by which people gain mastery over their affairs.

Psychological empowerment is defined as a motivational construct demonstrated in four cognitions: meaning, competence, self-determination, and impact (Thomas \& Velthouse, 1990).

Psychological empowerment (meaning) is the value the nurse places on his/her work based upon the individual's beliefs.

Psychological empowerment (competence) is the belief that the nurse perceives him/herself capable of performing the job related work well. 
Psychological empowerment (self-determination) is the individual's sense of having choice in initiating and regulating work situations.

Psychological empowerment (impact) is the degree to which the nurse feels he or she influences ultimate outcomes related to work situations.

Perceived empowerment in nursing is the nurse's view of oneself as having control over ones practice (Page, 2004) and the ability to act according to ones knowledge and judgment in context of ones nursing practice.

$\underline{\text { Work Status is defined as full-time (36 hours a week or greater), part-time (less than } 36}$ hours a week) and per diem (hours worked per week or month as defined by individual institution).

AACN Certification is the certification granted by the American Association of Critical Care Nurses. Types of AACN certifications include CCRN (adult, neonatal and pediatric), PCCN (progressive care), CCNS (adult, neonatal, and pediatric clinical nurse specialist), CMC (Cardiac machine), CSC (cardiac surgery), ACNPC (acute care nurse practitioner), and CNML (certified nurse manager and leader). Certification validates a nurse's qualifications and knowledge in critical care nursing, promotes continuing excellence in the specialty area, and enhances continued competence (AACN, 2010). Multidisciplinary refers to a holistic approach to patient care involving several disciplines developing the patient's plan of care. These disciplines may include medicine, nursing, social services, chaplaincy, pharmacy, respiratory therapy, among others.

Collaboration is the articulation of the nurse's reasoning for decisions related to patient care; the facilitation of the nurse's views in a multidisciplinary milieu. 
End-of-Life Care is the care administered to dying patients and their families. The care of this patient population often involves complex decisions related to life support treatments.

Education refers to the educational level or the nursing degree acquired, Doctoral degree, MSN, BSN, ADN, or Diploma.

End-of-Life Nursing Education Consortium ELNEC: critical care training is a three day course designed to equip nurses in the delivery of EOLC to critically ill patients; emphasizes training nurses to assist patients and families in the transition from curative to palliative care paradigms.

EOLC Continuing Education refers to any organized training related to EOLC.

\section{Implications for Nursing Practice}

If there is a relationship between increased psychological empowerment and decreased moral distress, then perhaps future work to develop effective strategies to increase psychological empowerment of critical care staff nurses could in effect decrease levels of moral distress. Nurses with lower levels of moral distress may in turn be able to practice more efficiently, with less turn-over and lower attrition rates, functioning more effectively in patient care, thus improving patient care outcomes. There have been no studies to date specifically examining the relationship between moral distress and psychological empowerment in nurses. There is currently a need for research to examine the relationship between psychological empowerment and moral distress in critical care nurses.

Recommendations for improving psychological empowerment of critical care staff nurses administering EOLC include improving communication between nursing 
staff and nursing management, patients and families, nursing colleagues, and other members of the health care team. Other recommendations for improving psychological empowerment among critical care nurses caring for adults encountering EOL decisions are more clearly defined institutional guidelines for EOLC and palliative care decision making, where nurses have a significant role. More organized forums for EOLC decision making, such as regular multidisciplinary rounds and patient care/family conferences where staff nurses are more effectively equipped and empowered to participate and articulate moral reasoning. Improving the role of the critical care nurse as advocate for patients and families may decrease moral distress in critical care nurses, potentially enhancing patient care outcomes. However, all of these suggestions are speculative. Little research has been conducted on these strategies. Examining the relationship between moral distress, psychological empowerment and related demographics may be insightful in determining interventions that may decrease moral distress and or increase psychological empowerment in critical care nurses administering EOLC.

Evolving out of the International Council of Nurses, in 2004 the American Association of Colleges of Nurses formulated competencies necessary for nurses to provide high-quality care to patients and families during transitions at EOL. A group of health care ethicists and palliative care experts composed competency statements to assist nurse educators in incorporating EOL content into nursing curricula at the undergraduate level.

There continues to be a need for further curricular development in nursing education related to EOLC. Further investigation of how specific EOLC course content at the undergraduate, graduate and post graduate levels may affect moral distress and 
psychological empowerment in critical care nurses is needed. Research is also needed in assessing degrees of moral distress in relationship to psychological empowerment in the population of nurses who have undergone coursework through the End of Life Care Nursing Education Consortium specifically formulated in 2006 to advance the expertise of practicing critical care nurses. 


\section{CHAPTER 2}

\section{Literature Review}

This chapter will expound upon classic and current literature relevant to the concepts of moral distress and psychological empowerment as presented in the conceptual framework. Literature addressing nursing characteristics that may influence moral distress and psychological empowerment will be discussed subsequently.

\section{Moral Distress}

The phenomenon of moral distress first appeared in the literature in 1984 in the work of Andrew Jameton. Jameton defined moral distress as unpleasant psychological disequilibrium resulting from recognizing the appropriate ethical action but not being able to see that action carried out. Moral distress results in nurses when they are unable to perform according to what they believe to be ethically correct. Following Jameton's (1985) initial work on moral distress, Wilkinson (1987/88) was the first of many studies to examine moral distress in nurses. Corley (1995) was the first to construct a psychometric instrument in order to measure moral distress intensity and moral distress frequency in nurses. 
Research with other health care professions such as respiratory therapists and pharmacists suffering from moral distress has been conducted (Schwenzer \& Wang, 2006; Kälvemar, Höglund, \& Arnetz, 2006). However, the majority of the research on moral distress has been performed primarily with nurses in various settings and specialty areas (Fenton, 1987; Rodney, 1988; Corley, 1995; Powell, 1998; Hefferman \& Heilig, 1999; Hamric, 2000; Gutierrez, 2005; Hamric \& Blackhall, 2007; Kain, 2007; Zuzelo, 2007; Rice et al., 2008; Pauly et al.,2009).

Jameton (1984) originally identified moral distress as resulting from institutional constraints preventing the nurse from performing nursing practice considered necessary and appropriate. Corley continued to advance Jameton's work in moral distress over a ten year period $(1995,2001,2002,2005)$.

Beginning in 1995 Corley elaborated more specifically on the causes of moral distress in nurses to include lack of time, lack of supervisory support, medical power, institutional policies and legal limitations. Corley premised that institutional goals may conflict with patient's personal wishes. Nurses' perception of this conflict has led to moral distress in nurses. In this initial study examining moral distress intensity and moral distress frequency in critical care nurses $(n=111)$ using the Moral Distress Scale (MDS), the greatest score (out of a possible 7) of moral distress frequency was experienced in situations related to EOLC: 1) life saving actions prolonging death (mean=5.9: $\mathrm{SD}=1.37$ ) 2) giving care to hopeless patients being maintained on ventilators (mean=5.9; $\mathrm{SD}=1.27$ ) and 3 ) following family wishes to continue life support not in patient's best interest (mean $=5.5 ; \mathrm{SD}=1.27$ ). However, all of the respondents in this 
study were members of the American Association of Critical Care Nurses thus limiting the generalizability of the findings.

As in her previous study of moral distress, a significant percentage (15\%) of the sample had left a position due to moral distress (Corley, 2001). In order to gain insight into ways of reducing moral distress, Corley advocated for additional studies using larger sample sizes examining possible factors associated with moral distress. However, none of the demographic variables using the MDS to measure moral distress intensity and moral distress frequency examined by Corley (2001), including years of critical care experience or education, predicted levels of moral distress. Corley speculated that variables that might reduce moral distress could include being assertive, participating in the team effort, having significant role models, and relating to peers. Overall, the literature examining the relationship of moral distress and nurse demographics to date is lacking.

In 2002, Corley described in a moral distress research agenda a model for a theory of moral distress. In this model nurses are faced with two alternatives, a) to act in accordance with moral convictions (moral intent to act) leading to moral comfort or b) to not act in accordance with ones convictions leading to moral distress. Since that time several interventions have been presented in the literature as potential modalities to help combat moral distress. These include shared governance (Kramer, et al, 2008), a nursing management innovation that potentially increases control of nursing practice (CNP) which in turn may decrease moral distress. The use of clinical ethicists (Faith \& Chikwick, 2009) in the development of collaborative paradigms between health professions is another potential mechanism for decreasing moral distress in nurses. 
Epstein \& Delgado (2010) propose the use of a moral distress consult service as part of a strategic agenda to assist in the decrease of moral distress in nursing.

In 2005 Corley conducted a study of registered nurses $(n=106)$ working on medical surgical units in two large medical centers examining the relationship between moral distress intensity and moral distress frequency using the revised 38 item moral distress scale (MDS-38) and ethical work environment using the Ethical E Questionnaire (EEQ). The mean moral distress intensity score out of a possible 7 was $3.64(\mathrm{SD}=1.57)$, indicating a moderate amount of moral distress intensity and a moral distress frequency score of (mean=1. $45 ; \mathrm{SD}=0.67$ ) illustrating the majority of the items causing moral distress were not occurring often. Corley speculated that this may have been due to a phenomenon called 'moral residue' (Webster \& Baylis, 2000) whereby unresolved moral distress accumulates over time but is not perceived by the participant as continuing to frequently occur.

In Corley's (2005) study, the correlation between moral distress frequency and moral distress intensity was significant $(r=0.42 ; p=0.01)$. A negative correlation was found between moral distress intensity and age $(r=-0.215 ; p=0.05)$ perhaps due to nurses learning how to deal with morally distressing situations over time. Ethnicity (African American) was correlated with moral distress intensity (Kendall's tau $=0.27 ; p=0.01$ ). Lack of power was reflected on the EEQ. The author postulated this may have been due to the sample population being $21 \%$ African American. In any case, the author confirms the significance of nurse empowerment as a means of combating moral distress in nurses.

Other investigators have also examined moral distress in nurses. The relationship between perceptions of moral distress and ethical climate was examined by Pauly, 
Varcoe, Storch and Newton (2009). This study used the 38 item MDS along with the hospital ethical climate survey (HECS) to obtain information related to moral distress in a sample of nurses in British Columbia $(n=374)$. Moral distress intensity findings revealed $($ mean $=3.88 ; \mathrm{SD}=1.609)$ on a range of $0-5.95$. None of the demographic variables (age, gender, years of experience, education and employment status) were found to be significantly related to mean moral distress intensity scores (Pauly et al., 2009); however, this study suggested there is currently an urgent need to generate additional data relating nursing demographics to moral distress.

Moral distress in nursing instrumentation. Because most published research on the topic of moral distress has been based upon one instrument, the Moral Distress Scale (MDS), this section provides background information on the MDS. Corley first developed a 32 item instrument (MDS-32) designed to measure two dimensions of moral distress in nurses, intensity and frequency. Intensity is the degree to which the nurse experiences the painful feeling and frequency is how often the nurse experiences the painful situation.

In order to describe moral distress and psychometrically test the instrument, Corley (1995) administered this first instrument to critical care nurses $(n=111)$. Each item was scored twice; once for intensity and once for frequency. The scoring used a 7 point Likert scale. Corley's original (1995) 32-item moral distress scale scored on a 7point Likert score (1=low to $7=$ high). The response anchors for intensity is from "none" to "great". The response anchors for frequency is from "never" to "very frequently". The three-factor structure of the MDS includes 1) action response (participating in care not agreed with or ignoring actions one should take), 2) individual responsibility 
(providing aggressive care to the hopelessly ill), and 3) deception (not addressing impending death honestly). Item level, subscale (factors), and mean total item scores were calculated (Corley, 1995, 2005).

The MDS-32 was tested for content validity utilizing three $\mathrm{PhD}$ prepared nurses with expertise in ethics and three staff nurses. These panels of nurses agreed all items were relevant and indicated no new items were needed. Using a convenience sample of 35 , test-retest reliability was $r=.86(p=.01)$ (Corley, 1995). Cronbach's Alpha was .93 $(p<.01)$, demonstrating reliability of the MDS. Such high reliabilities can sometimes reflect over redundancy of some items.

After Corley's initial study, the initial MDS-32 scale was decreased to 30 items (MDS-30) because two items referring to situations related to children accounted for a significant amount of missing data (over $50 \%$ of the respondents). Therefore, these two items were eliminated from the instrument in the subsequent study (Corley, 2001). Corley (2001) studied participants from several hospital sites in the United States $(n=214$ nurses) using this version of the instrument.

In determining if the MDS-30 items were measuring a commonality of moral distress, an exploratory factor analysis was conducted using three factors: 1) Individual responsibility, referring to the nurse participating in care not agreed with or ignoring actions the nurse should take ( 20 items) $(\mathrm{m}=4.98 ; \mathrm{SD}=1.53$; Cronbach's alpha=0.97; all factor loadings $>0.42$ ), 2) Not in patient's best interest, participating in care that the nurse considers inappropriate due to patient futility ( 7 items $)(m=4.93 ; \mathrm{SD}=1.12$; Cronbach's alpha $=0.82$; all factor loadings $>0.52$ ), and 3) Deception, referring to the 
nurse not addressing issues related to impending death of a patient honestly ( 3 items) $(\mathrm{m}=4.34 ; \mathrm{SD}=1.61 ;$ Cronbach's alpha $0.84 ;$ all factor loadings $>0.66)$.

The MDS was later expanded to 38 items including additional items related to pain management, managed care, and incompetent health care personnel (Corley et al, 2005). The 38 item instrument remained a 7-point Likert format but the range was changed from 1-7 in the MDS-32 to 0-6 in the MDS-38, the higher the score, the higher the intensity of moral distress and the higher the frequency of moral distress. Content validity of the revised MDS-38 instrument was reviewed by three doctorally prepared nurse experts with research experience related to nursing ethics. Based on the reviewer's evaluation, the content validity index resulted in $100 \%$ agreement that no items needed revision.

Radzvin (2011) used the Ethics Stress Scale (ESS) to evaluate moral distress in certified registered nurse anesthetists (CRNAs). This study showed moderate levels of moral distress in participants) $(\mathrm{n}=302)$. A strong recommendation by the author is the need for greater support by physicians in ethical decision making due to the life and death critical nature of the CRNA's responsibilities.

In summary, moral distress among nurses has been measured using the MDS in several studies. Using various versions of this instrument moral distress has been identified as a significant phenomenon in critical care nurses with Corley contributing to a majority of the published research. The significance of moral distress has been identified primarily in the population of critical care nurses caring for patients during EOL. 
Moral distress in critical care nurses related to end of life care. Several studies have associated levels of moral distress with the delivery of EOLC to patients (Corley, 1995; Sundin-Huard \& Fahy,1999; Hansen, Goddell, DeHaven, \& Smith, 2009). In the majority of the studies reviewed, the literature reflects that the most common phenomenon causing moral distress in critical care nurses related to EOLC is the delivery of futile care. There are many disparaging definitions of futile care. For purposes of this discussion futile care is defined as the administration of aggressive treatments or interventions, such as life support modalities, used to treat patients who are highly unlikely to survive or have any successful outcome (Council on Ethical and Judician Affairs - AMA, 1999).

Sundin-Huard \& Fahy (1999) conducted a qualitative survey ( $\mathrm{n}=10)$ of critical care nurses that revealed nurses' moral distress intensified with their attempts to advocate for dying patients leading to burnout and nurses leaving critical care and or nursing. The participants in this study expressed a desire for increased involvement in patient care decision-making and a desire that their opinions be better heard and respected.

Nathaniel (2006) in a qualitative study examining moral distress using a grounded theory approach found that powerlessness was a reoccurring theme emerging from nurses' stories about morally distressing situations, especially related to patient care decision making. Nurses claimed they had insight into how patients' problems should be handled but were unable to act as effective patient advocates due to experiences of powerlessness with physicians and family members. Nurses felt that they did not have adequate voice when they attempted to express what they felt to be the morally correct actions. Nurses felt conflicted with physicians and families that they perceived as higher 
authorities not acting in accordance with patient wishes. For instance, nurses felt powerless when physicians and family members made decisions pertaining to resuscitation or the placement of feeding tubes when the nurses felt this was not in accordance with what the patients wanted.

Moral distress related to futile care at EOL. The delivery of futile care during EOL was first examined by Wilkinson (1987/88) who built on the work of Jameton (1984). Multiple studies have found that futile care, where nurses perceived that the patient would not benefit from care, caused the most significant levels of moral distress in nurses (Wilkinson, 1987/88; Corley, 1995; Meltzer \& Huchkabay, 2004; Elpern, 2005; Guitierrez, 2005; Mobley, 2007; Hamric \& Blackhall, 2007).

\section{Qualitative and mixed methods relating futile care to moral distress at EOL.}

Futile care involving unnecessary treatments performed on patients was perceived by nurses as unnecessarily prolonging life and was morally distressing to nurses in Wilkinson's (1987/88) study. This qualitative study used phenomenology in constructing a theory relating moral distress in nurses to patient care.

Guitierrez (2005) examined moral distress in critical care nurses ( $\mathrm{n}=12)$ using phenomenological inquiry. This study found that overly aggressive medical treatment (futile care) resulting in increased patient suffering among other factors was the most significant source of moral distress in the nurses studied. The researcher in this study used open-ended guided interviewing questions regarding the nurse's clinical encounters with experiences that elicited moral distress. Recommendations for future research resulting from this study involved the improvement of collaborative methods among the 
multidisciplinary health care team that empowers nurses facilitating their more active voice.

Elpern (2005) associated the administration of aggressive (futile) care to patients who were not expected to benefit from that care with the highest levels of moral distress intensity and frequency. Elpern used a mixed methods approach examining moral distress in critical care staff nurses $(\mathrm{n}=28)$. The 38 item MDS and an open ended questionnaire asking nurses to describe the implications of situations in which they experienced moral distress were utilized. The mean moral distress intensity score for all participants on the MDS-38 was 3.66 (range 1.76-5.79; SD 1.73). A moderate level of moral distress intensity was found on the moral distress intensity subscales. The moral distress frequency score for all participants was 1.73 (range 0.74-4.42; SD-0.90) indicating that items of moral distress intensity did not occur frequently overall. Educational preparation had no significant associations to moral distress.

The qualitative portion of Elpern's (2005) study revealed themes such as nurses' feelings of powerlessness, hopelessness, and lack of support. Elpern postulated the feelings causing moral distress may be related to the complexity of the use of life support systems and heightened expectations of patients and families related to patient care outcomes during EOLC. Limitations of this study include the small sample size and data collected from one single facility, therefore the findings may not be generalizable to critical care nurses administering EOLC to patients in other institutions. The phenomenon of 'moral residue' (Webster \& Baylis, 2000) discussed earlier may also apply to the low level of moral distress frequency. 
Quantitative methods relating futile care to moral distress at EOL. Corley

(1995) found that the three most frequently occurring situations (reflected in the items on the MDS) causing moral distress in nurse participants $(n=111)$ were specifically related to the delivery of futile care at EOL. On a Likert scale coded 1 to 7 (1-low to 7-high) the situations occurring most frequently were as follows: 1) initiating life-saving actions that prolonged the patient's death (mean $=5.9 ; \mathrm{SD}=1.37) 2$ ) continuing to participate in care for hopelessly injured patients because no one would "pull the plug" (mean=5.9; $\mathrm{SD}=1.25$ ) 3) following the family's wishes to continue life support when this was not in the best interest of the patient (mean=5.5; $\mathrm{SD}=1.27$ ).

In Corley's (1995) study, 55 participants worked in a private hospital and 36 participants were employed in a medical center. All participants were members of a local chapter of the American Association of Critical Care Nurses. Age, education, and length and types of experience had no significant effects on level of moral distress using one way analysis of variance. In this study however, the private hospital population of critical care nurses reported significantly higher levels of moral distress on items related to unnecessary aggressive care (mean $=5,88: \mathrm{F}=6.12 ; p=.05)$ than the academic medical center facility.

Meltzer \& Huckabay (2004) also examined futile care as a source of moral distress in a sample of critical care nurses $(n=60)$ examining the relationship of moral distress to burn out. Futile care was defined as life-sustaining interventions and treatments that had no benefit to the patient. This study found the frequency of situations perceived as morally distressing, when the nurse considered care of patients to be futile were significantly related to emotional exhaustion. Higher moral distress frequency 
scores were significantly related to items addressing futile care and higher scores on the scale measuring burnout on the Maslach Burnout Inventory (MBI) $(\mathrm{r}=0.317, p=0.05)$. Using the MDS, Meltzer \& Huckabay (2004) found a significant relationship between educational level and moral distress, indicating that critical care nurses with bachelor's degrees experienced significantly higher moral distress frequencies on items related to futility than did associate degree nurses. This may be due to the bachelor nurse's ability to more intently recognize situations of futility. According to the authors, a possible limitation of this study was that nurses who were experiencing moral distress may not have been motivated to participate in the study.

In a study surveying critical care nurses' $(n=44)$ perception of futile care, using the 38 item MDS categorized the items as follows: physician, practice, nursing practice, institutional factors, futile care, deception, and euthanasia (Mobley et al, 2007). Moral distress frequency from the futile care category was the highest in comparison to the other categories. The sum score of moral distress intensity in the futility category was 28 out of a maximum score of 42 . The sum score of moral distress frequency in the futility category was 18 out of a maximum score of 42 . Items related to futile care were encountered by $66-89 \%$ of the critical care nurses in the study. This study showed no significant associations between moral distress intensity and years in critical care nursing practice. The moral distress frequency from items categorized as related to futile care was significantly associated with greater than four years of critical care nursing practice. Two possible explanations were offered for this: 1) the encounter of futile care situations was proportionate to time spent in the care of critically ill populations 2) experience acquired over the years spent in caring for critically ill populations assisted critical care 
nurses in being able to identify what they perceived as situations of futility more frequently than nurses with less number of years working in critical care. Possible limitations of this study are related to the study being performed at a single institution where specific patterns of nurse/physician collaboration existed, thus perhaps limiting the representation of the study's implications.

Hamric \& Blackhall (2007) found the three highest ranking items causing moral distress in the nurses studied were related to the delivery of futile care. Nurse-physician perspectives on the care of dying patients in intensive care units was examined related to collaboration, moral distress and ethical climate ( $\mathrm{n}=196 \mathrm{RNs}$ and 29 MDs). The authors adapted several instruments appropriate for use with both nurses and physicians. This study formulated a new instrument using a combination of the MDS-38, reducing it to 19 items and investigator-designed questions. The highest rated situations causing moral distress in the nurses ranging from 0-16 (16 being the highest degree of moral distress) were following the family's wishes to continue life support even though not in the patient's best interest, site $1 \mathrm{RNs}(\mathrm{n}=106)($ mean $=10.24$; $\mathrm{SD}=4.70)$ and site $2 \mathrm{RNs}(\mathrm{n}=88)$ (mean=9.33; $\mathrm{SD}=4.39$ ). Initiating lifesaving actions that only prolong death ranked second between the 2 groups, site $1 \mathrm{RNs}(\mathrm{n}=106)($ mean=9.88; $\mathrm{SD}=4.83)$ and site $2 \mathrm{RNs}$ $(\mathrm{n}=88)($ mean $=8.92 ; \mathrm{SD}=4.61)$. Continuing to participate in care when no one will make the decision to "pull the plug" ranked third highest in situations of moral distress, site $1 \mathrm{RNs}(\mathrm{n}=88)($ mean=8.60; $\mathrm{SD}=4.84)$ and site $2 \mathrm{RNs}(\mathrm{n}=106)($ mean=8.39; $\mathrm{SD}=4.96)$. Participants were recruited from 14 separate intensive care units in 2 institutions, a 631bed community hospital and a 481-bed university affiliated hospital. Participants rated both intensity (termed level of disturbance) and frequency (termed how often the 
disturbance occurs) related to moral distress. The description of these three situations resonates with nurses having to perform life sustaining treatments when the nurse feels this is not the correct action to take.

Rice et al (2008) determined a significant correlation between recognition of situations involving futile care and years of medical surgical nursing experience in an acute care environment. The repeated exposure to these types of situations was correlated with higher degrees of moral distress intensity and moral distress frequency on the MDS $(n=260)$.

In summary, moral distress in critical care nurses related to caring for patients during EOL is prolific. The most significant phenomenon related to moral distress in critical care nurses caring for patients during EOL is related to the care of patients whereby the nurse considers aggressive life sustaining treatments to be futile. However, there is limited research examining moral distress in critical care nurses caring for adults at EOL related to other important phenomena in nursing and no research examining moral distress related to psychological empowerment in nursing.

\section{Empowerment}

Empowerment is a mechanism by which people gain mastery over their affairs. In the nursing literature empowerment has been examined on the basis of two conceptualizations, structural empowerment (external structural components related to ones work environment such as specialty certification) and psychological empowerment (ones belief in one's ability to be empowered). For purposes of this study psychological empowerment will be discussed. 
Theories of psychological empowerment. Bandura (1986), a renowned psychologist noted for his work on social learning theory, developed a model of social self-efficacy in empowerment. He theorized that degrees of empowerment are perceived as ones sense of self-efficacy is facilitated. Self-efficacy occurs when ones sense of selfdetermination is strengthened or ones sense of powerlessness is weakened. Bandura (1977), in his earlier writings pointed out, "The strength of peoples' conviction in their own effectiveness is likely to affect whether they would even try to cope with given situations...they get involved in activities and behave assuredly when they judge themselves capable of handling situations that would otherwise be intimidating..." (p. 193-194).

Conger and Kanungo (1988) took self-efficacy a step further by applying motivational theory to self-efficacy theory. They reiterate that true empowerment occurs, when convictions of ones own effectiveness are in fact successfully executed and not merely hoped for. This sense of capability by the individual or group can be significantly influenced by the individuals who are in a perceived position of power over the perceived subordinates. Furthermore, the strength of ones perceived empowerment determines how obstacles are viewed and the degree to which one overcomes the obstacles (Bandura, 2007).

Thomas and Velthouse (1990) postulated a step further that empowerment is multi-faceted encompassing four cognitions: (1) meaning (2) competence (synonymous with self-efficacy) (3) self-determination and (4) impact. Meaning is the value one attaches to ones standards. Competence is the belief that one is able to carry out ones beliefs in action. Self-determination is the sense that one has control over ones 
autonomy. Impact is the degree to which one perceives his or her work as having influence.

Empowerment in nursing. Corbally, Scott, Matthews, Mac Gabhann, and Murphy (2007) conducted a qualitative study examining empowerment in nurses and midwives ( $\mathrm{n}=93$ ). Ten focus groups were conducted with between 5 and 13 participants in each group. The following 4 themes were identified in impacting empowerment related to personal or psychological power of the participants: confidence, being educated, feeling respected and having a voice. Education for practice was determined to be an antecedent to empowerment.

Williamson (2007) utilized a mixed method research design to examine home health registered nurses' perceptions of psychological empowerment $(n=15)$. Interview and observation methods were combined with use of the Psychological Empowerment Instrument (PEI). Means were calculated for each of the 16 items on the PEI. Means were as follows in each category (range=0-7): Choice (mean=5.7), Impact (mean=4.2), Meaning (mean=6.2) and Competence (mean=6.5). Standard deviations were not provided. Average overall PEI score was 5.7. Interviews identified that nurses in this study expressed trust, collaboration, and communication amongst fellow members of the health care team and patients as the most important facets of empowerment. A potential limitation of this study was the small sample size making it difficult to generalize results to other populations of nursing specialties. Another limitation was the examination of the ability to have an impact as a dimension of empowerment was not addressed in this study. 
In Manojlovich's (2007) discussion of empowerment three types of power that nurses need to perform optimally were proposed. These types are control over 1) the content of practice, 2) the context of practice, and 3) competence. The content of practice refers to the nurse's ability to act according to ones knowledge and judgment. This ability is restricted in cases of moral distress by definition. The context of practice refers to the nurse's ability to actively participate in the collaboration of patient care decisionmaking. The control over competence refers to the nurse's educational preparation. It can be safely conjectured that moral distress may result from a lack of control in any or all of these types of power. Manojlovich (2007) offers a fairly comprehensive overview of the historical review of a nurse's power over nursing practice; however in discussing the overview of empowerment and power in nursing, it is unclear at times the distinction between the use of these two phenomena by definition. In the theorization of the three types of power that nurses need in order to make significant contributions, the leap to the application of empowerment in nursing is conceptually weak and somewhat speculative.

Knol \& van Linge (2009) found in a cross sectional study that registered nurses $(n=516)$ with more years of working experience had a statistically significant positive, but weak relationship with perceived psychological empowerment. Using the PEI instrument (Cronbach's alpha=0.87) and the Dutch questionnaire Innovative Behaviour (Cronbach's alpha $=0.96$ ), the authors found that psychological empowerment is positively correlated to innovative behavior by nurses using a Pearson's $r$ correlation $(r=0.53 ; p<0.01)$. This study found registered nurses who worked more hours per week perceived themselves as more greatly psychologically empowered $(r=0.51 ; p=0.001)$. 


\section{Critical Care Nursing Expertise in the Delivery of Patient Care at EOL}

The development of nursing expertise specific to EOLC may decrease moral distress and increase empowerment in critical care nurses. Select demographics such as critical care nurses taking an active participation in multidisciplinary EOL patient care conferences, continuing education related to EOLC, and the End-of-Life Nursing Education Consortium (ELNEC) training, are essential in decreasing potential causes for moral distress and in possibly empowering critical care nurses caring for adult populations at EOL.

\section{Active collaboration in multidisciplinary EOL patient care conferences.}

Several studies support the exploration of nurse collaboration in EOLC patient conferences as a potential significant demographic influencing moral distress and perceived empowerment (Ferrand et al., 2003; AACN, 2005; Guitierrez 2005; Hamric \& Blackhall, 2007; Mobley et al., 2007; \& Vollers, Hill, Roberts Dambaugh, \& Benner, 2009). The literature supports critical care nurses perceive a lack of nursing collaboration in patient care decision making between members of the health care team, identifying this as one of the major causes of moral distress in critical care nurses (Gutierrez, 2005). In a study analyzing EOLC decision making in critical care (Ferrand et al, 2003) $90 \%$ of physicians and nurses believed decisions should be collaborative, yet only $27 \%$ of the nurses perceived themselves as involved in the decision making process $(\mathrm{n}=3,156$ nurses).

In Corley's research agenda in 2002, Corley stated that moral distress is possibly related to a lack of nurse activism. Activism being defined as nurses taking a more proactive role in making their voices heard. Activism takes place when nurses are able to 
actively collaborate with other members of the health care team. Perceived empowerment if increased may play a part in promoting collaboration and decreasing moral distress. Hamric \& Blackhall (2007) found in a descriptive pilot study using a survey design that nurses reported a lower perception of collaboration and higher moral distress than did attending physicians.

The AACN developed and published Standards for Establishing and Sustaining Healthy Work Environments (AACN, 2005). Standard \#2 is True Collaboration: Nurses must be relentless in pursuing and fostering true collaboration. The purpose of these standards is to create an environment whereby nurses are empowered to provide optimum care to the critically ill (Vollers et al., 2009). Collaboration, as defined by AACN, involves critical care nurses being able to proactively articulate well regarding moral reasoning in a multidisciplinary arena resulting in accurate and effective patient care decisions. Data is needed that evaluates critical care nurses' multidisciplinary collaboration related to EOL patient conferences as it relates to empowerment and moral distress among critical care nurses.

Continuing nursing education related to EOLC. Mobley et al (2007) suggested that continuing educational course content emphasizing critical thinking and communication skills assists critical care nurses with the ability to collaborate with various disciplines in topics related to ethical decision making. The honing of such skills enabling more effective collaboration in a multidisciplinary environment has the potential to empower nurses as more competent practitioners. In a literature review of life support technology and the dying experience Browning (2010) explicitly stated the need for 
specific efforts to be made to educate critical care nurses as to the EOLC competencies set forth in the AACN peaceful death policy statement.

Corley (2002) stated that research studies addressing preventative solutions to moral distress, such as continuing education were gravely needed. Beckstrand et al (2006) in a study using a 72-item survey assessing critical care nurses' suggestions for improving EOLC, found that nurses felt frustration (moral distress) in prolonging a patient's inevitable death. It was suggested that further research is needed to explore the tension that critical care nurses experience related to EOLC in a highly technological environment. A strategy recommended in this study was the further development of educational programs related to EOLC.

\section{The End-of-Life Nursing Education Consortium (ELNEC) critical care}

training. The ELNEC critical care training course has been evaluated (Ferrell, 2007) but examination of the impact of this training in relationship to empowerment has not been studied. The End-of-Life Nursing Education Consortium (ELNEC) was initiated in 2000 in an attempt to better train nurses in various areas of nursing practice in caring for patients at EOL. In 2006, ELNEC incorporated a comprehensive training course specifically for critical care nurses. This endeavor was born out of studies that reflected a lack of education or training of critical care nurses about EOLC, resulted in critical care nurses being ill equipped to provide exemplary care to patient populations during EOL (Beckstrand \& Kirchoff, 2005).

ELNEC critical care training provides a 3 day course designed to enhance the ability of critical care nurses to care for patients at EOL. The course emphasizes equipping the critical care nurse in assisting the patient and family in making appropriate 
decisions and transitioning from curative to palliative care models when appropriate. Using a scale from 1 (poor) to 5 (excellent) attendees $(n=57)$ of this initial course were asked to evaluate the content. The overall rating of the course was 4.8 (Ferrell et al., 2007). Participants suggested that more attention be given to the moral distress felt by critical care nurses in the delivery of EOLC, especially types of patient care related to futility.

\section{Gaps in the Literature}

Several gaps in the literature exist. No studies have been conducted examining the relationship between moral distress and empowerment. Critical care staff nurses are to an extent in subordination to physicians, hospital administration and upper level nursing personnel, advanced practice nurses and nursing administrators. Perceived psychological empowerment in nurses may be jeopardized and moral distress increased

due to this phenomenon. There are no studies to date examining the relationship of moral distress and psychological empowerment in nurses.

Further data is needed exploring relationships between moral distress, empowerment, and select demographics. For example, nurses' development of expertise in the delivery of EOLC to critically ill populations should be explored in order to better understand relationships between these variables and sources of empowerment. Several authors support the exploration of nurse collaboration in EOLC patient conferences as a potential significant demographic in the study of moral distress and perceived empowerment (Ferrand et al, 2003; AACN, 2005; Guitierrez 2005; Hamric \& Blackhall, 2007; Mobley, 2007; \& Vollers, 2009). However, no such studies have been conducted. 
Several studies have recommended an increase in continuing education related to EOLC (Beckstrand, Callister \& Kirchhoff, 2006; Mobley, 2007; \& Hansen, 2009). However, data is needed examining the relationship between this demographic and nurses' moral distress and perceived empowerment. Although several studies have recommended continuing education related to EOLC as a means of reducing moral distress, no studies have examined this relationship. No studies have examined relationships between moral distress or empowerment in the population of nurses who have undergone the end-of-life care nursing education consortium (ELNEC) critical care training course.

In Corley's (2005) study examining the relationship between moral distress in nurses and ethical work environments, Corley stated, "The findings demonstrate the importance of nurse empowerment and an environment that supports ethical practice in decreasing the frequency of moral distress" (p. 388). In correspondence between the researcher of this study and Corley the need for this study was affirmed, examining the relationship between moral distress and perceived empowerment in critical care nurses caring for critically ill adults at end of life (M.C. Corley, personal communication, March 2, 2009).

Recently, a significant relationship between empowerment and AACN specialty certification has been established in limited studies (Piazza, Donahue, Dykes, Quinn, \& Fitzpatrick 2006; Fitzpatrick, Campo, Graham, \& Lavandero, 2010). A large innovative web-based study (Fitzpatrick et al., 2010) examined the value and influence of specialty certification by AACN as compared to noncertified critical care nurses $(n=6,589)$. The purpose of this study was to examine structural empowerment in nurses, whereby 
certification was defined as a structural component of empowerment. Empowerment scores were significantly higher among specialty certified critical care nurses vs. noncertified critical care nurses. However, no studies have been conducted that evaluate psychological empowerment (ones belief in the ability to be empowered) related to AACN specialty certification.

In light of an ongoing nursing shortage, Erlen (2004), Doctoral Program Director and Professor at the center for Bioethics and Health Law at the University of Pittsburgh, stated that empowering nurses has the potential to reduce the moral distress that nurses are experiencing. As a first step, this descriptive study seeks to generate knowledge related to this possible association. 


\section{CHAPTER 3}

\section{Methodology}

The purpose of this study is to examine the relationship between moral distress and psychological empowerment of critical care nurses caring for adults at EOL. This chapter includes a description of the design, sample, sampling method, psychometric instruments used, data collection and data analysis.

Specific Aims:

Aim 1

Describe the degree of moral distress intensity and moral distress frequency and psychological empowerment in critical care nurses caring for adults at EOL.

$\operatorname{Aim} 2 a$

Describe the relationship between moral distress intensity and moral distress frequency in critical care nurses caring for adults at EOL and select demographics [age, years of critical care nursing experience, work status, active collaboration in EOL patient care conferences, level of education, AACN specialty certification, End-of-Life Nursing Education Consortium (ELNEC) critical care training, continuing EOLC education in the last year and AACN membership]. 
$\operatorname{Aim} 2 b$

Examine the relationship between psychological empowerment in critical care nurses caring for adults at EOL and select demographics [age, years of critical care nursing experience, work status, active collaboration in EOL patient care conferences, level of education, AACN specialty certification, End-of-Life Nursing Education Consortium (ELNEC) critical care training, continuing education in the last year and AACN membership].

$\operatorname{Aim} 3 a$

Describe the relationship between moral distress intensity and psychological empowerment and the relationship between moral distress frequency and psychological empowerment in critical care nurses caring for adults at $\mathrm{EOL}$

$\operatorname{Aim} 3 b$

Examine the relationship/association of moral distress intensity and moral distress frequency and select demographics [age, years of critical care nursing experience, work status, active collaboration in EOL patient care conferences, level of education, AACN specialty certification, End-of-Life Nursing Education Consortium (ELNEC) critical care Training, continuing EOLC education in the last year and AACN membership] with psychological empowerment.

\section{Research Design}

A cross sectional descriptive survey design was used to study a target population of critical care nurses caring for adults at EOL. A survey design is a type of quantitative design that allows for the identification of the strength of multiple variables (Creswell, 2009). Using a survey methodology, numeric descriptions of critical care nurses' moral 
distress intensity, moral distress frequency and psychological empowerment in the workplace was determined with the intent of possibly generalizing from the sample population to a larger population. Two valid and reliable instruments were used, the Moral Distress Scale (MDS) and the Psychological Empowerment Instrument (PEI) in addition to the gathering of demographic data.

\section{Sampling and Recruitment Plan}

A sample of critical care nurses who were on the email newsletter list of the American Association of Critical Care Nurses (AACN) were recruited for this study. Inclusion criteria were as follows: a) a critical care staff nurse and b) had experience with caring for adults at EOL in the critical care setting prior to completing the survey tools.

Sample size. A power analysis was conducted in order to estimate the sample size required for a moderate effect size of 0.15 for a product moment correlation $\left(r^{2-} .09\right.$, estimated) and a power of 0.80 , insuring no more than a $20 \%$ chance of making a type II error. The effect size was determined by the differences in the means between the scores on each instrument expressed as standard deviations (Creswell, 2009). Considering the effect size, the conventional alpha level of significance set at (0.05), a two tailed test, and the conventional power of $(0.80), 127$ participants were needed (Faul, 2010) to detect robust relationships between moral distress intensity and moral distress frequency and psychological empowerment.

Recruitment. Participants were recruited through AACN and identified by their newsletter email roster after the proposal was presented to AACN and permission was granted. Verbal authorization by AACN's research specialist that this study was consistent with the organization's agenda was granted. Final authorization by AACN 
was granted after approval of the proposal by the dissertation committee following IRB approval by the University of San Diego.

\section{Study Variables}

Dependent variables. Moral distress intensity and moral distress frequency were two separate dependent or outcome variables. For the purposes of this study the operational definition of moral distress intensity is defined as the level at which the nurse experienced painful feelings related to a given situation. Moral distress frequency is defined as how often the nurse experienced the painful feeling associated with the distressful situation. Perception of moral distress intensity and moral distress frequency were measured using the Moral Distress Scale (MDS).

Independent variables. Psychological empowerment and the demographics as follows: age, years of critical care nursing experience, work status, active collaboration in EOL patient care conferences, level of education, American Association of Critical Care Nurses (AACN) specialty certification, End-of-Life Nursing Education Consortium (ELNEC) critical care training, continuing EOLC education in the last year, and AACN membership were the independent or predictor variables. The operational definition of psychological empowerment in critical care nurses is defined as a motivational construct demonstrated in four cognitions: meaning, competence, self-determination, and impact (Thomas \& Velthouse, 1990).

Years of critical care experience was measured as a continuous variable by the number of years the staff nurse had practiced in the critical care setting, caring for adult patients, including populations at end of life. Work status was measured as nominal level data using 3 categories, full-time, part-time, or per diem. Level of education was 
measured as ordinal data with 4 options as follows: associates degree (ADN)/diploma, baccalaureate degree (BSN), master's degree (MSN) or doctoral degree. AACN specialty certification, active collaboration in EOL patient care conferences, End-of-Life Nursing Education Consortium (ELNEC) critical care training, continuing EOLC education in the last year and $\mathrm{AACN}$ membership were measured as dichotomous data using 2 options, yes or no.

\section{Instrumentation}

Data collection was obtained using three separate instruments. The instruments included the Moral Distress Scale (MDS), the Psychological Empowerment Instrument (PEI), and a demographic questionnaire.

Moral distress scale (MDS). The moral distress scale is an instrument used to measure two separate dimensions of the nurse's perception of moral distress, the level of intensity to which the nurse experiences moral distress and the frequency of the situations causing moral distress. There is no summative score of intensity and frequency calculated; therefore there is no total score for moral distress. Within the MDS there are three subscales (individual responsibility, not in patient's best interest and deception). Each of the subscales has a separately calculated intensity total score and a frequency total score.

As background, the MDS, originally a 32 item scale was developed by Corley (1995) and based on Jameton's (1984) concept of moral distress. Moral distress was defined as a painful feeling and/or psychological disequilibrium caused by a situation in which one knows the ethically appropriate action to take but believes that action cannot be carried out due to a variety of obstacles. It was determined that these obstacles may be 
institutional in nature, such as lack of time, supervisory disinterest, medical power, institutional policy or legal limitations. Corley (1995) formulated the MDS to measure moral distress in critical care staff nurses caring for critically ill populations. The MDS was devised from research on moral problems that nurses confronted in the critical care setting.

The MDS-32 was tested for content validity twice. First, interviews with 3 staff nurses revealed no new items. Second, in assessments of the items conducted with three $\mathrm{PhD}$ nurses who had expertise in nursing ethics, all items were considered relevant. This original 32 item instrument used exploratory factor analysis for grouping items measuring moral distress: 1) not in patient's best interest (participating in care the nurse considered inappropriate due to patient futility), ( 9 items), $(\mathrm{m}=2.7, \mathrm{SD}=1.1, \alpha=0.81), 2)$ individual responsibility (the nurse participating in care not agreed with or ignoring actions the nurse should take) (14 items), $(\mathrm{m}=2.5, \mathrm{SD}=1.2, \alpha=0.93)$ and 3 ) deception (not addressing issues related to impending death of a patient honestly) ( 8 items $)(m=2.4$, $\mathrm{SD}=1.3, \alpha=0.85)$.

Test-retest reliability of the MDS-32 was conducted (Corley, 2001) with a convenience sample $(\mathrm{n}=35)$ was $0.86(p=0.01)$. However, the high reliability may reflect redundancy of some items. Cronbach's Alpha was .93 ( $p<.01)$, demonstrating reliability of the MDS.

Corley (2001) studied participants from several hospitals in the United States using the MDS-32. Using an exploratory factor analysis this study identified three factors: 1) individual responsibility ( 20 items) $(m=4.98 ; S D=1.53) 2)$ not in patient's best interest $(7$ items $)(\mathrm{m}=4.93 ; \mathrm{SD}=1.12)$ and 3$)$ deception $(3$ items $)(\mathrm{m}=4.34 ; \mathrm{SD}=1.61)$. 
For purposes of this research study the 32 item MDS instrument was used (see Appendix A). The level of data is interval because response options are not related to one another. Items were scored separately for intensity (none to great extent) and frequency (never to very frequently) on a Likert from 1 to 7 . Item level, subscale (factors), and mean total item scores were calculated separately for intensity and frequency (Corley, 1995, 2005).

\section{The Psychological Empowerment Instrument (PEI)}

Psychological empowerment in the workplace is defined as a motivational construct manifesting itself in four cognitive dimensions: meaning, competence, selfdetermination, and impact (Spreitzer, 1996). Spreitzer defined meaning as the congruence between the work role and an individual's beliefs and values, competence refers to a belief in one's ability to perform work activities, self-determination is the individual's sense of choice reflecting autonomy, and impact is the degree to which an individual can influence operational outcomes.

For purposes of this study the PEI 16 item instrument was used (see Appendix B). The PEI is a 16 item scale compiled by Spreitzer (1995) using 4 items to measure each of the 4 cognitive dimensions as interval data on a 7-point Likert scale from very strongly disagree to very strongly agree. The 4 dimensions are 1) meaning 2) competence 3 ) selfdetermination and 4) impact, each domain addressing 4 items. Items were scored as follows: 7) Very strongly disagree 6) Strongly disagree 5) Disagree 4) Neutral 3) Agree 2) Strongly agree 1) Very strongly agree. Each item was scored in addition to subscale scores and total scores calculated. 
Spreitzer (1995) obtained a random sample $(\mathrm{n}=393)$ of business managers, and examined the four dimensions of psychological empowerment and how each dimension contributed to an overall construct of psychological empowerment. Several instruments were used, one of which was the PEI, 12 item version which contains 3 items per domain. Items loaded on the appropriate factors and the four factors significantly correlated with each other, suggesting further studies were needed on validity of the domains.

The PEI has been found to be highly reliable and valid (Spreitzer, 1995; 1996) and reported reliability coefficients ranged from 0.62 to 0.74 . Subsequently, the PEI has been used in over 50 studies examining various populations, including nurses and manufacturing workers. The validity of the instrument has been confirmed, dimensions have averaged .80 (Spreitzer \& Quinn, 2001) and test-retest reliability has been strong.

Knol and van Linge (2008) used the PEI to investigate the relationship between structural/psychological empowerment and innovative behavior in 519 nurses in the Netherlands. Cronbach's alpha is this study was 0.87 . The PEI has been used in a wide range of work environments, from nursing to manufacturing workers. Test-retest reliability in these environments has been shown to be strong with validity approximating 0.80 .

\section{Demographic Data}

A brief 9-item questionnaire developed for this study was used to obtain information regarding the participant's age, years of critical care nursing experience, work status, active collaboration in EOL patient care conferences, level of education, AACN specialty certification, End-of-Life Nursing Education Consortium (ELNEC) 
critical care training, continuing EOLC education in the past, and AACN membership (see Appendix C).

\section{Data Collection Procedures}

This study's topic was approved as congruent with AACN's agenda by AACN's Clinical Practice Specialist (personal communication). Per AACN policy, final approval of the study was obtained after submission of a study abstract, a copy of Chapter 1 , the 3 instruments (MDS, PEI and demographic questionnaire), a cover letter explaining the study to prospective participants (see Appendix D), and a copy of the Institutional Review Board (IRB) approval by the University of San Diego was obtained (see Appendix E). A short paragraph describing the study was placed in the AACN weekly newsletter recruiting subscribers who met the study criteria (critical care nurses who were participating in caring for adults at EOL). This informational paragraph regarding the research study was placed in four consecutive weekly AACN newsletters.

AACN sends out a weekly newsletter to approximately 100,000 recipients as per AACNs Clinical Practice Specialist. The recipients of the AACN newsletter are health professionals but not all are critical care nurses. Approximately 80,000 of the recipients are estimated by AACN to be critical care nurses; however anyone is eligible to subscribe to the newsletter upon request.

If subscribers were interested in participating in the study they used a link in the newsletter paragraph leading them to an online survey where the research investigator of this study posted an authored cover letter explaining the details and instructions related to the research study. After reading the cover letter, if the subscriber wished to participate in the study he or she proceeded with the on-line survey mechanism (SurveyMonkey). 
The researcher previously uploaded the anonymous study materials (MDS, PEI and demographic questionnaire) to SurveyMonkey. The University of San Diego IRB determined that the return of the completed survey indicated informed consent. Average data completion time for the surveys and demographic information was estimated to be less than 40 minutes.

\section{Data Collection}

Data collection was accomplished via the internet using the on-line mechanism in SurveyMonkey that uploads data. Upon receipt of data from Survey Monkey in the form of EXCEL spread sheets the data was transferred to Statistical Package for Social Sciences (SPSS), version 17.0 SPSS.

\section{Data Analysis}

The Statistical Package for the Social Sciences (SPSS/17) was used for data analysis. Descriptive and inferential statistics were used to calculate the results. Descriptive statistics using ranges, means, and standard deviations were used to describe the continuous data variables. Percentages were used to describe the categorical variables. Appropriate correlational statistics, based upon variable level of data (continuous or categorical), were used to examine relationships among variables.

Multiple linear regression analysis was used to examine associations between the dependent variable of moral distress intensity and the independent variables of the demographics and psychological empowerment and the dependent variable of moral distress frequency and the independent variables of the demographics and psychological empowerment. Multiple regression is appropriately used with data examining one dependent variable and two or more independent variables (Mertler \& Vannatta, 2005). 
The power of a statistical test is the probability that significant relationships amongst variables exist. Power is determined by 1 - the beta weight that is determined by a series of complex computations. The extent of the power will determine the robust nature of the data results. To determine the most significant relationships between the dependent variables and the independent variables, a sequential multiple regression examines one select independent variable at a time. As each independent variable (demographic) is examined, its relationship to the dependent variables (moral distress intensity and moral distress frequency) was assessed along with the primary independent variable (psychological empowerment).

\section{Protection of Human Subjects}

Approval by the Institutional Review Board (IRB) of the University of San Diego (USD) for the protection of human subjects was obtained for this study. The USD IRB determined that a written informed consent was not required. An IRB approved cover letter was included in the study informing the readers about the following information: participation in the study as voluntary, study data was kept confidential, risks and benefits of participation, and how to contact the investigator for questions. The participants were assured of their anonymity both in data collection and the publication of data. All data was stored on a password protected computer. No identifying information, including e-mail addresses, was included in the Excel spreadsheet uploaded from SurveyMonkey.

\section{Risks}

In completing the questionnaires the participants could have suffered a degree of discomfort from the recollection of adverse memories related to the subject matter. 
Participants were encouraged in the cover letter they read at the beginning of the selfadministered survey to discontinue the survey if that occurred.

\section{Benefits}

There were no direct benefits to participants for participating in this study. However, participant's awareness of the conditions of moral distress both personally and in their facilities may have been heightened. This increased self-awareness may have prompted participants to seek support professionally and/or privately. Another potential benefit to participants was that participants may have gained an increased awareness that they contributed to the addition of significant data in the literature related to moral distress. The significant findings from this research study may spur future interventional studies designed to aid in the decrease of moral distress in populations of critical care nurses, benefiting critical care nurses over the long term.

\section{Limitations and Strengths of the Study}

Limitations of this study design may have been the nature of the convenience sampling as opposed to random sampling, thus limiting the study findings in terms of predictability and generalizability. By nature of the recruitment, AACN newsletter subscribers may possess different professional characteristics and have different feelings about psychological empowerment and moral distress in the workplace as opposed to critical care nurses who do not subscribe to the AACN newsletter. This may limit the generalizability of this study.

However, there are a number of advantages related to this research study design. The recruitment strategy increased the ability to readily identify, contact and recruit large numbers of the target population of qualified participants. In addition to participant 
accessibility, another advantage of the survey design was the feasibility and expeditious nature of on-line data collection. And finally, the approach to multivariate analysis allowed for a range of possible contributing factors in an attempt to learn more about moral distress in critical care nurses. 


\section{Results}

\section{CHAPTER 4}

The purpose of this quantitative cross sectional descriptive research study was to examine the relationship between moral distress intensity and moral distress frequency and psychological empowerment in critical care nurses caring for adults at end of life. Data collection included the moral distress scale (MDS), the psychological empowerment instrument (PEI), and a survey of select demographics.

The correlations between moral distress intensity and moral distress frequency, psychological empowerment and select demographics as well as results of the multiple regression analysis were analyzed. This chapter presents the findings for each of the three research questions.

Quantitative data was collected from October 28, 2010 to November 25, 2010. Of the approximate 80,000 emailed surveys, 277 were returned. The return rate was approximately $0.35 \%$. The Statistical Package for the Social Sciences 17.0 (SPSS) program for multivariate correlation was used to determine if relationships existed between the dependent variables (moral distress intensity and moral distress frequency) and the independent variables (psychological empowerment and the demographics). 


\section{Demographics}

The participants $(\mathrm{n}=277)$ had a mean age of $46.9(\mathrm{SD}=10.4)$. The mean number of years of experience working as a critical care nurse was reported as $17.45(\mathrm{SD}=11)$. The majority of the participants $(\mathrm{n}=234,87.6 \%)$ were working full-time in critical care. The percent of participants employed part-time was $12 \%(\mathrm{n}=32)$. Only one participant was working per diem. Greater than half of the nurses reported being active participants in EOL patient care conferences (54.6\%). The majority of the nurses were BSN graduates (47.1\%); $29.2 \%$ of the participants were ADN graduates; $19.7 \%$ of the nurses were MSN graduates and 3.3\% of the participating nurses were doctorally prepared. The majority of the participants $(55.2 \%)$ had specialty certification by the American Association of Critical Care Nurses (AACN). The majority of the participants (54.6\%) also reported having had End-of-life care (EOLC) education within the past year. A large majority of participating nurses ( $86 \%$ ) reported having membership with AACN. Only $5.9 \%$ of the participants $(n=16)$ reported participation in ELNEC critical care training. Descriptive statistics of these demographic variables can be found in Table 1. 
Table 1 Respondent Descriptive Statistics

\begin{tabular}{|c|c|c|c|}
\hline $\begin{array}{l}\text { Characteristics } \\
(\mathrm{n}=274)\end{array}$ & $\begin{array}{l}\mathrm{N} \\
(\%) \\
\end{array}$ & $\begin{array}{l}\text { Mean } \\
\text { (SD) }\end{array}$ & Range \\
\hline $\begin{array}{l}\text { Age } \quad \text { Total } \\
\end{array}$ & 274 & $\begin{array}{l}46.9 \\
(10.4)\end{array}$ & $22-70$ \\
\hline Years of CC Experience & & $\begin{array}{l}17.45 \\
(11.00) \\
\end{array}$ & $0.5-44.0$ \\
\hline $\begin{array}{l}\text { Work Status } \\
\text { Full-time }\end{array}$ & $\begin{array}{l}234 \\
(87.6 \%)\end{array}$ & - & - \\
\hline Part-time & $\begin{array}{l}32 \\
(12.0 \%)\end{array}$ & - & - \\
\hline Per Diem & $\begin{array}{l}1 \\
(0.4 \%)\end{array}$ & - & - \\
\hline $\begin{array}{l}\text { Collaboration in EOLC } \\
\text { Conferences }\end{array}$ & $\begin{array}{l}118 \\
(43.4 \%)\end{array}$ & - & - \\
\hline $\begin{array}{c}\text { Educational Background } \\
\text { Doctorate }\end{array}$ & $\begin{array}{l}9 \\
(3.3 \%)\end{array}$ & - & - \\
\hline MSN & $\begin{array}{l}54 \\
(19.7 \%)\end{array}$ & - & - \\
\hline BSN & $\begin{array}{l}129 \\
(47.1 \%)\end{array}$ & - & - \\
\hline ADN/Diploma & $\begin{array}{l}80 \\
(29.2 \%)\end{array}$ & - & - \\
\hline $\begin{array}{c}\text { AACN Specialty } \\
\text { Certification } \\
\text { Yes }\end{array}$ & $\begin{array}{l}149 \\
(55.2 \%)\end{array}$ & - & - \\
\hline $\begin{array}{c}\text { ELNEC Training } \\
\text { Yes }\end{array}$ & $\begin{array}{l}16 \\
(5.9 \%)\end{array}$ & - & - \\
\hline $\begin{array}{c}\text { Education r/t EOLC } \\
\text { Yes }\end{array}$ & $\begin{array}{l}148 \\
(54.6 \%)\end{array}$ & - & - \\
\hline $\begin{array}{c}\text { AACN Membership } \\
\text { Yes }\end{array}$ & $\begin{array}{l}234 \\
(86.0 \%)\end{array}$ & - & - \\
\hline
\end{tabular}




\section{Research Question 1}

What is the degree of moral distress [not in patient's best interest, individual responsibility and deception] intensity and moral distress [not in patient's best interest, individual responsibility and deception] frequency and psychological empowerment [meaning, competence, self-determination and impact] in critical care nurses caring for adults at EOL?

\section{Moral Distress Intensity and Moral Distress Frequency}

Moral distress intensity and moral distress frequency items were scored on a Likert Scale from 1-7 (none=1 to great extent=7 for intensity; never=1 to very frequently $=7$ for frequency). Table 2 presents the data for the 32 -item MDS. Data from two items (12 and 13) pertaining to children was omitted from being included in the data analysis due to the focus of the study on the care of adults. Additionally, MDS subscales and total scores were calculated for both intensity and frequency. The following summarizes the results in moral distress intensity and moral distress frequency for a) individual items, b) subscales, and c) total scores.

Individual items. Moral distress intensity item mean scores ranged from 4.39 to 6.05. The three highest moral distress intensity scoring items were "assisting MD who in my opinion is providing incompetent care" $(\mathrm{m}=6.05)$, "work in a situation when the number of staff is too low and care is inadequate," $(\mathrm{m}=5.97)$ and "continue to care for a hopelessly injured patient on a ventilator when no one will discontinue the ventilator" $(\mathrm{m}=5.88)$.

The lowest scoring moral distress intensity item was "carry out MD's orders for unnecessary tests and treatments on terminally ill patients" $(\mathrm{m}=4.39)$. Moral distress 
frequency item mean scores ranged from 1.43 to 4.45 . The three highest scoring moral distress frequency items were, "follow family's wishes to continue life support when not in patient's best interest," $(\mathrm{m}=4.45)$ "follow MD's orders for unnecessary tests" $(\mathrm{m}=4.28)$ and "follow family wishes for patient care I don't agree with" $(\mathrm{m}=4.08)$. The lowest scoring moral distress frequency item was, "Carry out order to discontinue treatment because patient can no longer pay" $(\mathrm{m}=1.43)$.

Subscale total scores. Means and standard deviation total scores for both moral distress intensity and moral distress frequency were determined for each of the three subscale categories as follows: not in patient's best interest, individual responsibility, and deception (See Table 2). All moral distress intensity subscale totals were high: a) not in patient's best interest $(\mathrm{m}=5.13, \mathrm{SD}=1.25), \mathrm{b})$ individual responsibility $(\mathrm{m}=5.50$, $\mathrm{SD}=1.47)$ and $\mathrm{c})$ deception $(\mathrm{m}=4.92, \mathrm{SD}=1.82)$.

Moral distress intensity subscales were all high as follows: a) not in patient's best interest $(m=5.14, \mathrm{SD}=1.25), \mathrm{b})$ individual responsibility $(\mathrm{m}=5.50, \mathrm{SD}=1.47)$ and $\mathrm{c})$ deception ( $\mathrm{m}=4.92, \mathrm{SD}=1.82)$. Moral distress frequency subscales were as follows: $\mathrm{a})$ not in patient's best interest $(\mathrm{m}=3.69, \mathrm{SD}=1.22), \mathrm{b})$ individual responsibility $(\mathrm{m}=2.15$, $\mathrm{SD}=.88)$, and $\mathrm{c})$ deception $(\mathrm{m}=2.16, \mathrm{SD}=1.43)$.

Total moral distress intensity and total moral distress frequency scores. As a reminder, there is no total score for moral distress. Total moral distress intensity score was high $(\mathrm{m}=5.34, \mathrm{SD}=1.32)$ with total moral distress frequency score being moderate $(\mathrm{m}=2.51, \mathrm{SD}=0.87)$. 
Table 2 Moral Distress Respondent Intensity and Frequency $(\mathbf{n}=277)$ according to subscales: Not in patient's best interest, Individual responsibility and Deception)

\begin{tabular}{|c|c|c|c|}
\hline & Item & $\begin{array}{l}\text { Intensity } \\
\text { Mean } \\
(\mathrm{SD})\end{array}$ & $\begin{array}{l}\text { Frequency } \\
\text { Mean } \\
(\mathrm{SD})\end{array}$ \\
\hline \multirow{8}{*}{$\begin{array}{l}\text { Not in } \\
\text { patient's best } \\
\text { interest Items }\end{array}$} & $\begin{array}{l}\text { 1. Follow family wishes for } \\
\text { patient care I don't agree with }\end{array}$ & $\begin{array}{l}4.81 \\
(1.52)\end{array}$ & $\begin{array}{l}4.08 \\
(1.66)\end{array}$ \\
\hline & $\begin{array}{l}\text { 2. Follow family's wishes to } \\
\text { continue life support when not in } \\
\text { patient's best interest }\end{array}$ & $\begin{array}{l}5.47 \\
(1.46)\end{array}$ & $\begin{array}{l}4.45 \\
(1.65)\end{array}$ \\
\hline & $\begin{array}{l}\text { 3. Follow MD's orders for } \\
\text { unnecessary tests }\end{array}$ & $\begin{array}{l}5.22 \\
(1.53)\end{array}$ & $\begin{array}{l}4.28 \\
(1.80)\end{array}$ \\
\hline & $\begin{array}{l}\text { 5. Initiate Life-saving actions } \\
\text { when I think it prolongs death }\end{array}$ & $\begin{array}{l}5.72 \\
(1.46)\end{array}$ & $\begin{array}{l}3.73 \\
(1.71)\end{array}$ \\
\hline & $\begin{array}{l}\text { 15. Carry out MD's orders for } \\
\text { unnecessary tests and treatments } \\
\text { on terminally ill patients }\end{array}$ & $\begin{array}{l}4.39 \\
(2.18)\end{array}$ & $\begin{array}{l}3.71 \\
(1.77)\end{array}$ \\
\hline & $\begin{array}{l}\text { 22. Prepare a terminally ill } \\
\text { elderly patient on a ventilator for } \\
\text { surgery to have a mass removed }\end{array}$ & $\begin{array}{l}5.09 \\
(1.91)\end{array}$ & $\begin{array}{l}2.42 \\
(1.41)\end{array}$ \\
\hline & $\begin{array}{l}\text { 23. Prepare an elderly severely } \\
\text { demented patient who is a no } \\
\text { code for gastrostomy tube }\end{array}$ & $\begin{array}{l}5.24 \\
(1.87)\end{array}$ & $\begin{array}{l}3.17 \\
(1.67)\end{array}$ \\
\hline & $\begin{array}{l}\text { Not in patient's best interest } \\
\text { Subscale Score }\end{array}$ & $\begin{array}{l}5.13 \\
(1.25)\end{array}$ & $\begin{array}{l}3.69 \\
(1.22)\end{array}$ \\
\hline \multirow[t]{4}{*}{$\begin{array}{l}\text { Individual } \\
\text { Responsibility } \\
\text { Items }\end{array}$} & $\begin{array}{l}\text { 4. Assist MD who performs test } \\
\text { or treatment without patient } \\
\text { consent }\end{array}$ & $\begin{array}{l}5.27 \\
(2.08)\end{array}$ & $\begin{array}{l}2.01 \\
(1.44)\end{array}$ \\
\hline & $\begin{array}{l}\text { 6. Ignore situations of suspected } \\
\text { patient abuse by caregivers }\end{array}$ & $\begin{array}{l}5.51 \\
(2.16)\end{array}$ & $\begin{array}{l}1.60 \\
(1.17)\end{array}$ \\
\hline & $\begin{array}{l}\text { 7. Ignore situations of inadequate } \\
\text { patient consent }\end{array}$ & $\begin{array}{l}5.42 \\
(1.76)\end{array}$ & $\begin{array}{l}2.22 \\
(1.52)\end{array}$ \\
\hline & $\begin{array}{l}\text { 8. Perform procedure when the } \\
\text { patient is not adequately } \\
\text { informed }\end{array}$ & $\begin{array}{l}5.36 \\
(1.71)\end{array}$ & $\begin{array}{l}2.21 \\
(1.46)\end{array}$ \\
\hline
\end{tabular}




\begin{tabular}{|c|c|c|c|}
\hline & $\begin{array}{l}\text { 9. Carry out work assignment in } \\
\text { which I do not feel professionally } \\
\text { competent }\end{array}$ & $\begin{array}{l}5.27 \\
(1.95)\end{array}$ & $\begin{array}{l}1.91 \\
(1.12)\end{array}$ \\
\hline & $\begin{array}{l}\text { 10. Avoid taking action when a } \\
\text { nurse colleague has made a } \\
\text { mediation error }\end{array}$ & $\begin{array}{l}4.89 \\
(1.84)\end{array}$ & $\begin{array}{l}2.05 \\
(1.20)\end{array}$ \\
\hline & $\begin{array}{l}\text { 11. Let medical students perform } \\
\text { painful procedures on patients } \\
\text { solely to increase their skill }\end{array}$ & $\begin{array}{l}5.40 \\
(2.09)\end{array}$ & $\begin{array}{l}2.00 \\
(1.52)\end{array}$ \\
\hline & $\begin{array}{l}\text { 14. Assist MDs practicing } \\
\text { procedures on a patient after CPR } \\
\text { has been unsuccessful }\end{array}$ & $\begin{array}{l}5.09 \\
(2.35)\end{array}$ & $\begin{array}{l}1.45 \\
(1.15)\end{array}$ \\
\hline & $\begin{array}{l}\text { 16. Work with "unsafe" levels of } \\
\text { nurse staffing }\end{array}$ & $\begin{array}{l}5.82 \\
(1.56)\end{array}$ & $\begin{array}{l}3.57 \\
(1.88)\end{array}$ \\
\hline & $\begin{array}{l}\text { 17. Carry out order to } \\
\text { discontinue treatment because } \\
\text { patient can no longer pay }\end{array}$ & $\begin{array}{l}5.36 \\
(2.39)\end{array}$ & $\begin{array}{l}1.43 \\
(1.26)\end{array}$ \\
\hline & $\begin{array}{l}\text { 18. Continue to care for a } \\
\text { hopelessly injured patient on a } \\
\text { ventilator when no one will } \\
\text { discontinue the ventilator }\end{array}$ & $\begin{array}{l}5.88 \\
(1.50)\end{array}$ & $\begin{array}{l}3.61 \\
(1.81)\end{array}$ \\
\hline & $\begin{array}{l}\text { 19. Observe without intervening } \\
\text { when personnel do not respect } \\
\text { patient's dignity }\end{array}$ & $\begin{array}{l}5.67 \\
(1.68)\end{array}$ & $\begin{array}{l}2.21 \\
(1.68)\end{array}$ \\
\hline & $\begin{array}{l}\text { 20. Follow MD's order not to tell } \\
\text { patient the truth when he/she asks } \\
\text { for it }\end{array}$ & $\begin{array}{l}5.83 \\
(1.78)\end{array}$ & $\begin{array}{l}1.86 \\
(1.24)\end{array}$ \\
\hline & $\begin{array}{l}\text { 21. Assist MD who in my } \\
\text { opinion is providing incompetent } \\
\text { care }\end{array}$ & $\begin{array}{l}6.05 \\
(1.56)\end{array}$ & $\begin{array}{l}2.49 \\
(1.36)\end{array}$ \\
\hline & $\begin{array}{l}\text { 24. Discharge patient based on } \\
\text { DRGs although he has many } \\
\text { teaching needs }\end{array}$ & $\begin{array}{l}5.15 \\
(2.04)\end{array}$ & $\begin{array}{l}1.95 \\
(1.43)\end{array}$ \\
\hline & $\begin{array}{l}\text { 25. Provide better care for those } \\
\text { who can afford to pay }\end{array}$ & $\begin{array}{l}5.20 \\
(2.23)\end{array}$ & $\begin{array}{l}1.67 \\
(1.40)\end{array}$ \\
\hline & $\begin{array}{l}\text { 26. Follow the family's request } \\
\text { not to discuss dying with a dying } \\
\text { patient who asks about dying }\end{array}$ & $\begin{array}{l}5.79 \\
(1.74)\end{array}$ & $\begin{array}{l}2.22 \\
(1.27)\end{array}$ \\
\hline & $\begin{array}{l}27 . \text { Follow MD's request not to } \\
\text { discuss death with a dying patient } \\
\text { who asks about dying }\end{array}$ & $\begin{array}{l}5.76 \\
(1.86)\end{array}$ & $\begin{array}{l}1.98 \\
(1.33)\end{array}$ \\
\hline
\end{tabular}




\begin{tabular}{|c|c|c|c|}
\hline & $\begin{array}{l}\text { 28. Work in a situation when the } \\
\text { number of staff is too low and } \\
\text { care is inadequate }\end{array}$ & $\begin{array}{l}5.97 \\
(1.72)\end{array}$ & $\begin{array}{l}2.91 \\
(1.79)\end{array}$ \\
\hline & $\begin{array}{l}\text { 32. Follow MD's request not to } \\
\text { discuss code status with family } \\
\text { when patient is incompetent }\end{array}$ & $\begin{array}{l}5.50 \\
(2.03)\end{array}$ & $\begin{array}{l}1.91 \\
(1.43)\end{array}$ \\
\hline & $\begin{array}{l}\text { Individual Responsibility } \\
\text { Subscale Score }\end{array}$ & $\begin{array}{l}5.50 \\
(1.47)\end{array}$ & $\begin{array}{l}2.15 \\
(.88)\end{array}$ \\
\hline \multirow[t]{5}{*}{$\begin{array}{l}\text { Deception } \\
\text { Items }\end{array}$} & $\begin{array}{l}\text { 29. Give meds IV during a code } \\
\text { with no compressions or } \\
\text { intubation }\end{array}$ & $\begin{array}{l}4.68 \\
(2.18)\end{array}$ & $\begin{array}{l}2.29 \\
(1.506)\end{array}$ \\
\hline & $\begin{array}{l}\text { 30. Give only hemodynamic } \\
\text { stabilizing meds IV during a code } \\
\text { with no compression or } \\
\text { intubation }\end{array}$ & $\begin{array}{l}4.49 \\
(2.20) \\
2.20\end{array}$ & $\begin{array}{l}2.30 \\
(1.46) \\
1.46\end{array}$ \\
\hline & $\begin{array}{l}\text { 31. Follow MD's request not to } \\
\text { discuss code status with patient }\end{array}$ & $\begin{array}{l}5.54 \\
(2.05) \\
2.05\end{array}$ & $\begin{array}{l}1.87 \\
(1.37) \\
1.37\end{array}$ \\
\hline & Deception Subscale Score & $\begin{array}{l}4.92 \\
1.82\end{array}$ & $\begin{array}{l}2.16 \\
1.20\end{array}$ \\
\hline & TOTAL OF ALL SUBSCALES & $\begin{array}{l}5.34 \\
(1.32)\end{array}$ & $\begin{array}{l}2.51 \\
(0.87)\end{array}$ \\
\hline
\end{tabular}

\section{Psychological Empowerment Instrument (PEI)}

The Psychological Empowerment Instrument was used to determine levels of psychological empowerment of critical care nurses in the workplace. Data from this instrument was scored in the following manner: individual item mean scores, mean subscale scores, and finally a mean total score was calculated for PEI (See Table 3).

PEI items. PEI items ranged from moderate $(\mathrm{m}=3.88)$ to high $(\mathrm{m}=6.22)$. The highest scoring PEI item was, "I really care about what I do on my job" $(\mathrm{m}=6.22$; $\mathrm{SD}=1.16$ ). The lowest scoring item was, "I have a great deal of control over what happens in my department" $(\mathrm{m}=3.88, \mathrm{SD}=1.52)$.

PEI subscales and total score. PEI subscales were all high as follows: meaning $(\mathrm{m}=6.06, \mathrm{SD}=1.09)$, competence $(\mathrm{m}=5.92, \mathrm{SD}=1.02)$, self-determination $(\mathrm{m}=5.03$, 
$\mathrm{SD}=1.18)$, and impact $(\mathrm{m}=4.22, \mathrm{SD}=1.47)$. And overall, the total PEI mean score indicated a high degree of psychological empowerment $(\mathrm{m}=5.31, \mathrm{SD}=1.00)$.

Table 3 Psychological Empowerment $(n=277)$ according to subscales, Meaning, Competence, Self-Determination \& Impact

\begin{tabular}{|c|c|c|}
\hline & & $\begin{array}{l}\text { Mean } \\
\text { (SD) }\end{array}$ \\
\hline \multirow[t]{5}{*}{$\begin{array}{l}\text { Meaning } \\
\text { Items }\end{array}$} & 2. The work that I do is important to me & $\begin{array}{l}6.07 \\
(1.568)\end{array}$ \\
\hline & 5. My job activities are personally meaningful to me. & $\begin{array}{l}5.77 \\
(1.16) \\
\end{array}$ \\
\hline & 8. I really care about what I do on my job. & $\begin{array}{l}6.22 \\
(1.16) \\
\end{array}$ \\
\hline & 13. The work I do is meaningful to me. & $\begin{array}{l}6.17 \\
(1.18)\end{array}$ \\
\hline & Meaning Subscale Total Score & $\begin{array}{l}\mathbf{6 . 0 6} \\
(1.18)\end{array}$ \\
\hline & - & \\
\hline \multirow[t]{5}{*}{$\begin{array}{l}\text { Competence } \\
\text { Items }\end{array}$} & 1. I am confident about my ability to do my job. & $\begin{array}{l}5.95 \\
(1.36) \\
\end{array}$ \\
\hline & 9. My job is well within the scope of my abilities. & $\begin{array}{l}6.05 \\
(1.22) \\
\end{array}$ \\
\hline & 11. I have mastered the skills necessary for my job. & $\begin{array}{l}5.81 \\
(1.14)\end{array}$ \\
\hline & $\begin{array}{l}\text { 15. I am self-assured about my capabilities to } \\
\text { perform my work activities. }\end{array}$ & $\begin{array}{l}5.88 \\
(1.12) \\
\end{array}$ \\
\hline & Competence Subscale Total Score & $\begin{array}{l}\mathbf{5 . 9 2} \\
(1.12) \\
\end{array}$ \\
\hline \multirow[t]{5}{*}{$\begin{array}{c}\text { Self- } \\
\text { Determination } \\
\text { Items }\end{array}$} & $\begin{array}{l}\text { 3. I have significant autonomy in determining how I } \\
\text { do my job. }\end{array}$ & $\begin{array}{l}4.98 \\
(1.37)\end{array}$ \\
\hline & $\begin{array}{l}\text { 7. I can decide on my own how to go about doing } \\
\text { my own work. }\end{array}$ & $\begin{array}{l}4.97 \\
(1.32) \\
\end{array}$ \\
\hline & $\begin{array}{l}\text { 10. I have a great deal of control over what happens } \\
\text { in my department. }\end{array}$ & $\begin{array}{l}4.84 \\
(1.50)\end{array}$ \\
\hline & $\begin{array}{l}\text { 16. I have a chance to use personal initiative in } \\
\text { carrying out my work. }\end{array}$ & $\begin{array}{l}5.28 \\
(1.28)\end{array}$ \\
\hline & Self-Determination Subscale Total Score & 5.03 \\
\hline
\end{tabular}




\begin{tabular}{|c|c|c|}
\hline & & $\begin{array}{l}\text { Mean } \\
\text { (SD) }\end{array}$ \\
\hline \multirow[t]{5}{*}{ Impact Items } & $\begin{array}{l}\text { 4. My impact on what happens in my department is } \\
\text { large. }\end{array}$ & 4.47 \\
\hline & $\begin{array}{l}\text { 6. I have a great deal of control over what happens in } \\
\text { my department. }\end{array}$ & 3.88 \\
\hline & $\begin{array}{l}\text { 12. My opinion counts in departmental decision- } \\
\text { making. }\end{array}$ & 4.41 \\
\hline & $\begin{array}{l}\text { 14. I have significant influence over what happens in } \\
\text { my department. }\end{array}$ & 4.09 \\
\hline & Impact Subscale Total Score & $\begin{array}{l}4.22 \\
(1.47)\end{array}$ \\
\hline \multirow[t]{2}{*}{$\begin{array}{l}\text { TOTAL PEI } \\
\text { Score } \\
\text { (all items) }\end{array}$} & & $\begin{array}{l}5.31 \\
(1.00)\end{array}$ \\
\hline & Self-Determination Subscale Total Score & 5.03 \\
\hline \multirow[t]{5}{*}{ Impact Items } & $\begin{array}{l}\text { 4. My impact on what happens in my department is } \\
\text { large. }\end{array}$ & 4.47 \\
\hline & $\begin{array}{l}\text { 6. I have a great deal of control over what happens in } \\
\text { my department. }\end{array}$ & 3.88 \\
\hline & $\begin{array}{l}\text { 12. My opinion counts in departmental decision- } \\
\text { making. }\end{array}$ & 4.41 \\
\hline & $\begin{array}{l}\text { 14. I have significant influence over what happens in } \\
\text { my department. }\end{array}$ & 4.09 \\
\hline & Impact Subscale Total Score & $\begin{array}{l}4.22 \\
(1.47)\end{array}$ \\
\hline $\begin{array}{c}\text { TOTAL PEI } \\
\text { Score } \\
\text { (all items) }\end{array}$ & & $\begin{array}{l}5.31 \\
(1.00)\end{array}$ \\
\hline
\end{tabular}

\section{Research Question 2a}

Is there a relationship between moral distress [individual responsibility, not in patient's best interest and deception] intensity and moral distress [individual responsibility, not in patient's best interest and deception] frequency in critical care nurses caring for adults at EOL and select nurse demographics [age, years of critical care nursing experience, work status, active collaboration in multidisciplinary EOLC patient conferences, level of education, AACN (American Association of Critical Care Nurses) 
certification, End-of-Life Nursing Education Consortium (ELNEC) Critical Care Training, continuing education in the last year and AACN membership]?

Correlations were computed to identify relationships between participant demographics and a) moral distress intensity subscales and the total moral distress intensity score and b) moral distress frequency subscales and the total moral distress frequency score.

Moral distress intensity and demographics. Two demographics correlated with moral distress intensity, both in the "not in patient's best interest" subscale. Significant but weak positive correlations (Huck, 2008) were found between "not in patient's best interest" subscale and a) age $(r=.179, p=.011$,) and b) ELNEC critical care training $(r=.185, p=.008)$.

As nurse's age increased so did moral distress intensity. Also, nurses who reported having ELNEC critical care training experienced significant levels of greater moral distress intensity in items related to "not in patient's best interest" (participating in care that the nurse considered inappropriate due to futility for the patient). No demographics were significantly correlated with the total moral distress intensity score. (See table 4a.) 
Table 4a: Relationship between Moral Distress \& Demographics

\begin{tabular}{|c|c|c|c|c|}
\hline \multirow[b]{2}{*}{ Demographics } & \multicolumn{4}{|c|}{ Moral Distress Intensity } \\
\hline & $\begin{array}{l}\text { Not in patient's } \\
\text { Intensity } \\
\text { best interest }\end{array}$ & $\begin{array}{l}\text { Individual } \\
\text { responsibilit }\end{array}$ & Deception & Total MD \\
\hline Age & $\begin{array}{l}\mathrm{r}=.179^{*} \\
\mathrm{n}=202\end{array}$ & $\begin{array}{l}\mathrm{r}=.087 \\
\mathrm{n}=176\end{array}$ & $\begin{array}{l}\mathrm{r}=.113 \\
\mathrm{n}=203\end{array}$ & $\begin{array}{l}\mathrm{r}=.119 \\
\mathrm{n}=169\end{array}$ \\
\hline $\begin{array}{l}\text { Years of CC } \\
\text { Experience }\end{array}$ & $\begin{array}{l}\mathrm{r}=.057 \\
\mathrm{n}=201\end{array}$ & $\begin{array}{l}\mathrm{r}=.044 \\
\mathrm{n}=175\end{array}$ & $\begin{array}{l}\mathrm{r}=.076 \\
\mathrm{n}=202\end{array}$ & $\begin{array}{l}\mathrm{r}=.023 \\
\mathrm{n}=168\end{array}$ \\
\hline Work Status & $\begin{array}{l}\mathrm{r}=.048 \\
\mathrm{n}=198\end{array}$ & $\begin{array}{l}\mathrm{r}=.026 \\
\mathrm{n}=172\end{array}$ & $\begin{array}{l}\mathrm{r}=.038 \\
\mathrm{n}=199\end{array}$ & $\begin{array}{l}\mathrm{r}=.001 \\
\mathrm{n}=165\end{array}$ \\
\hline $\begin{array}{l}\text { Collaboration in } \\
\text { EOLC Conferences }\end{array}$ & $\begin{array}{l}\mathrm{r}=100 \\
\mathrm{n}=200\end{array}$ & $\begin{array}{l}\mathrm{r}=-.058 \\
\mathrm{n}=174\end{array}$ & $\begin{array}{l}\mathrm{r}=.076 \\
\mathrm{n}=201\end{array}$ & $\begin{array}{l}r=-.005 \\
n=167\end{array}$ \\
\hline Education & $\begin{array}{l}\mathrm{r}=.068 \\
\mathrm{n}=202\end{array}$ & $\begin{array}{l}\mathrm{r}=.028 \\
\mathrm{n}=176\end{array}$ & $\begin{array}{l}\mathrm{r}=124 \\
\mathrm{n}=203\end{array}$ & $\begin{array}{l}\mathrm{r}=.063 \\
\mathrm{n}=169\end{array}$ \\
\hline AACN Certification & $\begin{array}{l}\mathrm{r}=-.004 \\
\mathrm{n}=200\end{array}$ & $\begin{array}{l}\mathrm{r}=.051 \\
\mathrm{n}=174\end{array}$ & $\begin{array}{l}\mathrm{r}=.021 \\
\mathrm{n}=201\end{array}$ & $\begin{array}{l}\mathrm{r}=.039 \\
\mathrm{n}=167\end{array}$ \\
\hline $\begin{array}{l}\text { ELNEC CC } \\
\text { Training }\end{array}$ & $\begin{array}{l}\mathrm{r}=.185^{*} \\
\mathrm{n}=201\end{array}$ & $\begin{array}{l}\mathrm{r}=.066 \\
\mathrm{n}=175\end{array}$ & $\begin{array}{l}\mathrm{r}=.122 \\
\mathrm{n}=202\end{array}$ & $\begin{array}{l}\mathrm{r}=.111 \\
\mathrm{n}=168\end{array}$ \\
\hline $\begin{array}{l}\text { EOLC Education in } \\
\text { the Past Year }\end{array}$ & $\begin{array}{l}\mathrm{r}=.068 \\
\mathrm{n}=200\end{array}$ & $\begin{array}{l}\mathrm{r}=.058 \\
\mathrm{n}=174\end{array}$ & $\begin{array}{l}\mathrm{r}=.124 \\
\mathrm{n}=201\end{array}$ & $\begin{array}{l}\mathrm{r}=.072 \\
\mathrm{n}=167\end{array}$ \\
\hline AACN Membership & $\begin{array}{l}\mathrm{r}=-.101 \\
\mathrm{n}=201\end{array}$ & $\begin{array}{l}\mathrm{r}=-.071 \\
\mathrm{n}=175\end{array}$ & $\begin{array}{l}\mathrm{r}=-.079 \\
\mathrm{n}=202\end{array}$ & $\begin{array}{l}\mathrm{r}=-.107 \\
\mathrm{n}=168\end{array}$ \\
\hline
\end{tabular}

*Denotes significance at $\alpha<0.05$

Moral distress frequency and demographics. Significant positive correlations were found between ELNEC training and the a) "not in patient's best interest" subscale $(r=.194, p=.006)$, and b) moral distress frequency total score $(r=.165, p=.025)$. Nurses having undergone ELNEC critical care training reported significantly greater levels of moral distress frequency overall.

A significant negative correlation was found between active collaboration in EOL patient care conferences and items in the deception subscale $(r=-.191, p=.007)$. Nurses participating in EOL patient care conferences reported less moral distress frequency related to deception items. Nurses participating in EOL patient care conferences reported less distress in being able to address issues related to impending death of a patient 
honestly (see table 4b). All of the significant correlations for moral distress frequency and demographics were weak (Huck, 2008).

Table 4b: Relationship between Moral Distress Frequency \& Demographics

\begin{tabular}{|c|c|c|c|c|}
\hline \multirow[b]{2}{*}{ Demographics } & \multicolumn{4}{|c|}{ Moral Distress Frequency } \\
\hline & $\begin{array}{l}\text { Not in patient's } \\
\text { Freq. } \\
\text { best interest }\end{array}$ & $\begin{array}{l}\text { Individual } \\
\text { responsibilit }\end{array}$ & Deception & Total MD \\
\hline Age & $\begin{array}{l}\mathrm{r}=.087 \\
\mathrm{n}=202\end{array}$ & $\begin{array}{l}r=.052 \\
n=193\end{array}$ & $\begin{array}{l}\mathrm{r}=.017 \\
\mathrm{n}=202\end{array}$ & $\begin{array}{l}\mathrm{r}=.083 \\
\mathrm{n}=186\end{array}$ \\
\hline $\begin{array}{l}\text { Years of CC } \\
\text { Experience }\end{array}$ & $\begin{array}{l}\mathrm{r}=.019 \\
\mathrm{n}=201\end{array}$ & $\begin{array}{l}\mathrm{r}=-.080 \\
\mathrm{n}=192\end{array}$ & $\begin{array}{l}\mathrm{r}=-.019 \\
\mathrm{n}=201\end{array}$ & $\begin{array}{l}\mathrm{r}=-.039 \\
\mathrm{n}=185\end{array}$ \\
\hline Work Status & $\begin{array}{l}\mathrm{r}=-.097 \\
\mathrm{n}=198\end{array}$ & $\begin{array}{l}r=-.103 \\
n=189\end{array}$ & $\begin{array}{l}r=-.031 \\
n=198\end{array}$ & $\begin{array}{l}r=-.107 \\
n=182\end{array}$ \\
\hline $\begin{array}{l}\text { Collaboration in } \\
\text { EOLC Conferences }\end{array}$ & $\begin{array}{l}\mathrm{r}=.106 \\
\mathrm{n}=200\end{array}$ & $\begin{array}{l}\mathrm{r}=-.063 \\
\mathrm{n}=191\end{array}$ & $\begin{array}{l}\mathrm{r}=-.191^{*} \\
\mathrm{n}=200\end{array}$ & $\begin{array}{l}\mathrm{r}=-.022 \\
\mathrm{n}=184\end{array}$ \\
\hline Education & $\begin{array}{l}\mathrm{r}=-.061 \\
\mathrm{n}=202\end{array}$ & $\begin{array}{l}\mathrm{r}=-.111 \\
\mathrm{n}=193\end{array}$ & $\begin{array}{l}\mathrm{r}=-.024 \\
\mathrm{n}=202\end{array}$ & $\begin{array}{l}\mathrm{r}=-.089 \\
\mathrm{n}=186\end{array}$ \\
\hline AACN Certification & $\begin{array}{l}\mathrm{r}=.050 \\
\mathrm{n}=200\end{array}$ & $\begin{array}{l}\mathrm{r}=-.076 \\
\mathrm{n}=192\end{array}$ & $\begin{array}{l}\mathrm{r}=.022 \\
\mathrm{n}=200\end{array}$ & $\begin{array}{l}\mathrm{r}=-.028 \\
\mathrm{n}=185\end{array}$ \\
\hline $\begin{array}{l}\text { ELNEC CC } \\
\text { Training }\end{array}$ & $\begin{array}{l}\mathrm{r}=.194^{*} \\
\mathrm{n}=201\end{array}$ & $\begin{array}{l}\mathrm{r}=.122 \\
\mathrm{n}=192\end{array}$ & $\begin{array}{l}\mathrm{r}=.132 \\
\mathrm{n}=201\end{array}$ & $\begin{array}{l}\mathrm{r}=.165^{*} \\
\mathrm{n}=185\end{array}$ \\
\hline $\begin{array}{l}\text { EOLC Education in } \\
\text { the Past Year }\end{array}$ & $\begin{array}{l}\mathrm{r}=.063 \\
\mathrm{n}=200\end{array}$ & $\begin{array}{l}r=-.007 \\
n=191\end{array}$ & $\begin{array}{l}\mathrm{r}=.055 \\
\mathrm{n}=200\end{array}$ & $\begin{array}{l}\mathrm{r}=.034 \\
\mathrm{n}=184\end{array}$ \\
\hline AACN Membership & $\begin{array}{l}\mathrm{r}=-.011 \\
\mathrm{n}=201\end{array}$ & $\begin{array}{l}\mathrm{r}=-.135 \\
\mathrm{n}=192\end{array}$ & $\begin{array}{l}r=.027 \\
n=201\end{array}$ & $\begin{array}{l}\mathrm{r}=-.094 \\
\mathrm{n}=185\end{array}$ \\
\hline
\end{tabular}

*Denotes significance at $\alpha<0.05$

\section{Research Question 2b}

Is there a relationship between psychological empowerment [meaning, competence, self-determination and impact] in critical care nurses caring for adults at EOL and select demographics [age, years of critical care nursing experience, work status, active collaboration in multidisciplinary EOLC patient conferences, level of education, AACN specialty certification, End-of-Life Nursing Education Consortium (ELNEC) Critical Care Training, continuing education in the last year, and AACN membership]? 
A correlation matrix was computed to identify relationships between psychological empowerment total scores and each of the subscale totals (meaning, competence, self-determination, and impact) with each of the demographic variables (See Table 5). Several positive correlations were found between psychological empowerment and the demographics. All of the significant correlations were weak (Huck, 2008).

Meaning subscale. A positive correlation was also found between the empowerment meaning subscale and EOLC education in the past year $(r=.150, p=.016)$. Nurses who reported participating in EOLC education in the past year reported higher levels of empowerment related to the meaning subscale (the value they placed on the importance of their work).

Competence subscale. A positive correlation was also found between empowerment in the competence subscale and age $(r=.194, p=.002)$, years of critical care experience $(r=.255, p=.001)$ and EOLC education in the past year $(r=.177, p=.005)$. As age and years of critical care experience increased, nurses reported higher levels of psychological empowerment in the competence subscale (how well they viewed themselves as capable to perform their duties at work). Nurses who were actively participating in EOL patient care conferences also viewed themselves as more competent and empowered.

Self-determination subscale. Positive correlations were found between empowerment in the subscale of self-determination and select demographics including, collaboration in EOLC conferences $(r=.217, p=.001)$, ELNEC critical care training ( $r=.133, p=.033)$, and EOLC education in the past year $(r=.209, p=.001)$. These 
demographic groups perceived themselves as being more empowered, as having greater autonomy.

Impact subscale. The impact subscale had significant positive correlations to the following demographic variables: work status $(r=.151, p=.017)$, collaboration in EOLC conferences $(r=.253, p=.001)$, educational level $(r=.149, p=.018)$, ELNEC critical care training $(r=.128, p=.043)$, and EOLC education in the past year $(r=.196, p=.002)$. Nurses who worked more hours per week, reported active collaboration in EOL patient care conferences, had higher levels of education, had undergone ELNEC critical care training and had EOLC education in the past year had higher degrees of psychological empowerment in the impact domain. These demographic groups perceived themselves as having a greater influence over what occurs in the workplace. The impact subscale had more significant correlations with demographics than any of the other subscales or the total score. Additionally, the EOLC education in past year demographic was significantly correlated to all of the empowerment subscales and the total score. 
Table 5: Relationship between Psychological Empowerment \& Demographics

\begin{tabular}{|l|l|l|l|l|l|}
\hline & \multicolumn{5}{|c|}{ Psychological Empowerment } \\
Demographics & Meaning & Competence Self-Determination Impact & \multicolumn{1}{c|}{ Empotal } \\
& $\mathrm{r}=.083$ & $\mathrm{r}=.194^{*}$ & $\mathrm{r}=.090$ & $\mathrm{r}=.076$ & $\mathrm{r}=.139^{*}$ \\
$\mathrm{n}=258$ & $\mathrm{n}=255$ & $\mathrm{n}=257$ & $\mathrm{n}=253$ & $\mathrm{n}=242$ \\
\hline Years of CC & $\mathrm{r}=.077$ & $\mathrm{r}=.255^{*}$ & $\mathrm{r}=.110$ & $\mathrm{r}=.096$ & $\mathrm{r}=.165^{*}$ \\
Experience & $\mathrm{n}=257$ & $\mathrm{n}=254$ & $\mathrm{n}=256$ & $\mathrm{n}=252$ & $\mathrm{n}=241$ \\
\hline Work Status & $\mathrm{r}=-.064$ & $\mathrm{r}=.005$ & $\mathrm{r}=.036$ & $\mathrm{r}=.151^{*}$ & $\mathrm{r}=.034$ \\
& $\mathrm{n}=253$ & $\mathrm{n}=250$ & $\mathrm{n}=252$ & $\mathrm{n}=249$ & $\mathrm{n}=238$ \\
\hline Collaboration in & $\mathrm{r}=.016$ & $\mathrm{r}=.022$ & $\mathrm{r}=.217^{*}$ & $\mathrm{r}=.253^{*}$ & $\mathrm{r}=.163^{*}$ \\
EOLC Conferences & $\mathrm{n}=256$ & $\mathrm{n}=253$ & $\mathrm{n}=255$ & $\mathrm{n}=251$ & $\mathrm{n}=240$ \\
\hline Education & $\mathrm{r}=-.021$ & $\mathrm{r}=-.037$ & $\mathrm{r}=.116$ & $\mathrm{r}=.149^{*}$ & $\mathrm{r}=.099$ \\
& $\mathrm{n}=258$ & $\mathrm{n}=255$ & $\mathrm{n}=257$ & $\mathrm{n}=253$ & $\mathrm{n}=242$ \\
\hline AACN Certification & $\mathrm{r}=-.002$ & $\mathrm{r}=.118$ & $\mathrm{r}=.018$ & $\mathrm{r}=.008$ & $\mathrm{r}=.045$ \\
& $\mathrm{n}=254$ & $\mathrm{n}=251$ & $\mathrm{n}=253$ & $\mathrm{n}=250$ & $\mathrm{n}=239$ \\
\hline ELNEC CC & $\mathrm{r}=.051$ & $\mathrm{r}=.093$ & $\mathrm{r}=.133^{*}$ & $\mathrm{r}=.128^{*}$ & $\mathrm{r}=.125$ \\
Training & $\mathrm{n}=256$ & $\mathrm{n}=253$ & $\mathrm{n}=255$ & $\mathrm{n}=251$ & $\mathrm{n}=240$ \\
\hline EOLC Education in & $\mathrm{r}=.150^{*}$ & $\mathrm{r}=.177^{*}$ & $\mathrm{r}=.209^{*}$ & $\mathrm{r}=.196^{*}$ & $\mathrm{r}=.221^{*}$ \\
the Past Year & $\mathrm{n}=256$ & $\mathrm{n}=253$ & $\mathrm{n}=256$ & $\mathrm{n}=251$ & $\mathrm{n}=241$ \\
\hline AACN Membership & $\mathrm{r}=.041$ & $\mathrm{r}=.061$ & $\mathrm{r}=-.016$ & $\mathrm{r}=.001$ & $\mathrm{r}=.029$ \\
& $\mathrm{n}=257$ & $\mathrm{n}=254$ & $\mathrm{n}=256$ & $\mathrm{n}=252$ & $\mathrm{n}=241$ \\
\hline
\end{tabular}

*Denotes significance at $\alpha<0.05$

\section{Research Question 3a}

What is the relationship between psychological empowerment [meaning, competence, self-determination and impact] and a) moral distress intensity [not in patient's best interest, individual responsibility and deception] and b) moral distress frequency [not in patient's best interest, individual responsibility and deception] in critical care nurses caring for adults at EOL?

\section{Psychological empowerment and moral distress intensity. A correlation}

matrix was computed to identify relationships between psychological empowerment (subscales and total psychological empowerment score) and moral distress intensity (subscales and total moral distress intensity scores) using a Person Product Coefficient.

Statistically significant positive but weak correlations (Huck, 2008) were found between 
the moral distress intensity deception subscale and psychological empowerment subscales a) meaning ( $r=.144, p=.04)$, b) self-determination $(r=.168, p=.017)$, and c) impact $(r=.164, p=.021)$

A weak but significant positive correlation (Huck, 2008) was also found between the moral distress intensity deception subscale total and the psychological empowerment total score $(r=.166, p=.021)$ (See table 6a). Nurses who scored higher in the following empowerment subscales: a) meaning (attaching greater value to their work), b) selfdetermination (feeling higher levels of autonomy) and c) impact (having greater influence at work) experienced higher levels of moral distress intensity in the deception subscale (situations where they felt unable to honestly address issues related to the impending death of a patient).

Table 6a: Pearson's $r$ Level of Moral Distress Intensity with Degree of Psychological Empowerment

\begin{tabular}{|c|c|c|c|c|}
\hline \multirow{2}{*}{$\begin{array}{l}\text { Psychological } \\
\text { Empowerment }\end{array}$} & \multicolumn{4}{|c|}{ Moral Distress Intensity } \\
\hline & $\begin{array}{l}\text { Not in patient's } \\
\text { best interest }\end{array}$ & $\begin{array}{l}\text { Indivic } \\
\text { respor }\end{array}$ & Dece & Total \\
\hline Meaning & $\begin{array}{l}r=.032 \\
n=202\end{array}$ & $\begin{array}{l}r=.119 \\
n=177\end{array}$ & $\begin{array}{l}r=.144^{*} \\
n=203\end{array}$ & $\begin{array}{l}r=115 \\
n=170\end{array}$ \\
\hline Competence & $\begin{array}{l}r=.042 \\
n=199\end{array}$ & $\begin{array}{l}r=.079 \\
n=174\end{array}$ & $\begin{array}{l}r=.059 \\
n=200\end{array}$ & $\begin{array}{l}\mathrm{r}=.062 \\
\mathrm{n}=167\end{array}$ \\
\hline Self-Determination & $\begin{array}{l}r=.015 \\
n=201\end{array}$ & $\begin{array}{l}r=.056 \\
n=175\end{array}$ & $\begin{array}{l}r=.168^{*} \\
n=202\end{array}$ & $\begin{array}{l}r=.062 \\
n=167\end{array}$ \\
\hline Impact & $\begin{array}{l}r=.064 \\
n=196\end{array}$ & $\begin{array}{l}\mathrm{r}=.032 \\
\mathrm{n}=171\end{array}$ & $\begin{array}{l}r=164^{*} \\
n=197\end{array}$ & $\begin{array}{l}r=.057 \\
p=.460 \\
n=168\end{array}$ \\
\hline Total & $\begin{array}{l}r=.064 \\
n=189\end{array}$ & $\begin{array}{l}\mathrm{r}=.085 \\
\mathrm{n}=166\end{array}$ & $\begin{array}{l}\mathrm{r}=.166^{*} \\
\mathrm{n}=190\end{array}$ & $\begin{array}{l}\mathrm{r}=.095 \\
\mathrm{n}=159\end{array}$ \\
\hline
\end{tabular}

*Denotes significance at $\alpha<0.05$ 


\section{Psychological empowerment and moral distress frequency. Next, a}

correlation matrix was constructed examining the relationship between psychological empowerment (total psychological empowerment score and total empowerment subscales scores) and moral distress frequency (subscales and total moral distress frequency score). Several weak but significant negative correlations (Huck, 2008) were found.

The psychological empowerment self-determination subscale was negatively correlated with the a) individual responsibility moral distress frequency subscale scores $(r=-.177, p=.014)$ and $\mathrm{b})$ total self-determination was correlated with total moral distress frequency score $(r=-.161, p=.029)$. Nurses who scored higher in the empowerment selfdetermination subscale (perceived themselves as more self-regulating) experienced less moral distress frequency correlated with the moral distress individual responsibility subscale (nurses participating in situations requiring them to ignore taking actions they felt they should take). And the empowerment self-determination group experienced less moral distress frequency overall.

Additional significant negative correlations were found between the psychological empowerment subscale of impact with moral distress frequency not in patient's best interest $(r=-.161, p=.025)$ and $b)$ individual responsibility $(r=-.249, p=.001)$. The total psychological empowerment impact score also negatively correlated with the total moral distress frequency score $(r=-.229, p=.002)$. Nurses who perceived themselves as having more of an impact experienced less moral distress frequency in the not in patient's best interest subscale (dealing with situations involving the delivery of aggressive care in cases of patient futility) and in the individual responsibility subscale (participating in 
situations requiring them to ignore taking actions they should take). Nurses who were more empowered experienced less moral distress frequency overall.

The total psychological empowerment score negatively correlated with a) the individual responsibility moral distress frequency total score $(r=-.213, p=.004)$ and b) the total moral distress frequency score $(r=-.194, p=.010)$ (see table $6 \mathrm{~b}$ ). The nurses who perceived themselves as more empowered overall, experienced less moral distress. The more empowered nurses perceived themselves overall, the less frequently they experienced moral distress overall.

Table 6b: Pearson's $r$ Level of Moral Distress Frequency with Degree of Psychological Empowerment

\begin{tabular}{|l|l|l|l|l|}
\hline \multirow{2}{*}{ Psychological } & \multicolumn{3}{|c|}{ Moral Distress Frequency } \\
& $\begin{array}{l}\text { Not in patient's } \\
\text { best interest }\end{array}$ & \multicolumn{1}{|c|}{$\begin{array}{l}\text { Individual } \\
\text { responsibility }\end{array}$} \\
\hline Meaning & $\begin{array}{l}\mathrm{r}=-.056 \\
\mathrm{n}=202\end{array}$ & $\begin{array}{l}\mathrm{r}=-.056 \\
\mathrm{n}=193\end{array}$ & $\begin{array}{l}\mathrm{r}=-.041 \\
\mathrm{n}=202\end{array}$ & $\begin{array}{l}\mathrm{r}=-.064 \\
\mathrm{n}=186\end{array}$ \\
\hline Competence & $\mathrm{r}=.001$ & $\mathrm{r}=-.159$ & $\mathrm{r}=-.115$ & $\mathrm{r}=-.136$ \\
& $\mathrm{n}=199$ & $\mathrm{n}=190$ & $\mathrm{n}=199$ & $\mathrm{n}=183$ \\
\hline Self-Determination & $\mathrm{r}=-.103$ & $\mathrm{r}=-.177^{*}$ & $\mathrm{r}=-.121$ & $\mathrm{r}=-.161^{*}$ \\
& $\mathrm{n}=201$ & $\mathrm{n}=192$ & $\mathrm{n}=201$ & $\mathrm{n}=185$ \\
\hline Impact & $\mathrm{r}=-.161^{*}$ & $\mathrm{r}=-.249^{*}$ & $\mathrm{r}=-.065$ & $\mathrm{r}=-.229^{*}$ \\
& $\mathrm{n}=196$ & $\mathrm{n}=190$ & $\mathrm{n}=196$ & $\mathrm{n}=183$ \\
\hline Total & $\mathrm{r}=-.111$ & $\mathrm{r}=-.213^{*}$ & $\mathrm{r}=-.097$ & $\mathrm{r}=-.194^{*}$ \\
& $\mathrm{n}=189$ & $\mathrm{n}=183$ & $\mathrm{n}=189$ & $\mathrm{n}=176$ \\
\hline
\end{tabular}

*Denotes significance at $\alpha<0.05$

\section{Research Question 3b}

What is the relationship/association of psychological empowerment [meaning, competence, self-determination and impact] and select demographics [age, years of critical care nursing experience, work status, active collaboration in multidisciplinary EOLC patient conferences, education, AACN specialty certification, End-of-Life Nursing Education Consortium (ELNEC) Critical Care Training, continuing education in the last 
year, and AACN membership] with moral distress [not in patient's best interest, individual responsibility and deception] intensity and moral distress [not in patient's best interest, individual responsibility and deception] frequency?

Multiple regression analysis was used to test if any demographic variables combined with total PEI scores predicted the frequency of experiencing moral distress. The results of the regression indicated that two predictors explained $8.40 \%$ of the variance $(r=.289, \mathrm{~F}(2,171)=7.801, p<.01)$. It was found that nurses having had ELNEC critical care training significantly predicted moral distress frequency $(\beta=-.215, p<.01)$. ELNEC critical care trained nurses had, on average, $21.5 \%$ higher scores for moral distress frequency. Total psychological empowerment significantly predicted moral distress frequency $(\beta=.222, p<.01)$. For every 1 - point increase on the PEI, moral distress frequency scores decreased by 0.222 points $(p=<.01)$. The analysis indicated that it can be predicted that ELNEC critical care trained nurses will experience moral distress more frequently and nurses with higher levels of perceived empowerment will experience the frequency of moral distress less often.

\section{Summary}

In summary, while nurses reporting more psychological empowerment reported higher levels of moral distress intensity, they also, reported less moral distress frequency. Nurses reporting active collaboration in EOL patient care conferences also reported less moral distress frequency. Discussion of findings will be presented in the next chapter. 


\section{CHAPTER 5}

\section{Discussion}

The purpose of this study was to examine the relationships between moral distress, psychological empowerment and select demographics in critical care nurses caring for adults during end of life. This chapter will present the meaning and significance of the study findings, strengths and limitations of the study, and implications of the study suggesting recommendations for further research.

\section{Overview}

The inception of the concept of moral distress was formulated by Jameton (1984), who was the first to define moral distress in the nursing literature. Moral distress was defined as discomfort or internal conflict related to ethical dilemmas encountered in nursing practice when constraints prevented the nurse from following the course of action believed to be right. Moral distress has become a significant phenomenon in critical care nursing due to the progression of moral distress leading to increased attrition rates, nurses leaving critical care nursing and leaving the nursing profession all together, potentially resulting in adverse patient care outcomes. Understanding how moral distress is related to psychological empowerment and to select demographics may aid in the development and appropriation of interventions to assist in decreasing moral distress, thus preventing 
further attrition rates. Prior to this study, the relationship between moral distress and psychological empowerment had not been studied.

\section{Moral Distress}

In this study, moral distress was measured using the moral distress scale (MDS). The MDS is an instrument measuring two separate entities of moral distress in nurses, moral distress intensity and moral distress frequency. Each of these aspects of moral distress is further measured in three subscales or domains, a) not in patient's best interest (delivery of futile care to patients who would not benefit from that care), b) individual responsibility (participating in care not agreed with or ignoring actions one should take, and c) deception (not addressing issues related to the impending death of a patient honestly). Moral distress intensity was high among critical care nurses while moral distress frequency was moderate to low. These findings are consistent with Corley's (2005) results of moral distress intensity and moral distress frequency in that the frequency was lower than intensity, implying that the morally distressing events the nurses experienced were not occurring often. However, levels of moral distress intensity were higher in this study than in Corley's (2005).

\section{Moral Distress Intensity}

On individual items, this study showed high levels of moral distress intensity. Corley's (2005) data where mean item scores were moderate was more representative of previous studies in the literature. Possible explanations for this study's higher item scores will be discussed later in this chapter in the context of demographics influencing empowerment and the relationship of empowerment to moral distress. 
Congruently nurses also suffered high levels of moral distress intensity in all three domains as well as individual items. In this study nurses reported the highest level of moral distress intensity in the individual responsibility domain with the second highest level of moral distress intensity related to items, not in patient's best interest, although the difference in mean scores was negligible (0.37). Previous studies reported the highest moral distress intensity resulted from items related to not in patient's best interest (futile care) (Wilkinson (1987/88; Corley, 1995; Meltzer \& Huchkabay, 2004; Elpern, 2005; Guitierrez, 2005; Mobley, 2007; Hamric \& Blackhall, 2007).

Critical care nurse characteristics and moral distress intensity. In this study it was found that as nurses' age increased, moral distress increased. This may have been due to the phenomenon of moral residue, an accumulation of distress over time with older nurses experiencing increased levels of moral distress intensity. The association of age to moral distress intensity does not support past studies. For example, Corley (2005) and Radzvin (2011) found that older nurses reported less moral distress. These finding may be explained in that an increase in experience and perceived competency that comes with age contributes to a decrease in moral distress intensity.

Critical care nurses who had undergone ELNEC critical care training experienced more moral distress intensity compared to critical care nurses who had not undergone ELNEC critical care training. The positive relationship between moral distress intensity and ELNEC critical care training may be explained by nurses having gained more information regarding the correct actions to take when delivering futile care to patients at EOL, felt higher levels of moral distress intensity not being able to carry out those actions. The results of this study may be skewed however, due to the low number of 
participants $(\mathrm{n}=16)$ who reported receiving ELNEC training, representing only $5.8 \%$ of the total number of participants.

ELNEC critical care training has not been previously studied in relationship to moral distress intensity using a quantitative method as in this study. However, in the qualitative portion of Ferrell's, et al (2007) survey, following the first critical care ELNEC training in 2006, participants suggested more curriculum be devoted to distress, experienced by critical care nurses related to the delivery of futile care. The ELNEC critical care content has been subsequently expanded.

Nurse / MD orders and collaboration. The literature implies that a degree of moral distress in critical care nurses may be due to nurses having to comply with physician's orders they may not necessarily agree with or feel comfortable performing. Nurses found that the item, "assisting the MD who in my opinion is providing incompetent care" caused the highest level of moral distress intensity. This finding supports Corley's (2001) and Zuzelo's (2007) studies where "assisting the MD who in my opinion is providing incompetent care" also caused the highest level of moral distress intensity.

A recent study (Radzvin, 2011) of nurse anesthetists $(n=300)$ reported that certified registered nurse anesthetists (CRNAs) felt more moral distress in dealing with physicians (38\% of the time) as compared to numerous other members of the health care team. Zuzelo's (2007) mixed methods study $(n=100)$ revealed qualitative issues of concern causing moral distress in nurses related to physician interactions which included the following: physicians not proactively addressing EOLC issues and perceiving physicians' expectations of patient care goals as unrealistic. The nurses largely viewed 
themselves as functioning in a subservient role to physicians deterring them from impacting patient care decisions.

Additional literature supports that critical care nurses perceive a lack of collaboration in patient care decision making between nurses and physicians, identifying this as one of the major causes of moral distress in critical care nurses (Gutierrez, 2005; Hamric \& Blackhall, 2007). In a study analyzing EOLC decision making in critical care (Ferrand et al, 2003) $90 \%$ of physicians and nurses believed decisions should be collaborative, yet only $27 \%$ of the nurses perceived themselves as involved in the decision making process ( $\mathrm{n}=3,156$ nurses). Mores studies are needed examining effective collaboration between nurses and physicians. This will be discussed further with this study's recommendations.

Futile care. This study showed that nurses experienced the least amount of moral distress intensity related to "carrying out MD orders for unnecessary tests or treatments on terminally ill patients," although their moral distress intensity level related to this item was still moderate to high. These findings contradict previous studies' findings that showed the highest scoring moral distress intensity items were related to futile care. This may be due to a heightened awareness of critical care nurses regarding the need for critical care patients to move more readily from curative to palliative care models and therefore nurses may be observing fewer unnecessary treatments for terminally ill patients in critical care units. Another reason for the low score on this item may be the current economic climate requiring more cost effective treatment plans decreasing the number of superfluous treatments. 


\section{Moral Distress Frequency}

The item that nurses reported causing the highest level of moral distress frequency in this study was not in patient's best interest and was related to futile care, "Follow family's wishes to continue life support when not in patient's best interest." Overall, this item was moderate to high. This is consistent with several previous studies having shown relationships between moral distress in nurses related to futile care (Wilkinson (1987/88; Corley, 1995; Meltzer \& Huckabay, 2004; Elpern, 2005; Guiterrez, 2005, Mobley, 2007; Hamric \& Blackhall, 2007). It is worth noting that this item relates to family wishes. The high moral distress frequency rating on this item may be due to several factors: an overall increase in public knowledge of medicine due to the media and internet access, an increasing patient and family centered decision making model and an increased awareness in patient and family rights in general.

Demographics related to moral distress frequency. Nurses who reported active collaboration in EOL patient care conferences $(\mathrm{n}=118)$ experienced less moral distress frequency in situations related to addressing the impending death of a patient honestly. This may be a pertinent finding. Nurses who participated in the collaborative processes with patients, families and members of the health care team reported feeling less moral distress frequency perhaps due to the openness and honest communication facilitated by the patient care conference setting.

ELNEC critical care trained nurses reported experiencing greater moral distress frequency in situations related to administering futile care. Perhaps being better informed about how to assist in the prevention of prolonged patient suffering due to the use of 
inappropriate life sustaining treatments, but not being able to see the correct action being carried out, caused moral distress on more frequent occasions.

\section{Empowerment}

Total psychological empowerment as well as four subscales or domains of psychological empowerment were evaluated as follows: a) meaning (the value nurses placed on their work), b) competence (how well they perceived themselves performing their jobs, c) self-determination (how much autonomy they perceived themselves to have) and d) impact (the perceived extent of their influence at work). Nurses derived the most sense of empowerment from, "I really care about what I do on my job" in the meaning domain. Nurses derived the least sense of empowerment from, "I have a great deal of control over what happens in my department," in the impact domain.

Nurses felt the highest level of psychological empowerment related to meaning, competence and self-determination, meaning being the highest. Nurses felt a moderate sense of empowerment related to having an impact. Overall, psychological empowerment, among the population of critical care nurses studied was high.

This supports Williamson's (2007) findings examining psychological empowerment in home health nurses using the PEI where competence, self-determination and meaning were all high and the nurses' perception of psychological empowerment in the impact domain was moderate. Perhaps both critical care nurses and home health nurses are similar in that they place a high value on the work that they do, view themselves as being able to perform their duties well and see themselves as autonomous in their role, while feeling less able to influence the administration and or operational outcomes of their work. 


\section{Demographics Related to Empowerment}

Several demographics were positively related to empowerment. Nurses who were older and had more years of critical care experience reported feeling more competent and more empowered overall. It can be speculated that perhaps as nurses age they gain more experience, both factors which may contribute to them feeling better able to do their job well. The findings of this study are consistent with Knol and van Linge (2009) whose data also demonstrated a relationship between psychological empowerment and years of experience.

Nurses who worked more hours per week reported feeling more empowered in the impact domain. Knol and van Linge (2009) also found that registered nurses who worked more hours per week perceived themselves as more psychologically empowered. This may be attributed to nurses' increased duration of exposure to their work environment aiding in the perception of their ability to influence what happens in their workplace.

Educational level was associated with empowerment in the impact domain. Collaboration in EOLC conferences and ELNEC training was associated with empowerment in the self-determination and impact domains and with total psychological empowerment. EOLC education in the past year was associated with psychological empowerment in all 4 domains and with total empowerment. Further research is strongly suggested relating the potential significance of EOLC education to psychological empowerment in critical care nurses related to EOLC due to the associations between EOLC education in all four domains and with overall perceptions of psychological empowerment. Perhaps the element of the education occurring recently (within 1 year) 
aided in nurses' greater levels of psychological empowerment due to better recall of the content.

The majority of the nurses' ( $n=>240$ ) reported the highest levels of psychological empowerment in the impact domain (how they perceived themselves as having influence over their work). The nurses who worked more hours per week, who reported active participation in EOL patient care conferences, who had higher levels of education, who were ELNEC critically care trained, and who had undergone EOLC education in the past year all reported higher levels of empowerment related to how well they impact their work.

\section{Moral Distress Intensity and Empowerment}

Participants with higher levels of psychological empowerment in three of the four empowerment domains (meaning, self-determination, and impact) had a significantly higher level of moral distress intensity in situations where a patient's impending death was not addressed honestly.

Perhaps while nurses, who place a higher value on the work they do, feel a greater sense of autonomy, and feel they have more influence on what happens "on the job," they may feel limited in actually being able to care for dying patients in honest ways (such as having to follow instructions regarding withholding information or not truthfully disclosing information about a patient's situation), causing greater levels of moral distress intensity. Perhaps nurses who perceive themselves as less empowered are likely to feel less moral distress intensity because they may not value their work as highly, feel as much autonomy, or believe that they can have as much influence at work. Less empowered nurses may feel less confidence in their own abilities to assist the patient and 
family in making decisions about their EOLC situations, and thus may not perceive themselves as being as limited, as nurses who perceive themselves as more empowered.

\section{Moral Distress Frequency and Empowerment}

Several significant inverse relationships were found between moral distress frequency and levels of psychological empowerment. Nurses who perceived themselves as having more of an impact in situations related to not in patient's best interest and nurses taking individual responsibility experienced less moral distress frequency.

In other words, nurses who perceived themselves as having a greater choice in initiating and regulating their work situations and felt they had a greater influence over outcomes related to their work environments, experienced moral distress less frequently related to having to participate in care not agreed with or ignoring actions one should take. Overall nurses who perceived themselves as more empowered experienced less moral distress frequency. This may be a hallmark finding in this study. Interventions to further empower nurses may help to decrease the frequency of moral distress in critical care nurses.

\section{Empowerment and Nursing Characteristics Related to Moral Distress}

Nurses who perceived themselves as significantly empowered, having a sense of valuing their work, suffered significantly greater moral distress intensity being in situations where they felt they were not honestly addressing issues related to the impending death of a patient. A possible explanation for this is that nurses who perceived themselves as more empowered (positively correlated with age, years of critical care experience, work status, collaboration in EOLC conferences, level of education, ELNEC critical care training and EOLC education in the past year) suffered 
greater levels of moral distress intensity because they were more informed and possibly more acutely aware of the gravity of nurse behaviors they considered dishonest.

These demographic groups may have felt all the more distressed due to an inability to actualize their sense of empowerment. Another possibility is that nurses with these characteristics were more determined to make an impact on their work environment but perceived themselves without sufficient voice amongst the health care team to see their efforts carried out.

It is of interest to note that in relationship to education, the only statistically significant demographic that was related to increased moral distress intensity was ELNEC critical care training. This group of respondents also perceived themselves as significantly empowered in their sense of having choice and having input in regulating and ultimately influencing their work situations. Perhaps ELNEC trained nurses are more determined to make an impact but perceive themselves without sufficient voice amongst the health care team to see their efforts carried out. Multiple regression analysis confirmed the significant correlations related to the ELNEC critical care trained nurses experiencing greater levels of moral distress intensity and frequency.

Nurses who perceived themselves as more psychologically empowered overall experienced less moral distress frequency. Perhaps this was one of the most notable findings of this study. Although empowered nurses feel a greater depth of moral distress intensity when they feel distressed, more empowered nurses may not feel moral distress as often. 


\section{Strengths and Limitations}

The negative effect of moral distress in critical care nurses is well established in the literature. The need for further studies examining relationships of moral distress to other phenomena experienced by critical care nurses is also evident in the literature. This study sought to examine the relationship between moral distress and psychological empowerment that had not been previously researched. Strengths of this study were its unique design and the sample size $(\mathrm{n}=277)$.

A possible limitation of this study was that nurses who felt more empowered and/or felt greater degrees of moral distress may have been more likely to participate in the study than nurses who felt less empowered and/or lesser levels of moral distress, thus detracting from the generalizability of the data reported. The study did not differentiate between geographical areas or types of facilities in which nurses practiced, nor did it take into consideration gender or culture.

The sample was taken from subscribers to the American Association of Critical Nurses Newsletter. This population of nurses may be more apt to feeling empowered and/or feeling greater levels of moral distress. However, no significant correlations were found between AACN membership and any of the variables.

\section{Implications for Future Nursing Research}

This study offers several insights into the continuation of a research agenda concerning the potential for decreasing moral distress in critical care nurses related to EOLC. There is a need for further exploration of how empowerment is related to moral distress and the discovery of methods that may decrease moral distress in critical care nurses. There is a need for further exploration of how bioethical principles can be more 
effectively incorporated into nursing education so that nurses may be better able to articulate bioethical principles as they apply them to patient care situations in a multidisciplinary patient care conference setting.

Bioethical considerations related to moral distress. The relationship between psychological empowerment and moral distress intensity in critical care nurses is of great concern. This study reveals that although increased levels of education are related to increased levels of empowerment, nurses who perceive themselves as more empowered experienced greater levels of moral distress intensity.

By definition, moral distress is knowing the correct action but not being able to have an impact on seeing the action carried out. There are many complex phenomena that may be associated with this, for example: a lack of adequate knowledge of ethical principles, such as beneficence, maleficence, human dignity and principles of patient suffering. There is a need for increased curricular development in the area of bioethics at the undergraduate and graduate level, further emphasis on nurse practice acts, specialty practice guidelines, and professional codes of ethics related to EOLC (Ferrell, et al, 2007). Further studies are needed in determining if such measures may decrease moral distress in critical care nurses.

The literature supports that nurses may suffer from moral distress due to fear related to personal risk. LaSalla \& Bjarnason (2011) define moral courage as a possible construct combating moral distress. Moral courage is being able to recognize and respond to unethical practices by providing quality patient care without fear of personal risk. It can be postulated that knowledge of ethical principals alone may not facilitate nurses acting on what they believe to be moral and that commitment to optimal patient 
care outcomes needs to outweigh the nurse's fear of personal risk if nurses are to initiate what they believe to be the correct action. Further studies are needed exploring moral distress in critical care nurses related to moral courage.

EOLC education. The results of this study may be an indication that nursing education, particularly related to EOLC decision making in critical care, although historically beneficial needs further expansion in light of ELNEC nurses reporting higher moral distress intensity and frequency. Perhaps the increased knowledge base nurses gain by participating in advanced EOLC education such as ELNEC further distresses them by possibly not being able to articulate adequately to other members of the health care team the rationale for why the nurse believes the right course of action is correct or not being able to see the correct action carried out for a myriad of reasons discussed earlier.

However, both ELNEC critical care trained nurses and nurses who participated in EOLC education in the past years reported greater levels of psychological empowerment. There is a need for further development of nursing education related to EOLC in critical care in areas of public speaking and scholarly expression of ethical principles, facilitating the nurse's input in regard to patient care decisions. Studies are needed to further examine the structuring and potential success of such efforts that may potentially decrease moral distress in nurses.

\section{Increasing collaborative efforts between professions: nursing and medicine.}

Radzvin's (2011) recent study on moral distress in CRNA's reported 77\% of the respondents $(n=300)$ avoided working with or stopped working with physicians as a result of ethical decision making. The literature supports that large populations of nurses 
express inadequate collaboration among the health care team during EOLC decisionmaking.

The identification in the literature regarding the causes of moral distress in critical care nurses has been longstanding. These causes include lack of resources in the intensive care environment, legal limitations, institutional obstacles and hierarchical power struggles. There is a need for further research in each of these areas related to moral distress in critical care nurses. The advent of life support systems has drastically intensified the complexity of EOLC decision making for nurses and physicians in the ICU (Browning, 2010). The development of more effective collaboration between these two professional groups is vital. Faith \& Chidwick (2009) suggest the increased use of clinical nurse ethicists to assist in alleviating moral distress experienced by staff nurses. There is a need for research to evaluate the efficacy of this role; however, with the present day economic constraints the role may be limited.

Shared governance (SG) is a strategy created to improve nurses' control over their practice promoted in magnet hospitals (Kramer et al, 2008). Shared governance is an institutional structure by which nurses can be better able to participate in decision making in collaboration with physicians. More studies are needed examining the relationship between SG and moral distress in critical care nurses related to EOLC decision-making.

Epstein \& Delgado (2010) suggest the use of a moral distress consult service to assist nurses with issues related to moral distress. These consultants meet with the nursing staff to identify moral distress, its causes and possible solutions to reduce further occurrences. Physicians could be involved in this process, taking into consideration the 
eminent need for effective collaboration between nurses and physicians. Studies are needed to examine such innovative interventions.

Collaborative EOLC conferences may hold out some hope. Nurses who participated in collaborative EOLC conferences, multidisciplinary with physicians, reported less moral distress intensity related to participating in care not agreed with or ignoring actions one should take and less moral distress frequency related to honestly addressing patient situations involving impending death.

The American Association of Critical Care Healthy Work Environment Standards (Vollers, et al, 2009) advocate "true collaboration" in working with physicians. These standards promote nurses and physicians working together to create proactive interventions, developing prevention and patient care management protocols that have the potential to reduce the number of acute crises requiring immediate decisions that may not have sufficient time to be optimal. Further research is needed examining collaboration between nurses and physicians related to moral distress in critical care nurses in the delivery of EOLC.

\section{Summary}

This study sought to examine the relationship between moral distress and psychological empowerment in critical care nurses related to EOLC. The results reported a significant positive relationship between moral distress intensity and psychological empowerment in the surveyed population of nurses; however there was found to be an inverse relationship between psychological empowerment and moral distress frequency. Another pertinent finding was that nurses who participated in EOL patient care 
conferences experienced less moral distress frequency in situations related to honestly addressing issues dealing with patients facing impending death.

Nurses more advanced in age and nurses who participated in the critical care End of Life Care Nursing Education Consortium training reported more moral distress intensity related to administering care to critically ill patients that the nurse considered futile for the patient. This study resulted in findings supporting that nurses with the following demographics: age, years of critical care experience, work status, collaboration in EOL patient care conferences, level of education, ELNEC training and EOLC education in the past year had significantly higher levels of psychological empowerment. Despite the numerous significant positive relationships between the demographics and psychological empowerment participants did not experience decreased moral distress intensity in relationship to increased degrees of psychological empowerment.

However, the data supported that critical care nurses who perceive themselves as more psychologically empowered experience less moral distress frequency. The results of this study have reported relevant data that may provide insight into future interventional studies, potentially aiding in the reduction of moral distress in critical care nurses related to EOLC. 


\section{References}

American Association of Colleges of Nursing: policy statement, Peaceful Death:

Recommended Competencies and Curricular Guidelines for End-of-Life Nursing

Care Available at www.aacn.nche.edu.

American Association of Colleges of Nursing (2002). End-of-Life Competency

Statements for a Peaceful Death. Washington, DC: American Association of Colleges of Nursing.

American Association of Critical Care Nurses. (2004). AACN Public Policy Position

Statement: Moral Distress. Aliso Viejo, CA.

American Association of Critical Care Nurses (2006). AACN Position Statement on

Moral Distress. Aliso Viejo, CA: AACN.

American Association of Critical Care Nurses News (2008).

American Association of Critical Care Nurses. Standards for Establishing and Sustaining Healthy Work Environments. http://www.aacn.org/aacn/WD/HWE/Docs

American Association of Critical Care Nurses (2009). Options for excellence in career options. Critical Care Nurse, supplement, February.

American Nurses Association (2001). Code of ethics for nurses with interpretive statements.Washington, DC.

Anderson, C., \& Shafer, P. (2005). Deeper power in enlightened power. San Francisco, CA: Jossey-Bass.

Bandura, A. (1977). Self-efficacy. Toward a unifying theory of behavioral change. Psychological Review, 84(2), 191-215. 
Bandura, A. (1986). Social foundations of thought and action: A social cognitive theory. Englewood Cliffs, NJ: Prentice Hall.

Bandura, A. (2007). Health promotion by social cognitive means. Health Education and Behavior, 31(2), 143-164.

Beckstrand, L., Callister, L., \& Kirchhoff, K. (2006). Providing a "good death": critical care nurses' suggestions for improving end-of-life care. American Journal of Critical Care Nursing, 15(1), 38-45.

Beckstrand, R.L., \& Kirchhoff, K.T. (2005). Providing end-of-life care to patients: critical care nurses' perceived obstacles and supportive behaviors. American Journal of Critical Care, 14(5), 395-403.

Boudrias, J. S., Gaudreau, P., \& Laschinger, H. K. S. (2004). Testing the structure of psychological empowerment: Does gender make a difference? Educational and Psychological Measurement, 64(5), 861-877.

Browning, A. (2010). Life support technology and the dying experience. Implications for critical care nursing practice. Dimensions of Critical Care Nursing, 29(5), $230-237$.

Conger, J. \& Kanungo, R. (1988). The empowerment process: integrating theory and process. The Academy of Management Review, 13(3), 471-482.

Corbally, M.A., Scott, P.A., Matthews, A., Mac Gabhann, L. \& Murphy, C. (2007). Irish nurses' and midwives' understanding and experiences of empowerment. Journal of Nursing Management, 15, 169-179.H

Corley, M. (1995). Moral distress of critical care nurses. American Journal of Critical Care, 4(4), 280-285. 
Corley, M. (2002). Nurse moral distress: a proposed theory and research agenda. Nursing Ethics, 9(6), 637-650.

Corley, M. (2005). Nurse moral distress and ethical work environment. Nursing Ethics, $12(4), 382-390$.

Corley, M., Elswick, R., Gorman, M., \& Clor, T. (2001). Development and evaluation of a moral distress scale. Journal of Advanced Nursing, 33(2), 250-256.

Council on Ethical Judician Affairs - American Medical Association (1999). Medical futility in end-of-life care: report of the council on ethical and judician affairs. Journal of the American Medical Association, 281: 937-41).

Creswell, J. (2009). Research design, qualitative, quantitative and mixed method approaches, $3^{\text {rd }}$ ed. Thousand Oaks, CA: Sage Publications, Inc.

Elpern, E. (2005). Moral distress of staff nurses in a medical intensive care unit. American Journal of Critical Care, 14(6), 523-530.

Epstein, E.G. \& Delgado, S. (2010). Understanding and addressing moral distress. Online Journal of Issues in Nursing, 15(3): 1.

Erlen, J. (2004). Wanted - nurses. Ethical issues and the nursing shortage. Orthopaedic Nursing, 23(4), 289-292.

Faith, K. \& Chidwick, P. (2009). Role of clinical ethicists in making decisions about levels of care in the intensive care unit. Critical Care Nurse, 29(2), 77-84.

Faul, F., Erdfelder, E., Buchner. A., \& Lang, A-G. (2009). Statistical power analysis $\mathrm{G}^{*}$ Power 3.1: Tests for correlation and regression analysis. Behavior Research Methods, 41, 1149-1160. 
Fenton, M. (1987). Moral distress in clinical practice: implications for the nurse administrator. Canadian Journal of Nursing Administration, 1(3), 8-11.

Ferrand, E., Lemaire, F., Regnier, B., Kuteifan, K., Badet, M., Asfar, P., Jaber, S., Chagnon, J., Renault, A., Robert, R., Pochard, F., Herve, C., Brun-Buisson, C., \& Duvaldestin, P. (2003). Discrepancies between perceptions by physicians and staff nurses of intensive care unit end-of-life decisions. American Journal of Respiratory and Critical Care Medicine, 167.

Ferrell, B.R., Dahlin, C., Campbell, M.L., Paice, J.A., Malloy, P. \& Virani, R. (2007). End-of-life nursing education consortium (ELNEC) training program: improving palliative care in critical care. Critical Care Nursing Quarterly, 30(3), 206-212.

Fitzpatrick., J., Campo, T., Graham, G., \& Lavandero, R. (2010). Certification and intent to leave current position and the profession among critical care nurses. American Journal of Critical Care Nursing, 19(3), 1-9.

Gutierrez, K. (2005). Critical care nurses' perceptions of and responses to moral distress. Dimensions of Critical Care, 24(5), 229-241.

Hamric, A. (2000). Moral distress in everyday ethics. Nursing Outlook, 48, 199-201.

Hamric, A. \& Blackhall, L. (2007). Nurse-physician perspectives on care of dying patients in intensive care units: Collaboration, moral distress, and ethical climate. Critical Care Medicine, 35(2):422-429.

Hefferman, P., \& Heilig, S. (1999). Giving "moral distress" a voice: ethical concerns among neonatal intensive care unit personnel. Cambridge Quarterly of Health Ethics, 8,173-178.

Huck, S. (2008). Reading statistics and research, $5^{\text {th }}$ ed., Boston, MA: Pearson 
Education, Inc.

International Council of Nurses (2006), Palliative care improves the quality of life of patients and their treatments even for terminal illness and during the end of life. Available at www.icn.ch/matters_palliative.htm. Accessed April 9, 2010.

Jameton, A. (1984). Nursing Practice :The Ethical Issues. Englewood Cliffs, NJ: Prentice Hall.

Kain, V. (2007). Moral distress and providing care to dying babies in neonatal nursing. International Journal of Palliative Nursing, 13(5), 243- 248.

Kälvemark, S., Höglund, A., \& Arnetz, B. (2006). Measuring moral distress in pharmacy and clinical practice. Nursing Ethics, 13, 416-27.

Knol, J., \& van Linge, R. (2009). Innovative behavior: the effect of structural and psychological empowerment on nurses. Journal of Advanced Nursing, 65(2), $359-370$.

Kramer. M., Schmalenberg, C., Maguire, P., Brewer, B., Burke, R., Chmielewski, L., Cox, K., Kishner, J., Krugman, M., Meeks-Sjostrom, D. \& Waldo, M. Structures and practices enabling staff nurses to control their practice. Western Journal of Nursing Research, $\quad 30(5), 539-559$.

LaSala, C. \& Bjarnason, D. (2010). Creating workplace environments that support moral courage. Online Journal of Issues in Nursing,15(3), 1. Doi:10:3912/OJIN. VolO3Man04.

Leiter, M., \& Laschinger, H. (2006). Relationships of work and practice environment to professional burnout. Nursing Research, 55(2), 137-146. 
Manojlovich, M., \& Lashinger, H. (2002). The relationship of empowerment and selected personality characteristics to nursing job satisfaction. Journal of Nursing Administration, 32(11), 586-595.

Manojlovich, M. (2007). Power and empowerment in nursing: Looking backward to inform the future. Online Journal of Issues in Nursing, 12(1), 1-16.

Meltzer, L., \& Huckabay, L. (2004). Critical care nurses' perceptions of futile care and its effect on burnout. American Journal of Critical Care, 13(3), 202-208.

Mertler, C., \& Vannatta R. (2005). Advanced and multivariate statistical methods, practical application and interpretations, $3^{\text {rd }}$ ed, Glendale, CA: Pyrczak Publishing.

Mobley, M., Rady, M., Verheijde, J., Patel, B., \& Larson, J. (2007). The relationship between moral distress and perception of futile care in the critical care unit. Intensive and Critical Care Nursing, 23, 256-263.

Morton, P., \& Fontaine, D. (2009). Critical Care Nursing a Holistic Approach, $9^{\text {th }}$ ed. Lippincott Williams \& Wilkins: Philadelphia, PA.

Nathaniel, A. (2006). Moral reckoning in nursing. Western Journal of Nursing Research, 28, 419-438.

Norton, S., Tilden V., Tolle, S., Nelson, C., \& Eggman, S. (2003) Life support withdrawal: communication and conflict. American Journal of Critical Care, $12(6), 548-554$

Page, A. (2004). Keeping patients safe: Transforming the work environment of nurses. Washington, D.C.: The National Academies Press. 
Pauly, B., Varcoe, C., Storch, J., \& Newton, L. (2009). Registered nurses' perceptions of moral distress and ethical climate. Nursing Ethics, 16(5), 561-573.

Piazza, I.M., Donahue, M., Dykes, P.C., Quinn, M.T., \& Fitzpatrick, J.J. (2006).

Differences in perceptions of empowerment among nationally certified and noncertified nurses. Journal of Nursing Administration, 36(5), 277-283.

Pickett, J. (2000). The American Heritage Dictionary of the English Language, $\left(4^{\text {th }} \mathrm{ed}\right)$ Boston, MA: Houghton Co.

Powell, R. (1998). Lived experiences of moral distress among staff nurses. Discussions of Abstracts International, 58(09B), 4721.

Radzvin, L. (2011). Moral distress in certified registered nurse anesthetists: implications for nursing practice. American Association of Nurse Anesthetists Journal, 79(1), $39-45$

Rice, E., Rady, M., Hamrick, A., Verheijde, J., \& Pendergast, D. (2008). Determinants of moral distress in medical and surgical nurses at an adult acute tertiary care hospital. Journal of Nursing Management, 12, 360-373.

Rodney, P. (1988). Moral distress in critical care nursing. Canadian Critical Care Nursing Journal, 5(2), 9-11.

Schwenzer, K., \& Wang, L. (2006). Assessing moral distress in respiratory care practitioners. Critical Care Medicine, 34, 2967-2873.

Spreitzer, G. (1995). Psychological empowerment in the workplace: Dimensions, measurement, and validation. Academy of Management Journal, 38(5), 14421465 . 
Spreitzer, G. (1996). Social structural characteristics of psychological empowerment. Academy of Management Journal, 39(2), 483-504.

Spreitzer, G., \& Quinn, R. (2001). A company of leaders: five disciplines for unleashing the power in your workforce. San Francisco, CA: Jossey-Bass.

Sundin-Huard, D., \& Fahy, K. (1999). Moral distress, advocacy and burnout: theorizing the relationships, International Journal of Nursing Practice, 5:8-11.

Thelen, M. (2005). End-of-Life decision making in the intensive care. Critical Care Nursing, 25(6), 28-37.

Thomas, K., \& Velthouse, B. (1990). Cognitive elements of empowerment. Academy of Management Review, 15, 666-681.

Vollers, D., Hill, E., Roberts, C., Dambaugh, L., \& Benner, Z. (2009). AACN's healthy work environment standards and an empowering nurse advancement system. Critical Care Nurse, 29(6), 20-27.

Webster, G.C., \& Baylis, F.E. (2000). Margin of error: the ethics of mistakes in the practice of medicine. Hagerstown, MD: University Publishing Group, 217-230.

Wilkinson, J.M. (1987/88). Moral distress in nursing practice: experience and effect. Nursing Forum, 23(1), 16-27.

Williamson, K. (2007). Home health care nurses' perceptions of empowerment. Journal of Community Health Nursing, 24(3), 133-153.

Zuzelo, P. (2007). Exploring the moral distress of registered nurses. Nursing Ethics, 14(3), 344-359. 
Appendix A

\section{Moral Distress Scale}

Moral Distress is defined as a painful feeling and/or psychological disequilibrium caused by a situation where you believe

a) you know the ethically ideal action to take, AND

b) you cannot carry out that action because of obstacles, such as lack of time, supervisory disinterest, medical power, institution policy or legal limits.

This survey measures your perceptions on two dimensions:

a) level of moral distress, and

b) frequency of this situation

So, you will be responding twice for each item. Once for the level of moral distress ("painful feelings") and next for the frequency you experience the item.

For your current position, please indicate for each of the following situations, the extent and frequency to which you experience MORAL DISTRESS.

1. Follow the family's wishes for the patient care when I do not agree with them.

\begin{tabular}{|l|l|l|l|l|l|l|l|}
\hline & 1 & 2 & 3 & 4 & 5 & 6 & 7 \\
\hline $\begin{array}{l}\text { PAINFUL FEELING none (1) } \\
\text {.....to...... great extent (7) }\end{array}$ & $r$ & $r$ & $r$ & $r$ & $r$ & $r$ & $r$ \\
\hline $\begin{array}{l}\text { FREQUENCY never (1) } \\
\text {....to...... very frequently (7) }\end{array}$ & $r$ & $r$ & $r$ & $r$ & $r$ & $r$ & $r$ \\
\hline
\end{tabular}

2. Follow the family's wishes to continue life support even though it is not in the best interest of the patient.

\begin{tabular}{|l|c|c|c|c|c|c|c|}
\hline & 1 & 2 & 3 & 4 & 5 & 6 & 7 \\
\hline $\begin{array}{l}\text { PAINFUL FEELING none (1) } \\
\text {......to...... great extent (7) }\end{array}$ & $r$ & $r$ & $r$ & $r$ & $r$ & $r$ & $r$ \\
\hline $\begin{array}{l}\text { FREQUENCY never (1) } \\
\text {.....to...... very frequently (7) }\end{array}$ & $r$ & $r$ & $r$ & $r$ & $r$ & $r$ & $r$ \\
\hline
\end{tabular}

3. Carry out the physician's order for unnecessary tests and treatments.

\begin{tabular}{|c|c|c|c|c|c|c|c|}
\hline & 1 & 2 & 3 & 4 & 5 & 6 & 7 \\
\hline $\begin{array}{l}\text { PAINFUL FEELING none (1) } \\
\text {......to...... great extent }(7)\end{array}$ & $r$ & $c$ & $r$ & $r$ & $m$ & $r$ & $r$ \\
\hline $\begin{array}{l}\text { FREQUENCY never (1) } \\
\ldots . \text { to ..... very frequently (7) }\end{array}$ & $r$ & $r$ & $r$ & $r$ & $r$ & $r$ & $r$ \\
\hline
\end{tabular}


4. Assist the physician who performs a test or treatment without informed consent.

\begin{tabular}{|c|c|c|c|c|c|c|c|}
\hline & 1 & 2 & 3 & 4 & 5 & 6 & 7 \\
\hline $\begin{array}{l}\text { PAINFUL FEELING none (1) } \\
\ldots \ldots . \text { to } . . . . \text { great extent }(7)\end{array}$ & $r$ & $r$ & $r$ & $r$ & $r$ & $r$ & $r$ \\
\hline $\begin{array}{l}\text { FREQUENCY never (1) } \\
\text {.....to...... very frequently (7) }\end{array}$ & $r$ & $r$ & $r$ & $c$ & $c$ & $r$ & $r$ \\
\hline
\end{tabular}

5. Initiate dramatic life-saving actions when I think it prolongs death.

\begin{tabular}{|l|c|c|c|c|c|c|c|}
\hline & 1 & 2 & 3 & 4 & 5 & 6 & 7 \\
\hline $\begin{array}{l}\text { PAINFUL FEELING none (1) } \\
\text {......to...... great extent (7) }\end{array}$ & $r$ & $r$ & $r$ & $r$ & $r$ & $r$ & $r$ \\
\hline $\begin{array}{l}\text { FREQUENCY never (1) } \\
\text {.....to....... very frequently (7) }\end{array}$ & $r$ & $r$ & $r$ & $r$ & $r$ & $r$ & $r$ \\
\hline
\end{tabular}

6. Ignore situations of suspected patient abuse by caregivers.

\begin{tabular}{|c|c|c|c|c|c|c|c|}
\hline & 1 & $\overline{2}$ & $\overline{3}$ & $\overline{4}$ & 5 & 6 & 7 \\
\hline $\begin{array}{l}\text { PAINFUL FEELING none (1) } \\
\ldots . . . \text { to...... great extent }(7)\end{array}$ & $r$ & $r$ & $r$ & $r$ & $r$ & $r$ & $r$ \\
\hline $\begin{array}{l}\text { FREQUENCY } \\
\text {.....to...... very frequently (7) }(1)\end{array}$ & $r$ & $r$ & $r$ & $r$ & $r$ & $r$ & $r$ \\
\hline
\end{tabular}

7. Ignore situations in which I suspect the patients have not been given adequately informed consent.

\begin{tabular}{|c|c|c|c|c|c|c|c|}
\hline & 1 & 2 & 3 & 4 & 5 & 6 & 7 \\
\hline $\begin{array}{l}\text { PAINFUL FEELING none (1) } \\
\text {......to...... great extent (7) }\end{array}$ & $r$ & $r$ & $r$ & $r$ & $r$ & $r$ & $r$ \\
\hline $\begin{array}{l}\text { FREQUENCY } \\
\text {....to...... very frequently (1) }\end{array}$ & $r$ & $r$ & $r$ & $r$ & $r$ & $r$ & $r$ \\
\hline
\end{tabular}

8. Perform a procedure when the patient is not adequately informed about procedures which he/she is about to undergo.

\begin{tabular}{|c|c|c|c|c|c|c|c|}
\hline & 1 & 2 & 3 & 4 & 5 & 6 & 7 \\
\hline $\begin{array}{l}\text { PAINFUL FEELING none (1) } \\
\ldots . . \text { to } . . . . \text { great extent }(7)\end{array}$ & r & $r$ & $r$ & $r$ & $r$ & $r$ & $r$ \\
\hline $\begin{array}{l}\text { FREQUENCY } \\
\text {.....to...... very frequently (7) }\end{array}$ & $r$ & $r$ & $r$ & $r$ & $r$ & $r$ & $r$ \\
\hline
\end{tabular}


9. Carry out a work assignment in which I do not feel professionally competent.

\begin{tabular}{|c|c|c|c|c|c|c|c|}
\hline & 1 & 2 & 3 & 4 & 5 & 6 & 7 \\
\hline $\begin{array}{l}\text { PAINFUL FEELING none (1) } \\
\text {.......to...... great extent }(7)\end{array}$ & $c$ & $r$ & $r$ & $r$ & $r$ & $r$ & $r$ \\
\hline $\begin{array}{l}\text { FREQUENCY } \\
\text {.....to...... very frequently (7) }\end{array}$ & $r$ & $r$ & $r$ & $r$ & r & $r$ & $r$ \\
\hline
\end{tabular}

10. Avoid taking any action when I learn that a nurse colleague has made a medication error and does not report it.

\begin{tabular}{|l|c|c|c|c|c|c|c|}
\hline & 1 & 2 & 3 & 4 & 5 & 6 & 7 \\
\hline $\begin{array}{l}\text { PAINFUL FEELING none (1) } \\
\text {......to...... great extent (7) }\end{array}$ & $r$ & $r$ & $r$ & $r$ & $r$ & $r$ & $r$ \\
\hline $\begin{array}{l}\text { FREQUENCY never (1) } \\
\text {.....to...... very frequently (7) }\end{array}$ & $r$ & $r$ & $r$ & $r$ & $r$ & $r$ & $r$ \\
\hline
\end{tabular}

11. Let medical students perform painful procedures on patients solely to increase their skill.

\begin{tabular}{|c|c|c|c|c|c|c|c|}
\hline & 1 & 2 & 3 & 4 & 5 & 6 & 7 \\
\hline $\begin{array}{l}\text { PAINFUL FEELING none (1) } \\
\ldots \ldots \text { to...... great extent }(7)\end{array}$ & $r$ & $r$ & $r$ & $r$ & $r$ & $r$ & $r$ \\
\hline $\begin{array}{l}\text { FREQUENCY } \\
\text {.....to...... very frequently (1) }\end{array}$ & $r$ & $r$ & 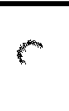 & $r$ & $r$ & $r$ & $r$ \\
\hline
\end{tabular}

12. Follow the patient's request not to discuss death with a dying child who asks about dying.

\begin{tabular}{|c|c|c|c|c|c|c|c|}
\hline & 1 & 2 & 3 & 4 & 5 & 6 & 7 \\
\hline $\begin{array}{l}\text { PAINFUL FEELING none (1) } \\
\text {......to...... great extent (7) }\end{array}$ & $r$ & $r$ & $r$ & $r$ & $r$ & $r$ & $r$ \\
\hline $\begin{array}{l}\text { FREQUENCY } \\
\text {....to...... very frequently (7) }\end{array}$ & $r$ & $r$ & $r$ & $m$ & $r$ & $r$ & $r$ \\
\hline
\end{tabular}

13. Follow the physician's order not to discuss death with dying children who ask about dying.

\begin{tabular}{|c|c|c|c|c|c|c|c|}
\hline & 1 & 2 & 3 & 4 & 5 & 6 & 7 \\
\hline $\begin{array}{l}\text { PAINFUL FEELING none (1) } \\
\text {......to...... great extent }(7)\end{array}$ & $r$ & $r$ & $r$ & $r$ & $r$ & $r$ & $r$ \\
\hline $\begin{array}{l}\text { FREQUENCY never (1) } \\
\text {.....to...... very frequently (7) }\end{array}$ & $r$ & $r$ & $r$ & $r$ & $r$ & $r$ & $r$ \\
\hline
\end{tabular}


14. Assist physicians who are practicing procedures on a patient after CPR has been unsuccessful.

\begin{tabular}{|c|c|c|c|c|c|c|c|}
\hline & 1 & 2 & 3 & 4 & 5 & 6 & 7 \\
\hline $\begin{array}{l}\text { PAINFUL FEELING none (1) } \\
\text {......to...... great extent }(7)\end{array}$ & $r$ & $r$ & $r$ & $r$ & $r$ & r & $r$ \\
\hline $\begin{array}{l}\text { FREQUENCY } \\
\text {.....to...... very frequently (7) }\end{array}$ & $r$ & $c$ & $r$ & $r$ & $r$ & $r$ & $\Gamma$ \\
\hline
\end{tabular}

15. Carry out the physician's orders for necessary tests and treatments for terminally ill patients.

\begin{tabular}{|c|c|c|c|c|c|c|c|}
\hline & 1 & 2 & 3 & 4 & 5 & 6 & 7 \\
\hline $\begin{array}{l}\text { PAINFUL FEELING none (1) } \\
\text {......to...... great extent (7) }\end{array}$ & $r$ & $r$ & $r$ & $r$ & $r$ & $r$ & $r$ \\
\hline $\begin{array}{l}\text { FREQUENCY } \\
\text {.....to...... very frequently (1) }\end{array}$ & $r$ & $r$ & $r$ & $r$ & $r$ & $r$ & $r$ \\
\hline
\end{tabular}

16. Work with "unsafe" levels of nurse staffing.

\begin{tabular}{|c|c|c|c|c|c|c|c|}
\hline & 1 & 2 & 3 & 4 & 5 & 6 & 7 \\
\hline $\begin{array}{l}\text { PAINFUL FEELING none (1) } \\
\ldots . . . \text { to...... great extent }(7)\end{array}$ & $r$ & r & $r$ & $r$ & $r$ & $r$ & $r$ \\
\hline $\begin{array}{l}\text { FREQUENCY never (1) } \\
\ldots \ldots \text { to ..... very frequently (7) }\end{array}$ & $r$ & $r$ & $c$ & $c$ & $r$ & $c$ & $r$ \\
\hline
\end{tabular}

17. Carry out orders for institutional policies to discontinue treatment because the patient can no longer pay.

\begin{tabular}{|c|c|c|c|c|c|c|c|}
\hline & 1 & 2 & 3 & 4 & 5 & 6 & 7 \\
\hline $\begin{array}{l}\text { PAINFUL FEELING none (1) } \\
\ldots . . . \text { to...... great extent }(7)\end{array}$ & $r$ & $r$ & $r$ & $r$ & $r$ & $r$ & $r$ \\
\hline $\begin{array}{l}\text { FREQUENCY never (1) } \\
\text {.....to...... very frequently (7) }\end{array}$ & $r$ & $r$ & $c$ & $r$ & $f$ & $r$ & $r$ \\
\hline
\end{tabular}

18. Continue to participate in care for a hopelessly injured patient who is being sustained on a respirator (ventilator), when no one will make a decision to "pull the plug".

\begin{tabular}{|c|c|c|c|c|c|c|c|}
\hline & 1 & 2 & 3 & 4 & 5 & 6 & 7 \\
\hline $\begin{array}{l}\text { PAINFUL FEELING none (1) } \\
\text {.......to...... great extent }(7)\end{array}$ & $r$ & $r$ & $r$ & r & $r$ & $r$ & $r$ \\
\hline $\begin{array}{l}\text { FREQUENCY } \\
\text {.....to...... very frequently (7) }\end{array}$ & $r$ & $\kappa$ & $r$ & 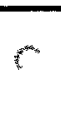 & $r$ & $r$ & $r$ \\
\hline
\end{tabular}


19. Observe without intervening when health care personnel do not respect the patient's dignity.

\begin{tabular}{|c|c|c|c|c|c|c|c|}
\hline & 1 & 2 & 3 & 4 & 5 & 6 & 7 \\
\hline $\begin{array}{l}\text { PAINFUL FEELING none (1) } \\
\ldots \ldots \text { to } . . . . . \text { great extent }(7)\end{array}$ & $r$ & $r$ & $r$ & $r$ & $r$ & $r$ & $r$ \\
\hline $\begin{array}{l}\text { FREQUENCY } \\
\text {....to...... very frequently ( }(7)\end{array}$ & $r$ & $r$ & $r$ & $r$ & $r$ & $r$ & $r$ \\
\hline
\end{tabular}

20. Follow the physician's order not to tell the patient the truth when he/she asks for it.

\begin{tabular}{|l|c|c|c|c|c|c|c|}
\hline & 1 & 2 & 3 & 4 & 5 & 6 & 7 \\
\hline $\begin{array}{l}\text { PAINFUL FEELING none (1) } \\
\text {......to...... great extent (7) }\end{array}$ & $r$ & $r$ & $r$ & $r$ & $r$ & $r$ & $r$ \\
\hline $\begin{array}{l}\text { FREQUENCY never (1) } \\
\text {.....to...... very frequently (7) }\end{array}$ & $r$ & $r$ & $r$ & $r$ & $r$ & $r$ & $r$ \\
\hline
\end{tabular}

21. Assist the physician who in your opinion is providing incompetent care.

\begin{tabular}{|c|c|c|c|c|c|c|c|}
\hline & 1 & 2 & 3 & 4 & 5 & 6 & 7 \\
\hline $\begin{array}{l}\text { PAINFUL FEELING none (1) } \\
\text {......to...... great extent (7) }\end{array}$ & $r$ & $r$ & $r$ & $\mathrm{c}$ & $r$ & $r$ & $r$ \\
\hline $\begin{array}{l}\text { FREQUENCY never (1) } \\
\text {.....to...... very frequently (7) }\end{array}$ & $r$ & $r$ & $r$ & $r$ & $r$ & $r$ & $r$ \\
\hline
\end{tabular}

22. Prepare a terminally ill elderly patient on a respirator (ventilator) for surgery to have a mass removed.

\begin{tabular}{|c|c|c|c|c|c|c|c|}
\hline & 1 & 2 & 3 & 4 & 5 & 6 & 7 \\
\hline $\begin{array}{l}\text { PAINFUL FEELING none (1) } \\
\text {......to...... great extent }(7)\end{array}$ & $r$ & $r$ & $r$ & $r$ & $r$ & $r$ & $r$ \\
\hline $\begin{array}{l}\text { FREQUENCY } \\
\text {....to...... very frequently (7) }\end{array}$ & $m$ & $r$ & $r$ & $r$ & $r$ & $r$ & $r$ \\
\hline
\end{tabular}

23. Prepare an elderly man who is severely demented and a "No Code" for surgery to have a gastrostomy tube put in.

\begin{tabular}{|c|c|c|c|c|c|c|c|}
\hline & 1 & 2 & 3 & 4 & 5 & 6 & 7 \\
\hline $\begin{array}{l}\text { PAINFUL FEELING none (1) } \\
\text {......to...... great extent }(7)\end{array}$ & r & 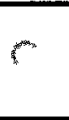 & $r$ & $r$ & c & $r$ & $r$ \\
\hline $\begin{array}{l}\text { FREQUENCY } \\
\text {.....to...... very frequently (7) }\end{array}$ & $r$ & $r$ & $c$ & 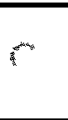 & $r$ & $r$ & 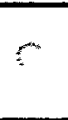 \\
\hline
\end{tabular}


24. Discharge a patient when he has reached the maximum length of stay based on Diagnostic Related Grouping (DRG) although he has many teaching needs.

\begin{tabular}{|c|c|c|c|c|c|c|c|}
\hline & 1 & 2 & 3 & 4 & 5 & 6 & 7 \\
\hline $\begin{array}{l}\text { PAINFUL FEELING none (1) } \\
\ldots \ldots \text {.......... great extent }(7)\end{array}$ & $r$ & $r$ & $r$ & $r$ & $r$ & $r$ & $r$ \\
\hline $\begin{array}{l}\text { FREQUENCY } \\
\text {.....to...... very frequently ( } 7 \text { ver }\end{array}$ & $r$ & $r$ & $r$ & $r$ & $r$ & $r$ & $r$ \\
\hline
\end{tabular}

25. Provide better care for those who can afford to pay than those who cannot.

\begin{tabular}{|l|c|c|c|c|c|c|c|}
\hline & 1 & 2 & 3 & 4 & 5 & 6 & 7 \\
\hline $\begin{array}{l}\text { PAINFUL FEELING none (1) } \\
\text {......to...... great extent (7) }\end{array}$ & $r$ & $r$ & $r$ & $r$ & $r$ & $r$ & $r$ \\
\hline $\begin{array}{l}\text { FREQUENCY never (1) } \\
\text {.....to...... very frequently (7) }\end{array}$ & $r$ & $r$ & $r$ & $r$ & $r$ & $r$ & $r$ \\
\hline
\end{tabular}

26. Follow the family's request not to discuss death with a dying patient who asks about dying.

\begin{tabular}{|l|c|c|c|c|c|c|c|}
\hline & 1 & 2 & 3 & 4 & 5 & 6 & 7 \\
\hline $\begin{array}{l}\text { PAINFUL FEELING none (1) } \\
\text {......to...... great extent (7) }\end{array}$ & $r$ & $r$ & $r$ & $r$ & $r$ & $r$ & $r$ \\
\hline $\begin{array}{l}\text { FREQUENCY never (1) } \\
\text {.....to...... very frequently (7) }\end{array}$ & $r$ & $r$ & $r$ & $r$ & $r$ & $r$ & $r$ \\
\hline
\end{tabular}

27. Follow the physician's request not to discuss death with a dying patient who asks about dying.

\begin{tabular}{|c|c|c|c|c|c|c|c|}
\hline & 1 & 2 & 3 & 4 & 5 & 6 & 7 \\
\hline $\begin{array}{l}\text { PAINFUL FEELING none (1) } \\
\text {......to...... great extent }(7)\end{array}$ & $r$ & 5 & $r$ & $r$ & $r$ & $r$ & $r$ \\
\hline $\begin{array}{l}\text { FREQUENCY never (1) } \\
\text {.....to...... very frequently (7) }\end{array}$ & $r$ & $r$ & $r$ & $r$ & $r$ & $r$ & $r$ \\
\hline
\end{tabular}

28. Work in a situation where the number of staff is so low that care is inadequate.

\begin{tabular}{|c|c|c|c|c|c|c|c|}
\hline & 1 & 2 & 3 & 4 & 5 & 6 & 7 \\
\hline $\begin{array}{l}\text { PAINFUL FEELING none (1) } \\
\text {.......to...... great extent (7) }\end{array}$ & $r$ & $c$ & $r$ & $r$ & $r$ & $r$ & $r$ \\
\hline $\begin{array}{l}\text { FREQUENCY } \\
\text {.....to } \ldots . . . \text { very frequently (1) } \\
\text { (7) }\end{array}$ & $r$ & $c$ & $r$ & $r$ & $r$ & $r$ & $r$ \\
\hline
\end{tabular}


29. Give medication intravenously during a Code Blue with no compressions or intubation.

\begin{tabular}{|c|c|c|c|c|c|c|c|}
\hline & 1 & 2 & 3 & $\overline{4}$ & 5 & $\overline{6}$ & 7 \\
\hline $\begin{array}{l}\text { PAINFUL FEELING none (1) } \\
\ldots . . \text { to } \ldots . . . \text { great extent }(7)\end{array}$ & $r$ & $r$ & $r$ & $r$ & $c$ & 5 & $r$ \\
\hline $\begin{array}{l}\text { FREQUENCY never (1) } \\
\text {.....to...... very frequently }(7)\end{array}$ & $r$ & $r$ & $r$ & 5 & $r$ & $r$ & $r$ \\
\hline
\end{tabular}

30. Give only hemodynamic stabilizing medication intravenously during a Code Blue with no compression or intubation.

\begin{tabular}{|c|c|c|c|c|c|c|c|}
\hline & 1 & 2 & 3 & $\overline{4}$ & 5 & 6 & 7 \\
\hline $\begin{array}{l}\text { PAINFUL FEELING none (1) } \\
\text {......to...... great extent (7) }\end{array}$ & $r$ & $r$ & $r$ & $r$ & $c$ & $r$ & $r$ \\
\hline $\begin{array}{l}\text { FREQUENCY } \\
\text {.....to...... very frequently ( }(7)\end{array}$ & $r$ & $r$ & $r$ & $r$ & $r$ & $r$ & $c$ \\
\hline
\end{tabular}

31. Follow the physician's request not to discuss a Code Blue status with the patient.

\begin{tabular}{|l|c|c|c|c|c|c|c|}
\hline & 1 & 2 & 3 & 4 & 5 & 6 & 7 \\
\hline $\begin{array}{l}\text { PAINFUL FEELING none (1) } \\
\ldots . . . \text { to...... great extent (7) }\end{array}$ & $r$ & $r$ & $r$ & $r$ & $r$ & $r$ & $r$ \\
\hline $\begin{array}{l}\text { FREQUENCY never (1) } \\
\text {.....to...... very frequently (7) }\end{array}$ & $r$ & $r$ & $r$ & $r$ & $r$ & $r$ & $r$ \\
\hline
\end{tabular}

32. Follow the physician's request not to discuss a Code Blue status with the family when the patient becomes incompetent.

\begin{tabular}{|l|c|c|c|c|c|c|c|}
\hline & 1 & 2 & 3 & 4 & 5 & 6 & 7 \\
\hline $\begin{array}{l}\text { PAINFUL FEELING none (1) } \\
\text {......to...... great extent (7) }\end{array}$ & $r$ & $r$ & $r$ & $r$ & $r$ & $r$ & $r$ \\
\hline $\begin{array}{l}\text { FREQUENCY never (1) } \\
\text {.....to...... very frequently (7) }\end{array}$ & $\odot$ & $r$ & $r$ & $r$ & $r$ & $r$ & $r$ \\
\hline
\end{tabular}


Appendix B

\section{Perceived Empowerment}

Listed below are a number of self-orientations that people may have with regard to their work role. Using the following scale, please indicate the extent to which you agree or disagree that each one describes your self-orientation.
A. Very Strongly Disagree
B. Strongly Disagree
C. Disagree
D. Neutral
E. Agree
F. Strongly Agree
G. Very Strongly Agree

1. I am confident about my ability to do my job.

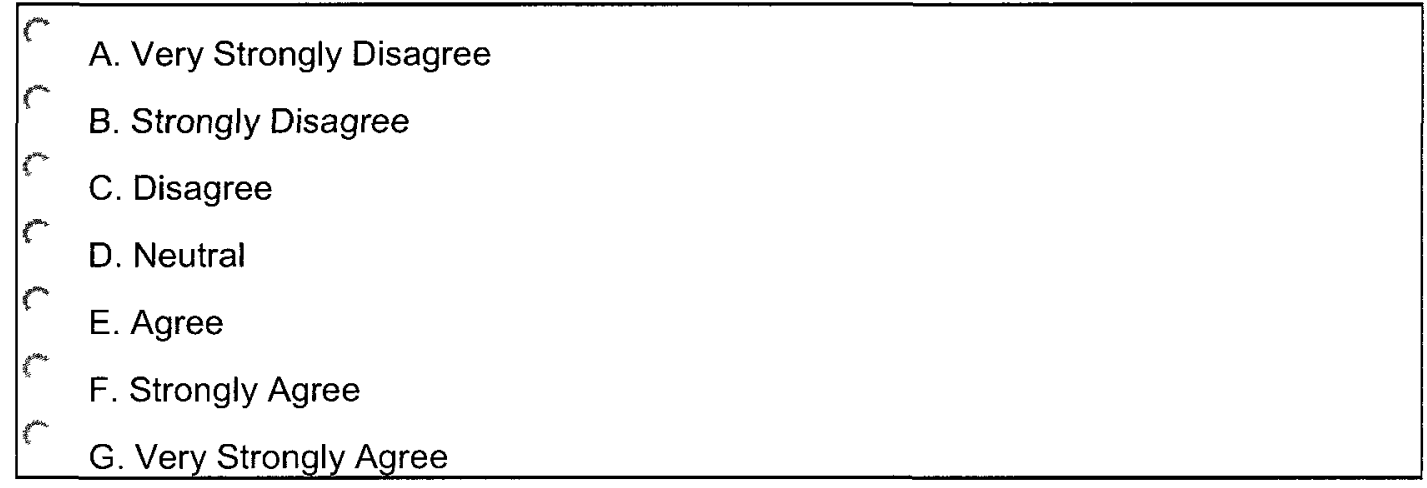

2. The work that I do is important to me.

A. Very Strongly Disagree
B. Strongly Disagree
C. Disagree
D. Neutral
E. Agree
F. Strongly Agree
G. Very Strongly Agree


3. I have significant autonomy in determining how I do my job.

\begin{tabular}{rl|} 
A. Very Strongly Disagree \\
B. Strongly Disagree \\
C. Disagree \\
D. Neutral \\
E. Agree \\
F. Strongly Agree \\
G. Very Strongly Agree
\end{tabular}

4. My impact on what happens in my department is large.

\begin{tabular}{ll|} 
A. Very Strongly Disagree \\
B. Strongly Disagree \\
C. Disagree \\
D. Neutral \\
E. Agree \\
F. Strongly Agree \\
G. Very Strongly Agree
\end{tabular}

\section{My job activities are personally meaningful to me.}

A. Very Strongly Disagree
B. Strongly Disagree
C. Disagree
D. Neutral
E. Agree
F. Strongly Agree
G. Very Strongly Agree


6. I have a great deal of control over what happens in my department.

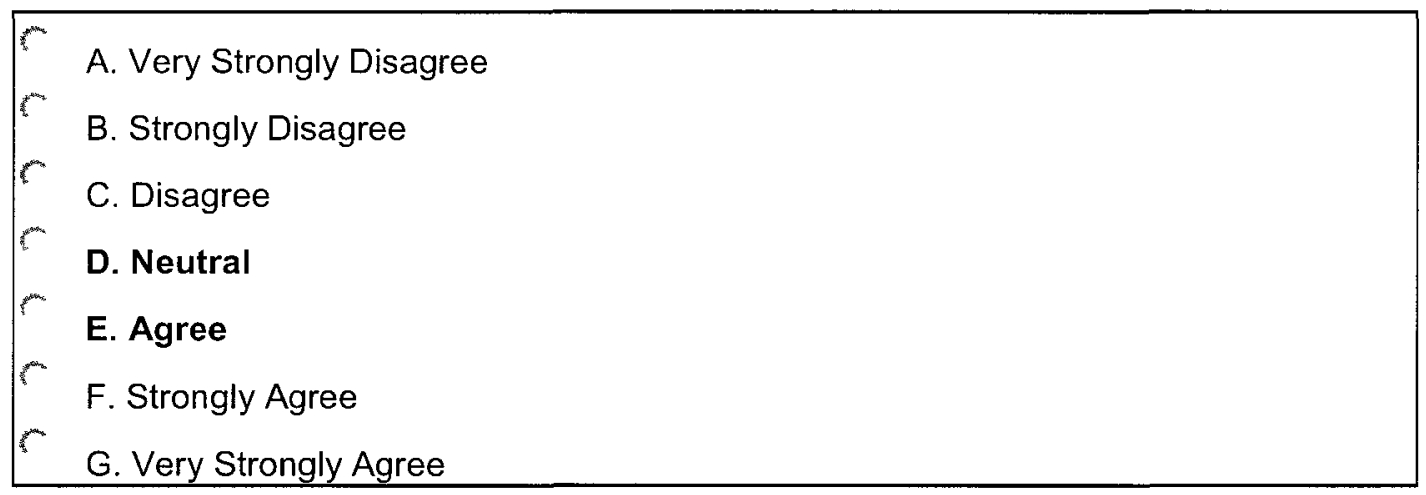

7. I can decide on my own how to go about doing my own work.

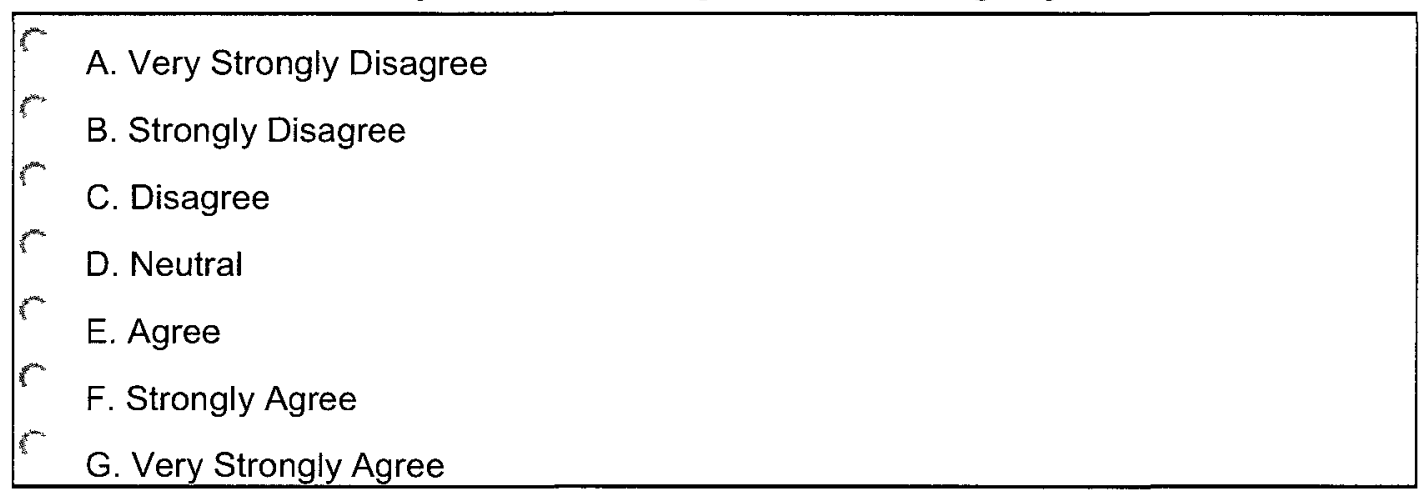

\section{I really care about what I do on my job.}

A. Very Strongly Disagree
B. Strongly Disagree
C. Disagree
D. Neutral
E. Agree
F. Strongly Agree
G. Very Strongly Agree


9. My job is well within the scope of my abilities.

\begin{tabular}{rl|}
$r$ & A. Very Strongly Disagree \\
& B. Strongly Disagree \\
& C. Disagree \\
& D. Neutral \\
E. Agree & F. Strongly Agree \\
& G. Very Strongly Agree
\end{tabular}

10. I have considerable opportunity for independence and freedom in how I do my job.

A. Very Strongly Disagree
B. Strongly Disagree
C. Disagree
D. Neutral
E. Agree
F. Strongly Agree
G. Very Strongly Agree

11. I have mastered the skills necessary for my job.

A. Very Strongly Disagree
B. Strongly Disagree
C. Disagree
D. Neutral
E. Agree
F. Strongly Agree
G. Very Strongly Agree


12. My opinion counts in departmental decision-making.

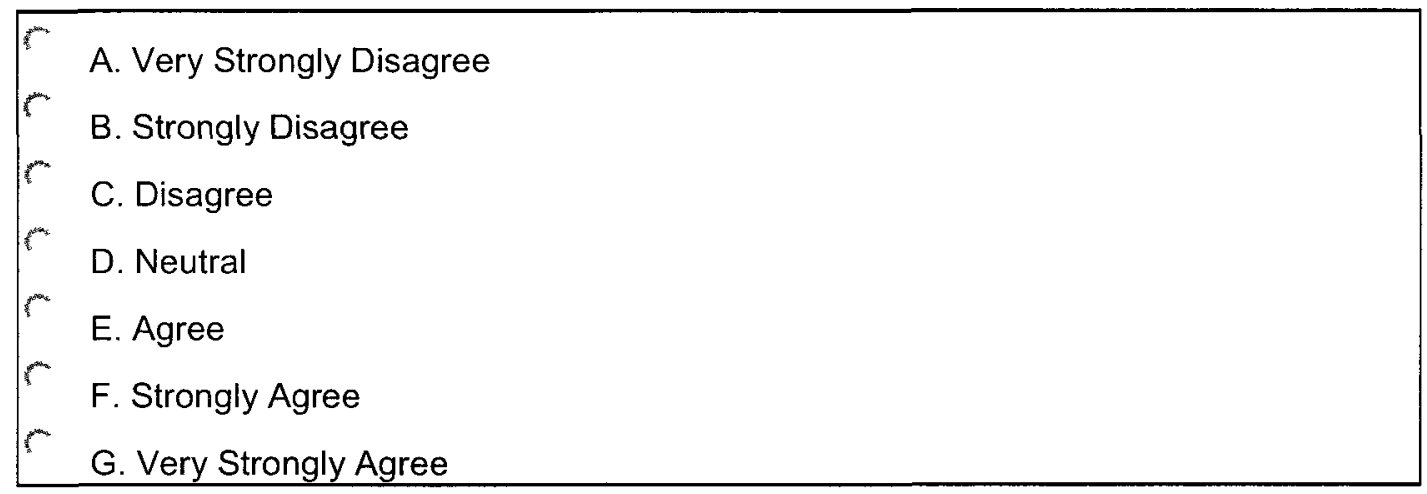

13. The work I do is meaningful to me.

\begin{tabular}{rl|} 
A. Very Strongly Disagree \\
B. Strongly Disagree \\
C. Disagree \\
D. Neutral \\
E. Agree \\
F. Strongly Agree \\
G. Very Strongly Agree \\
\hline
\end{tabular}

14. I have significant influence over what happens in my department.

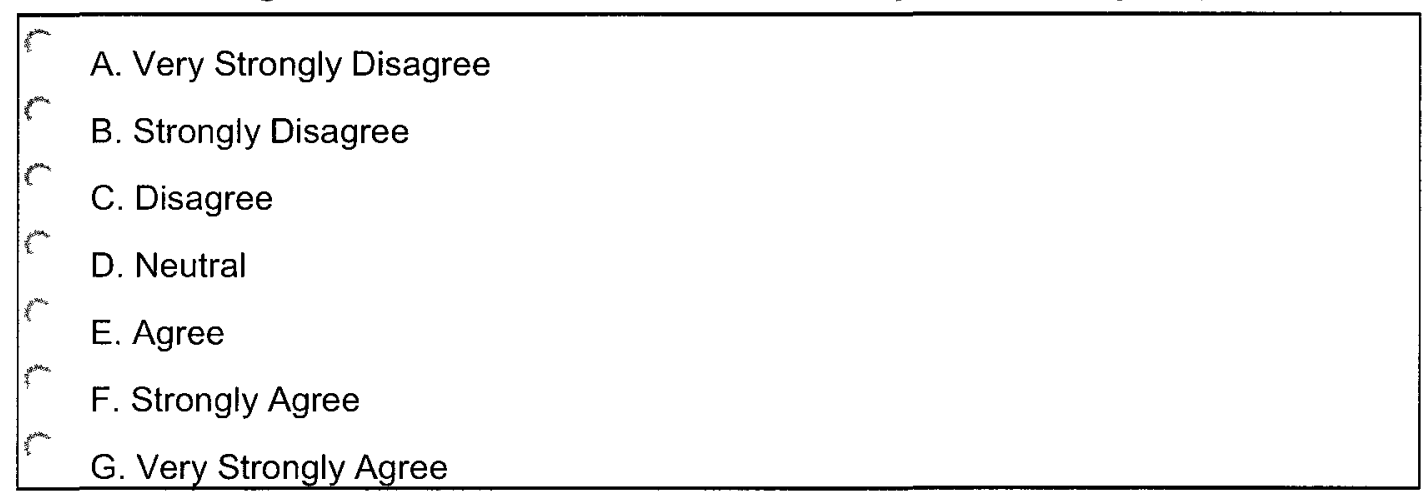


111

15. I am self-assured about my capabilities to perform my work activities.

$\begin{array}{ll}C & \text { A. Very Strongly Disagree } \\ & \text { B. Strongly Disagree } \\ & \text { C. Disagree } \\ & \text { D. Neutral } \\ r & \text { E. Agree } \\ r & \text { F. Strongly Agree } \\ \text { G. Very Strongly Agree }\end{array}$

16. I have a chance to use personal initiative in carrying out my work.

A. Very Strongly Disagree
B. Strongly Disagree
C. Disagree
D. Neutral
E. Agree
F. Strongly Agree
G. Very Strongly Agree 
Appendix C

Demographics

1. Age

2. Approximately how many years of critical care experience do you have?

3. What is your work status?

Full Time
Part Time
Per Diem

4. Are you actively in collaboration in multidisciplinary EOLC patient conferences?

$\begin{array}{lll}F & \text { Yes } \\ \text { No }\end{array}$

5. What is your educational background?

ADN/Diploma
BSN
MSN
Doctorate


6. Are you AACN (American Association of Critical Care Nurses) specialty certified?

$\begin{array}{rll}r & \text { Yes } \\ & \text { No }\end{array}$

7. Are you an End-of Life Nursing Education Consortium (ELNEC) Critical Care Trainer?

No

8. Have you had any continuing education related to end-of-life care in the past year?

$\begin{aligned} r & \text { Yes } \\ r & \text { No }\end{aligned}$

9. Are you a member of the American Association of Critical Care Nurses (AACN)?

\begin{tabular}{|ll|}
\hline & Yes \\
r no & No
\end{tabular}


Appendix D

Dear AACN Newsletter Subscribers,

My name is Annette Browning. I am a doctoral candidate in the School of Nursing at the University of San Diego, San Diego, CA. I am conducting a research study as part of the requirements of my doctoral dissertation, and I would like to invite you to participate.

The purpose of my research study is to examine the relationship between perceived empowerment and moral distress in critical care nurses caring for adults during end of life. The study will use a demographic questionnaire, the Psychological Empowerment Instrument and the Moral Distress Scale.

Taking part in this study is entirely optional. Choosing not to participate will have no effect on your employment status or any other benefits to which you are entitled. You may also quit being in the study at any time or decide not to answer any specific questions. This study has been approved by the University of San Diego Institutional Review Board.

If you decide to participate, you will be asked to complete a short online survey (questions) that takes about 30 minutes to complete. You will be asked to complete a brief 9 item demographic questionnaire and to evaluate 16 items related to how empowered you feel in your work role. You will then be asked to evaluate 32 items about how you perceive your experience of moral distress related to caring for patients in critical care at end of life.

The risks of participating in this study are minimal and no more than those encountered in everyday life. Your responses will be kept confidential, as no identifiers (URL or email addresses) will be recorded. Your institutional affiliation will not be recorded, so no one will know which responses came from a certain individual or institution.

I will be happy to answer any questions you have about the study. You may contact me at (714)345-7427 or annette.browning@biola.edu or my faculty advisor, Dr. Ann Mayo at (619) 260-4600 or amayo@sandiego.edu

Thank you for your consideration.

With kind regards,

Annette Browning annette.browning@biola.edu

714-345-7427 